UNIVERSIDADE DE SÃO PAULO

FACULDADE DE ODONTOLOGIA DE BAURU

DISCIPLINA DE DENTÍSTICA

\title{
Avaliação in vitro dos efeitos da aplicação de sistemas adesivos, do oxalato de potássio, ou a combinação de ambos, na permeabilidade dentinária.
}

Safira Marques de Andrade e Silva

Dissertação apresentada à Faculdade de Odontologia de Bauru, da Universidade de São Paulo, como parte dos requisitos para obtenção do título de mestre em odontologia, na área de Dentística.

(Edição Revisada) 
UNIVERSIDADE DE SÃO PAULO

FACULDADE DE ODONTOLOGIA DE BAURU

DISCIPLINA DE DENTÍSTICA

\begin{abstract}
Avaliação in vitro dos efeitos da aplicação de sistemas adesivos, do oxalato de potássio, ou a combinação de ambos, na permeabilidade dentinária.
\end{abstract}

Safira Marques de Andrade e Silva

Dissertação apresentada à Faculdade de Odontologia de Bauru, da Universidade de São Paulo, como parte dos requisitos para obtenção do título de mestre em odontologia, na área de Dentística.

(Edição Revisada)

Orientador: Prof Dr. Ricardo Marins de Carvalho 


\section{Dados Curriculares}

\section{Safira Marques de Andrade e Silva}

Nascimento $\quad 25$ de Outubro de 1977

Naturalidade Salvador - BA

1996-2001

Curso de Odontologia - Universidade Federal da Bahia

2002-2003 Curso de Especialização em Dentística Restauradora-

Fundação Bauruense de Estudos Odontológicos-

FUNBEO- USP

2003-2005 Curso de Pós-Graduação em Dentística Restauradora, em nível de Mestrado, na Faculdade de Odontologia de Bauru- USP

Associações

- $\mathrm{ABO}$ - Associação Brasileira de Odontologia

- ADM-Academic of Dental Materials

- GBPD- Grupo Brasileiro de Professores de Dentística

- SBPqO- Sociedade Brasileira de Pesquisa Odontológica

- IADR- International Association for Dental Research 
A conclusão deste trabalho encerra um ciclo muito importante na minha vida.

$\mathcal{N a ̃ o ~ s u b e s t i m o ~ a ~ c o n t r i b u i c ̧ a ̃ o ~ c i e n t i ́ f i c a ~ q u e ~ e s t e s ~ r e s u l t a d o s ~ t r a r a ̃ o , ~ m a s ~ s e m ~}$ dúvidas seu maior valor não está na conclusão ou nos resultados aqui apresentados. O maior valor deste trabalho se encontra na trajetória percorrida até chegar a este momento.

Durante este percurso aprendi lições de vida que não estão nos livros ou nos artigos; Encontrei pessoas especiais que me proporcionaram momentos especiais que jamais esquecerei;

Deparei-me com as minhas próprias limitações, procurei vencê-las e em alguns casos aceitá-las;

As dificuldades e adversidades também deixaram o seu legado;

Sirvo-me delas como lições de vida;

E saber viver é a grande sabedoria! 


\section{Dedicatória}

\section{Dedico este trabalho}

Aos meus pais Roque e Liane,

É muito difícil demonstrar em palavras todo amor, gratidão e admiração que sinto por vocês. Vocês são os maiores responsáveis por todas as minhas conquistas e merecem todo o meu reconhecimento. Obrigada por compartilharem dos meus sonhos, por serem tão constantes, tão amigos e especiais.... A concretização desta etapa só foi possivvel pela certeza e conforto do amor e apoio incondicional que sempre me dedicaram.

À Anha, Reconheço a nossa sorte de ter você na nossa família. Reconheço a felicidade de sempre ter tido você ao meu lado, cuidando de mim e do meu irmão, nos dando o carinho e o amor que só uma mãe seria capaz de dedicar a um filho. E como minha mãe, você tem e sempre terá uma participação muito especial em todas minhas conquistas. Obrigada!

Ao meu querido Joca,

Somente aqueles que têm a sorte e o prazer de conviver com você compreenderão a dimensão das minhas palavras. Acredito que existem no mundo pessoas especiais. Pessoas evoluidas que transmitem o bem, que nos confortam pelo simples fato de existir e mesmo longe fisicamente, nos transmitem a sensação estar sempre por perto. Agradeço a Deus existirem pessoas assim... e uma delas estar ao meu lado.

A tranqüilidade e a certeza dos sentimentos me serviram como sustentação nos momentos mais difíceis. $\mathcal{N}$ ão sei como seria sem você.....

À Bruno,

Tenho muito orgulho da amizade, respeito e sentimento verdadeiro que sempre compartilhamos. Acho que fazemos jus à nossa condição de "irmãos".

Agradeço a torcida, o seu carinho e todas as lições de vida que aprendi com você.

Aos meus familiares (tias, primos e avós);

Sou muito feliz de pertencer a uma família tão unida e tão especial!

Obrigada por serem tão presentes, por terem me proporcionado momentos tão felizes... Mesmo longe fisicamente compartilho esta felicidade com vocês! 


\section{Agradecimentos especiais}

"O valor das coisas não está no tempo em que elas duram,
mas na intensidade com que acontecem.
Por isso existem momentos inesquecíveis,
coisas inexplicáveis e
pessoas incomparáveis".

Fernando Pessoa

Ao meu orientador Prof. Ricardo Marins de Carvalho;

Você desempenhou um papel fundamental e muito especial durante esta minha trajetória do mestrado. Posso dizer que tive muita sorte de ter sido sua orientada e The sou extremamente grata por inúmeros motivos... Pela confiança desde o primeiro momento, pelas oportunidades valiosas que me engrandeceram profissionalmente e pela convivência tão enriquecedora! Apesar de sempre ter compartilhado do seu vasto conhecimento, você sempre me estimulou a pensar e a ter senso crítico, e este foi o seu maior legado.

São estas ferramentas que utilizarei daqui para frente para que possa continuar crescendo...... Obrigada!

À grande "amiga" Fer;

Agradeço a Deus o presente da sua companhia e amizade durante este tempo. Você fez com que os meus dias fossem leves e divertidos. Nossas inúmeras afinidades intensificaram nossa amizade e eu agradeço todos os momentos divertidíssimos que compartilhamos.

Conforta-me saber que a nossa amizade vai além das fronteiras e que os laços estabelecidos jamais serão rompidos.

À grande amiga profa Teresa,

Você para mim representa amizade, acolhimento... N Não sei como the agradecer por ter sido tão presente, por sempre ter me transmitido uma sensação de conforto... por me considerar sua amiga e por ter me dado o privilégio de compartilhar da sua vida, de conviver com você durante este tempo.... Todos os momentos que passamos juntas foram extremamente divertidos e enriquecedores, e hoje com a saudade, só me conforta saber que eu vivi todos eles intensamente! 
À grande amiga e orientadora Marcela...

Você para mim representa a certeza de que as mudanças mesmo quando sofridas vêem seguidas por compensações. Acredito que nada acontece por acaso, e o fato de eu estar em Piracicaba hoje, sendo sua aluna de doutorado, representa para mim algo de muito significativo e muito especial. Sou muito grata a você pelo empenho em ter tornado isso realidade, pela sua amizade sincera, pela sua presteza e apoio em todos os momentos.

A oportunidade de conviver com você é um presente e não tenho dúvidas de que a sua contribuição na minha vida vai muito além da profissional....

À grande "amiga" Wang....

Faltam-me palavras para expressar o carinho que sinto por você e o quanto você é especial.....Não poderia enumerar aqui todas as suas qualidades e características que te fazem U'NICA, mas quem tem o privilégio de conviver com você as conhecem muito bem... Agradeço pelos momentos inesquecíveis que compartilhamos e por você cuidar e nutrir a nossa amizade com gestos e atitudes que me comovem. Você mim foi um presente e eu sou grata por merecê-lo!

À Luis,

Sua participação foi muito importante na minha adaptação no laboratório. Agradeço pelos conhecimentos transmitidos, pela sua disponibilidade e presteza em todos os momentos que precisei...

À "casa do forno";

Minha segunda casa em Bauru (talvez primeira), onde eu sempre encontrei o acolhimento e apoio das pessoas especiais que ali trabalhavam. Foi no "forno" onde vivi alguns dos melhores momentos de Bauru e levarei estas lembranças comigo para sempre... Agradeço aos demais integrantes Adriana, Tiago, Lúcia, Fabrício, Tálita pelos momentos especiais e experiências compartilhadas.

Às amigas especiais e inesquecíveis,

Jú, obrigada pela harmonia do nosso lar. A nossa convivência foi uma experiência muito rica que levarei comigo. Débora, Tici, Marineli, Angélica, Aninha, Ana Paula, Rosa, Tata...todas vocês, cada uma do seu modo, em momentos diferentes deixaram marcas e boas lembranças que hoje carrego comigo. Obrigada por terem contribuído para minha formação pessoal e por terem me proporcionado estes momentos. 
Ás minhas maiores incentivadoras Olimpia e Rebeca, Agradeço imensamente a força, torcida e a confiança depositada. Vocês para mim representam um exemplo a ser seguido de dedicação, profissionalismo e amor à profissão. E através desses exemplos vocês contribuíram MVITO para este momento. Obrigada!

Aos meus colegas de curso, Mônica,Débora, Jú, Adriana, Paty, Aninha, Tici, Cecília, André, Miguel, Adilson, Odirlei, Carla G, Carla R. Kioshi, Flávia, Terezinha, Anuradha, Renato, Léo, Diego...agradeço pelas experiências compartilhadas.

$\mathcal{N} a ̃ o$ posso esquecer de agradecer algumas pessoas generosas e prestativas que foram fundamentais em algumas etapas do meu trabalho:

Etiene, obrigada pelos dentes.... Vinícios e Mirela, obrigada pela ajuda no MMEV, e Heitor, obrigada pela formatação da minha tese.

"Que a nossa mensagem seja a nossa própria vida." Mahatma Gandhi 


\section{Agradecimentos}

À Faculdade de Odontologia de Bauru, na pessoa da diretora Prof. Dra. Maria Fidela de Lima Savarro, do vice-diretor Luis Fernando Pegoraro e do coordenador da Pós-Graduação Prof. Dr. José Carlos Pereira.

Aos professores do Departamento de Dentística e Materiais Dentários: Prof. Dr. Ricardo Marins de Carvalho, Prof. ${ }^{a}$ Dr. ${ }^{a}$ Maria Teresa Atta, Prof. ${ }^{a}$ Dr. ${ }^{a}$ Maria Fidela de Lima Savarro, Prof. Dr. Eduardo Batista Franco, Prof. Dr. José Carlos Pereira, Prof. Dr. Carlos Eduardo Francischone, Prof. Dr.Aquira IshiKiriama, Prof. Dr.José Mondelli, Prof. Dr. Rafael Francisco Lia Mondelli, Prof. Dr. Paulo Amarante de Araújo, Prof. Dr.Paulo Afonso Silveira Francischone e Prof. Dr. César Antunes de Freitas, pela importante contribuição na minha formação profissional.

A todos os funcionários da Fo6, em especial: Karen, Elô, Rita, Valéria, Ângela, Seu Dito, Júnior, Ziley, Zuleica, vocês foram fundamentais para que eu conseguisse alcançar meu objetivo final. Obrigada!

A seu $\mathcal{N}$ elson, agradeço por você ter sido sempre tão solícito e disponível todos momentos que precisei. Sempre soube que poderia contar com você e eu sou extremamente grata por isso!

À $\mathcal{N}$ euza, sua presença e sua alegria transformou o nosso ambiente de trabalho em um lugar leve e acolhedor. Obrigada!

Aos funcionários da Pós-Graduação: Aninha, Cleusinha, Giane, Letícia, Soninha e Débora, pelo apoio, profissionalismo e prestatividade..

Ao pessoal do Xerox, por sua imensa simplicidade, sempre prontos a cooperar.

À Faculdade de Odontologia de Piracicaba- VNICAMP pela disponibilidade do MEV.

À FAPESP, pelo apoio à ciência e pelo financiamento dos meus estudos. Agradeço a confiança depositada e espero ter retribuído o investimento recebido. 


\section{Sumário}

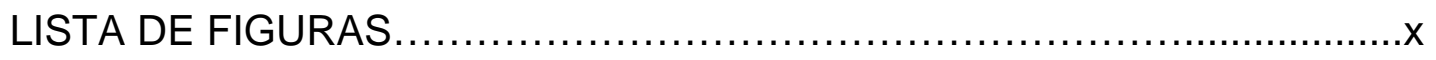

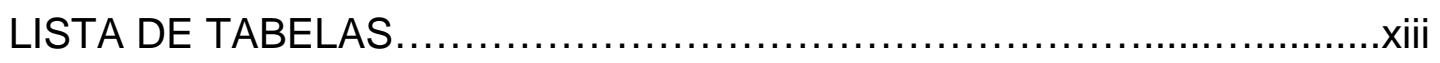

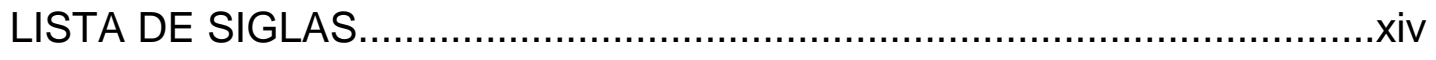

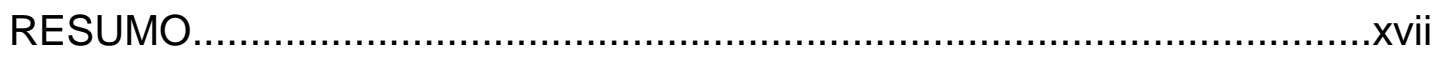

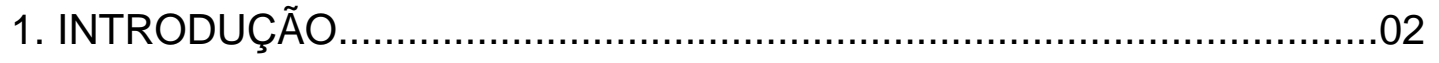

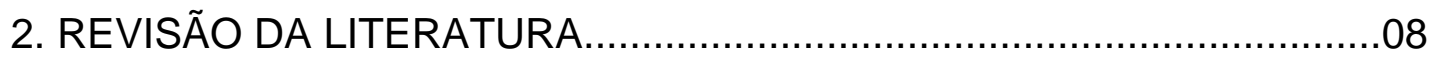

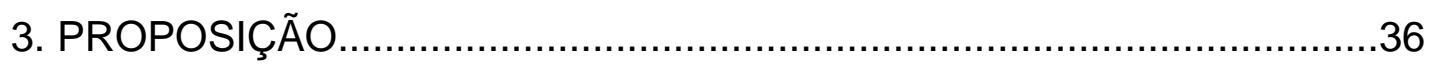

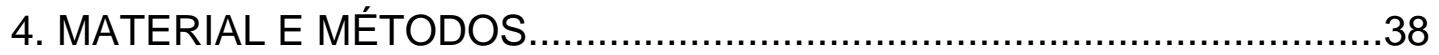

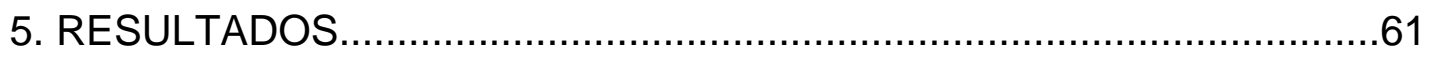

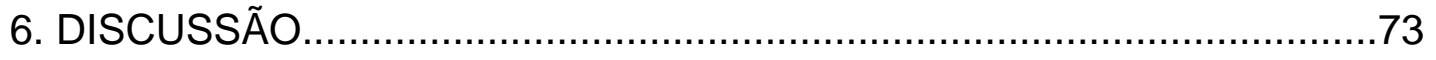

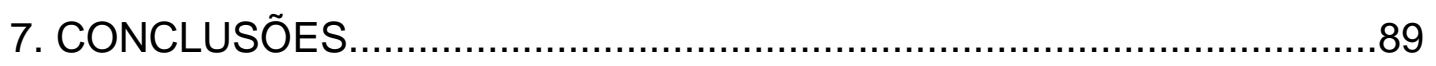

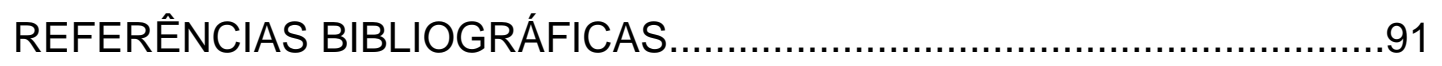

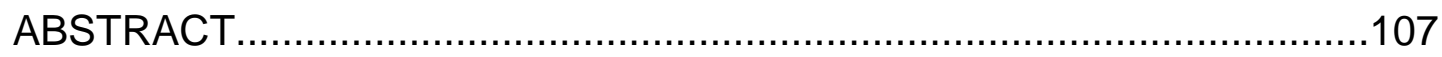




\section{Lista de Figurase Gráficos}

Figura 1. Realização do preparo coronário. .39

Figura 2. Seção da porção radicular e remoção da polpa coronária. .40

Figura 3. Preparo e montagem do espécime na placa de acrílico.

Figura 4. Aparato de medição da condutividade hidráulica. .43

Figura 5. Detalhes do aparelho Flodec indicando a forma de coleta e leitura dos dados de condutividade hidráulica. .45

Figura 6. Seqüência de aplicação dos diferentes tratamentos. 53

Figura 7. Seqüência do procedimento de moldagem da superfície adesiva. .56

Figura 8. Técnica de preparo da resina epóxica e vazamento dos moldes..58

Figura 9. Adesivo Single Bond aplicado segundo as recomendações do fabricante. A imagem mostra maior formação de bolhas na região cervical do preparo. .68 
Figura 10. Adesivo Single Bond aplicado após aplicação do gel de oxalato de potássio. A imagem mostra a formação de bolhas e a presença de irregularidades e provavelmente "sujeira" na superfície do adesivo

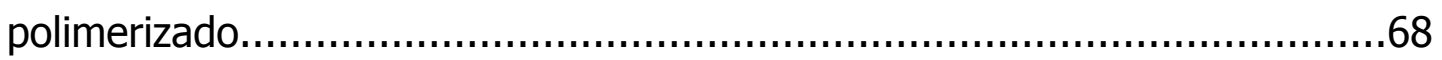

Figura 11. Adesivo One up Bond F aplicado segundo as recomendações do fabricante mostrando a presença de poucas bolhas, provavelmente em áreas

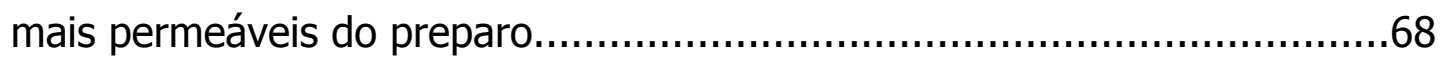

Figura 12. Adesivo One Up Bond $F$ em associação com o oxalato de potássio. A imagem mostra em maior aumento a presença de pequenas bolhas de água em toda superfície do adesivo 68

Figuras 13 e 14. Adesivo AdheSE aplicado segundo as recomendações do fabricante. 69

Figura 15 e 16. Adesivo AdheSE após aplicação do oxalato de potássio, mostrando a presença de poucas bolhas na superfície do adesivo. .70 
Gráfico 1. Média \pm desvio-padrão da condutividade hidráulica da dentina de acordo com os diferentes tratamentos de superfície para cada adesivo estudado. Os valores são percentuais relativos à

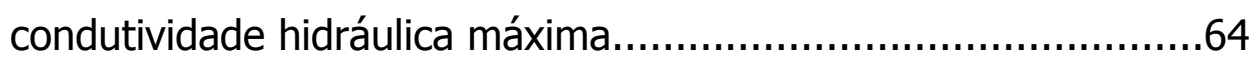




\section{Lista de Tabelase Quadros}

Quadro 1. Materiais selecionados e seus respectivos.

Tabela 1. Média \pm desvio-padrão da condutividade hidráulica verificada para grupos formados pelos diversos tratamentos e adesivos, tendo como base a medida de condutividade hidráulica máxima (100\%). Valores estão expressos em porcentagem.

Tabela 2. Efeitos da presença da smear layer e dos procedimentos adesivos na permeabilidade dentinária. Os valores expressam a permeabilidade como porcentagem do valor máximo, dentina condicionada, definido como $100 \%$. Valores designados com a mesma letra na mesma linha não são estatisticamente significantes quando comparados pelo teste $t$ de Student para dados pareados. 65 


\section{Lista de abreviaturas, siglase símbolos}

$\begin{array}{ll}\alpha & \text { significância } \\ { }^{0} \mathrm{C} & \text { graus celsius } \\ \% & \text { porcentagem } \\ 4 \text {-META } & \text { 4-metacriloxi-etil-trimetilato-anidrido } \\ \text { ADF } & \text { adesivo AdheSE segundo as recomendações do fabricante } \\ \text { ADE } & \text { adesivo AdheSE aplicado de forma experimental } \\ \text { ADO } & \text { adesivo AdheSE aplicado em associação com o oxalato de } \\ \text { potássio } & \\ \text { Bis-GMA } & \text { bisfenol-glicidil-metacrilato } \\ \text { cm } & \text { centímetro } \\ \text { DP } & \text { desvio-padrão } \\ \text { EDTA } & \text { ácido etileno diamino tetra-acético } \\ \text { g } & \text { grama } \\ \text { HEMA } & \text { hidróxi-etil-metacrilato } \\ \text { MEV } & \text { microscópio eletrônico de varredura } \\ \text { min } & \text { minutos } \\ \text { mg } & \text { miligrama } \\ \text { ml } & \text { mililitros }\end{array}$




\begin{tabular}{|c|c|}
\hline $\mathrm{mm}$ & milímetro \\
\hline $\mathrm{mm}^{2}$ & milímetro quadrado \\
\hline $\mathrm{mW}$ & miliwatts \\
\hline $\mathrm{n}$ & número de espécimes \\
\hline $\mathrm{nL}$ & nanolitro \\
\hline OBF & $\begin{array}{l}\text { adesivo One Up Bond F aplicado segundo as recomendações do } \\
\text { fabricante }\end{array}$ \\
\hline OBE & adesivo One Up Bond F aplicado de forma experimental \\
\hline OBO & $\begin{array}{l}\text { adesivo One Up Bond F aplicado em associação com o oxalato } \\
\text { de potássio }\end{array}$ \\
\hline $\mathrm{P}-\mathrm{H}$ & pontes de hidrogênio \\
\hline S & segundos \\
\hline SBF & $\begin{array}{l}\text { adesivo Single Bond aplicado segundo as recomendações do } \\
\text { fabricante }\end{array}$ \\
\hline SBO & $\begin{array}{l}\text { adesivo Single Bond aplicado em associação com o oxalato de } \\
\text { potássio }\end{array}$ \\
\hline SL & smear layer \\
\hline TEGDMA & trietilenoglicol de dimetacrilato \\
\hline$\mu \mathrm{m}$ & micrômetro \\
\hline$\mu \mathrm{L}$ & microlitro \\
\hline$X$ & número de vezes \\
\hline
\end{tabular}




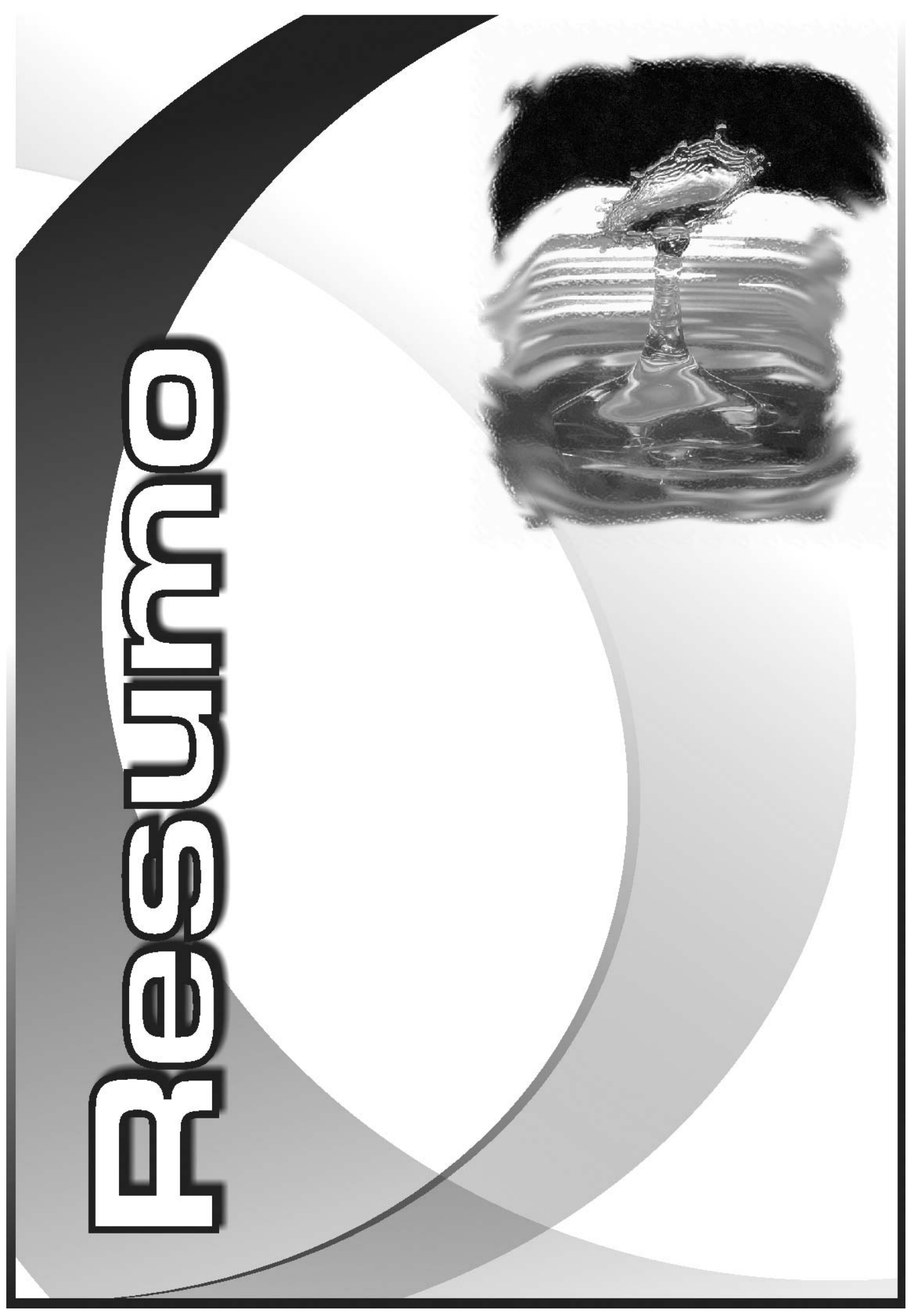




\section{Resumo}

A tendência atual de simplificação de sistemas adesivos transformou-os em polímeros altamente hidrofílicos e prontamente susceptíveis à permeação de água através de sua estrutura. Estudos recentes têm demonstrado que os sistemas adesivos simplificados se comportam como membranas semipermeáveis, permitindo o movimento de fluidos através da sua estrutura. Soluções a base de oxalato de potássio são efetivos agentes de redução da condutividade hidráulica dentinária. Quando são aplicados na dentina após o condicionamento ácido, podem ser utilizados em associação com os sistemas adesivos sem o comprometimento da adesão. Este trabalho objetivou avaliar os efeitos dos sistemas adesivos AdheSE, One Up Bond F e Single Bond, associados ou não a uma solução a base de oxalato de potássio, na condutividade hidráulica da dentina. Foram realizados preparos de coroas totais em terceiros molares humanos que tiveram suas raízes secionadas e a polpa coronária removida. Os segmentos coronários obtidos foram conectados ao "Medidor de Fluxo" (Flodec-System, De marco Engineering, Switzerland). A condutividade hidráulica dos espécimes foi mensurada antes e após a aplicação dos sistemas adesivos Single Bond -3M ESPE, One UP Bond F -Tokuyama Inc, AdheSe- Ivoclar- Vivadent. Os adesivos foram 
aplicados seguindo as recomendações do fabricante (grupos SBF, ADF e $\mathrm{OBF}$ ), de forma experimental (grupos $\mathrm{ADE}$ e $\mathrm{OBE}$ ), e em combinação com uma solução a base de oxalato de potássio (grupos SBO, ADO e OBO). Cada espécime teve seu valor de permeabilidade original (smear layer) e máxima (após condicionamento ácido) medidos anteriormente, os quais serviram como parâmetros para o cálculo das respectivas alterações frente aos tratamentos, expressas em porcentagem. Após a determinação da condutividade hidráulica, os preparos foram moldados para obtenção de réplicas em resina, as quais foram examinadas em MEV (JEOL 2800, Japão) para qualificar a permeação de fluido através do adesivo. A Análise de variância a 2 critérios mostrou que apesar dos procedimentos adesivos causarem uma redução significante $(p<0.05)$ na condutividade hidráulica da dentina condicionada, nenhum foi capaz de eliminar completamente a passagem de fluidos através do adesivo polimerizado. Para os três adesivos testados, o tratamento com o oxalato de potássio foi o tratamento mais eficaz na redução da permeabilidade dentinária e esta diferença foi estatisticamente significante quando comparada aos outros tratamentos $(p<0,05)$. Não houve diferença entre os três sistemas adesivos estudados com relação à redução da permeabilidade dentinária $(p>0,05)$. A análise das réplicas em MEV mostrou que mesmo após a polimerização do adesivo, a transudação de fluidos pôde ser identificada na superfície de todas réplicas examinadas. Nenhum dos sistemas adesivos testados foi capaz de eliminar a 
permeação de fluidos através da dentina, contudo a associação destes adesivos com uma solução a base de oxalato de potássio reduziu de forma significante a permeabilidade dentinária. 


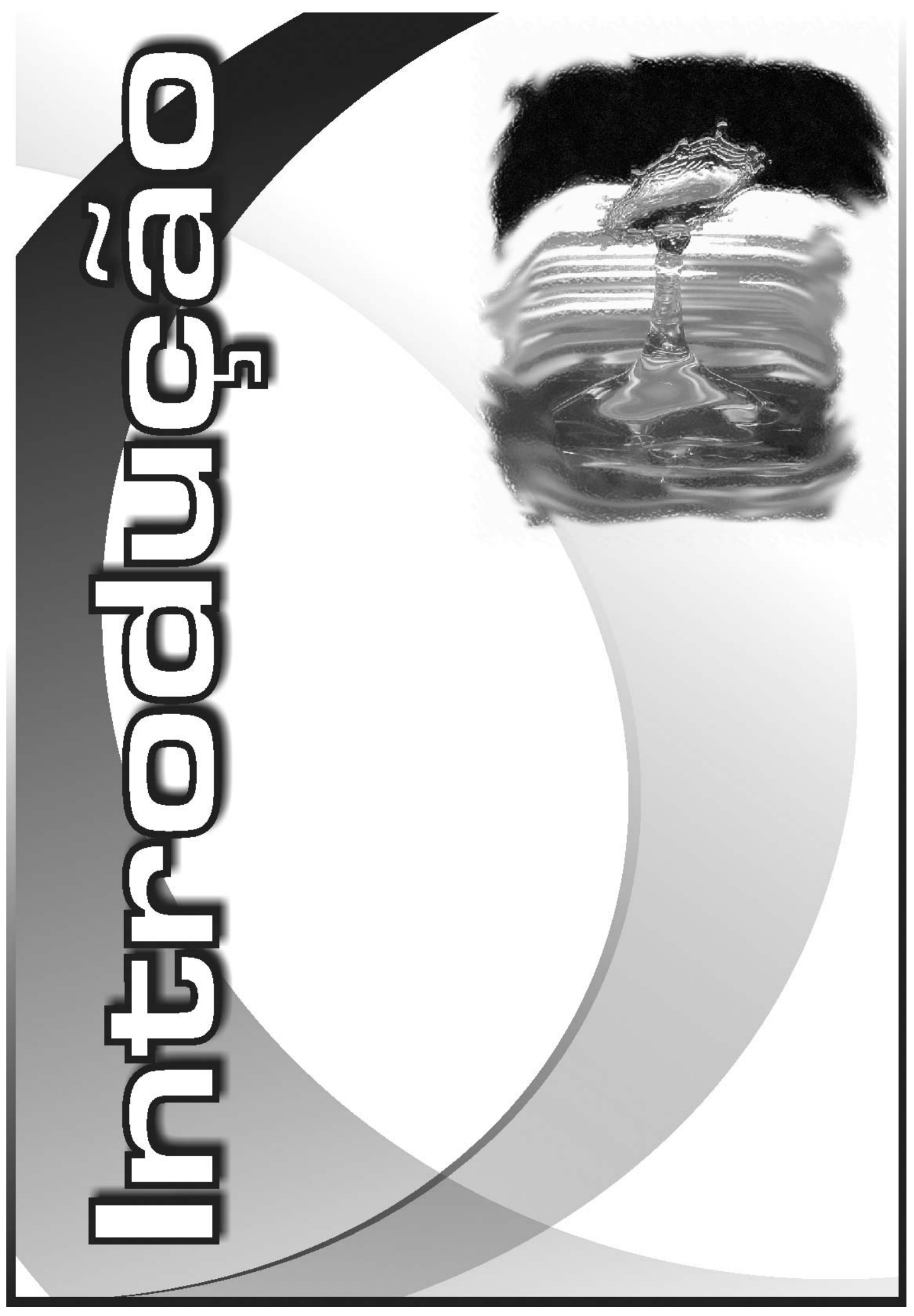




\section{Introdução}

Os maiores avanços obtidos nas pesquisas sobre os sistemas adesivos durante as últimas décadas estão estritamente ligados a um melhor entendimento das características do substrato dentinário e como este reage aos procedimentos adesivos.

A adesão ao esmalte pode ser considerada como um procedimento seguro, pois devido a homogeneidade da sua composição, a adesão conseguida a este substrato é uniforme e estável (SWIFT, PERDIGÃO e HEYMANN ${ }^{86}$, 1995). Ao contrário, a dentina se caracteriza por um substrato naturalmente heterogêneo, e suas variações regionais de morfologia e fisiologia determinam a não uniformidade de adesão. Devido a estes fatos, a eficácia de um adesivo dentinário depende de sua maior ou menor sensibilidade às variações do substrato, aliados ao conhecimento científico do operador (PASHLEY ${ }^{56}$, 1984; PASHLEY et al. ${ }^{67}, 1978$ ).

Os sistemas adesivos atuais são classificados em convencionais e autocondicionantes. Os convencionais empregam o passo operatório de condicionamento ácido da superfície dentária separadamente, enquanto que os autocondicionantes não requerem a aplicação isolada do ácido para produzir porosidades no substrato (CARVALHO et al. ${ }^{13}$, 2004). 
A técnica úmida de adesão é considerada um procedimento associado aos sistemas adesivos convencionais que utilizam o condicionamento ácido total. A água é a responsável por manter as fibrilas de colágeno da dentina desmineralizada expandidas, evitando seu colapso e mantendo os espaços interfibrilares, facilitando a permeação dos monômeros resinosos e conseqüentemente a formação da camada híbrida (CARVALHO et al. ${ }^{10}$, 1999; PASHLEY e CARVALHO ${ }^{63}$, 1997). Devido a este fato, esses sistemas contêm monômeros hidrofílicos dissolvidos em diferentes solventes (acetona, água e etanol) que auxiliam e são essenciais para a difusão da resina na superfície dentinária, tornando-os compatíveis com a característica de umidade superficial desse substrato.

A maior desvantagem desses sistemas é a difícil decisão no estabelecimento da apropriada extensão do molhamento do substrato dentinário, pois a umidade requerida varia para os diferentes sistemas adesivos (PEREIRA et al. ${ }^{73}$, 2001; REIS et al. ${ }^{78}$, 2003) sendo, portanto, sujeita a interpretações diversas (FERRARI e TAY ${ }^{23}$, 2003; PEREIRA et al. ${ }^{73}$, 2001).

O surgimento dos adesivos autocondicionantes possibilitou a redução dos passos operatórios e conseqüente diminuição das falhas advindas da sensibilidade técnica encontrada nos adesivos convencionais. Esses adesivos proporcionam uma adesão aos substratos dentais através da ação dos monômeros ácidos que penetram através da smear-layer, condicionando a 
dentina subjacente e criando espaços que são preenchidos pelos monômeros resinosos, simultaneamente ao processo de desmineralização (TAY e PASHLEY ${ }^{87}$, 2001). Porém, como o mecanismo de autocondicionamento depende da acidificação da solução no momento da aplicação, todos esses sistemas também contêm água em sua formulação, além de solventes orgânicos e diluentes que tornam a solução fluida o suficiente para infiltrarse nos tecidos dentais.

A "evolução" apresentada pelos sistemas adesivos atuais estabeleceu um grande paradoxo. A simplificação dos passos associada à incorporação de água e componentes hidrofílicos em sua composição os tornam mais susceptíveis à absorção de água e conseqüente degradação ao longo do tempo (CARRILHO et al ${ }^{9}$, , 2004; GARCIA et al. ${ }^{28}$, 2003).

Existe um conceito geral de que os adesivos dentinários sejam uma membrana impermeável com capacidade de selar a superfície da dentina exposta e proteger o complexo dentino-pulpar (COX, et al. $\left.{ }^{20}, 1999\right)$. Estudos recentes, entretanto, demonstram que a aplicação de sistemas adesivos em restaurações de resina composta não garante o completo selamento da dentina exposta, permitindo que ocorra a movimentação de fluidos através da dentina, mesmo sob a restauração finalizada (BOUILLAGUET et al. $^{2}$,2000). Isso ocorre não somente devido às imperfeições do processo adesivo, mas também pelo fato de que as resinas adesivas, ao contrário do 
que se acreditava, são membranas permeáveis e permitem a passagem de fluidos através de sua estrutura (TAY et al. ${ }^{93,94}$, 2002; 2003).

Esses fatores associados contribuem para os valores altos de condutividade hidráulica da dentina observados após os procedimentos adesivos (HASHIMOTO et al. ${ }^{36}$ 2004, CHERSONI, et al. ${ }^{14}, 2004$ ), e para os relatos de sensibilidade pós-operatória, ocasionalmente reportados após o uso de adesivos dentinários convencionais em procedimentos restauradores (OPDAM et al. ${ }^{53}, 1998$; UNEMORI et al $\left.{ }^{99},, 2001\right)$.

Soluções a base de oxalato de potássio são efetivos agentes de redução da condutividade hidráulica da dentina e têm sido recomendadas para o tratamento da sensibilidade dentinária (GREENHILL e PASHLEY ${ }^{33}$, 1981; CAMPS et al. ${ }^{6}$, 1998; CUENIN et al. ${ }^{21}$, 1991). O oxalato de potássio reage com íons cálcio da superfície e do fluido dentinário formando cristais insolúveis de oxalato de cálcio, os quais se precipitam sobre a dentina exposta e reduzem sua permeabilidade (KERNS et al ${ }^{42} ., 1991$, GILLAM et al. $\left.{ }^{29}, 2001\right)$.

Quando essas soluções de oxalato de potássio são aplicadas em preparos cavitários, sobre a smear layer, a formação dos cristais de oxalato de cálcio sobre a superfície compromete a posterior união dos adesivos dentinários (PASHLEY, TAO e PASHLEY ${ }^{66}$, 1993). Porém, se a dentina for previamente condicionada com uma solução ácida, os íons cálcio não estarão mais disponíveis na superfície e quando a solução de oxalato é aplicada, os 
íns de oxalato se difundem através dos túbulos dentinários até que encontrem íons cálcio na sub-superfície para reagir. Dessa maneira, os cristais de oxalato de cálcio se formam dentro dos túbulos dentinários, reduzindo ou eliminando o volume de fluidos que poderia permear através da camada do adesivo (TAY et al., 2003 95; PASHLEY et al. ${ }^{70}$, 2001).

O problema da permeabilidade dos adesivos tem profundas implicações clínicas e podem frustrar as expectativas de sucesso dos procedimentos adesivos, principalmente em longo prazo. Diante do exposto, torna-se oportuna a investigação dos efeitos de sistemas adesivos convencionais e autocondicionantes na condutividade hidráulica da dentina, o que reflete sua capacidade de selamento e ainda, os possíveis benefícios da associação destes com uma solução a base de oxalato de potássio na redução da permeabilidade dentinária. 


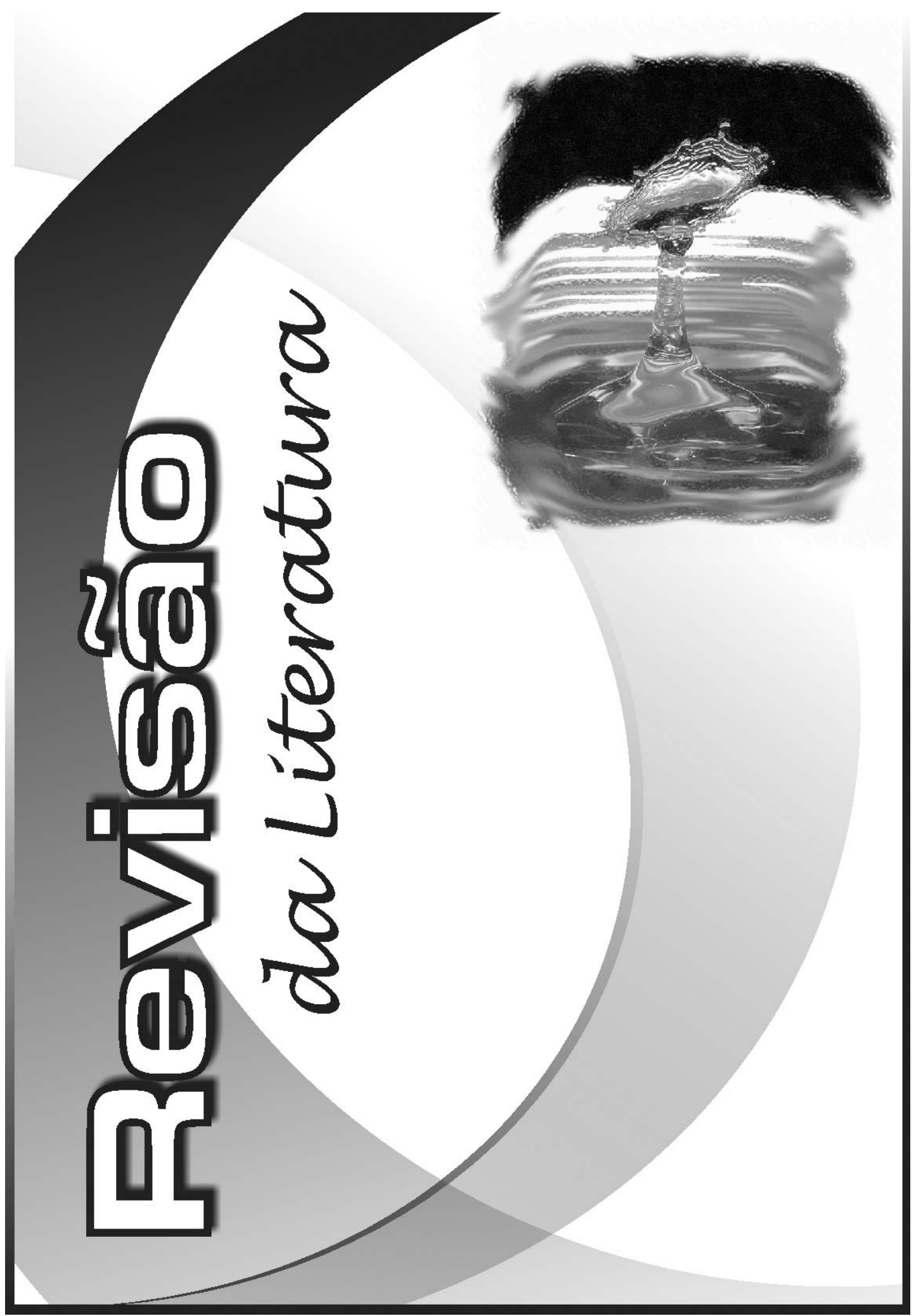




\section{Revisão da Literatura}

\section{Características morfológicas da dentina}

A dentina é um tecido duro, de características visco-elásticas e avascular que envolve a câmara pulpar. É composta quimicamente, por peso, de aproximadamente $70 \%$ de material inorgânico, 20\% de material orgânico e $10 \%$ de água. Seu componente inorgânico consiste basicamente de hidroxiapatita e a fase orgânica de colágeno tipo I (TEN CATE ${ }^{98}$, 1998).

Uma característica inerente à dentina é a sua permeação por túbulos que atravessam toda a sua espessura, permeando-a em um sistema canalicular com numerosas anastomoses. Como a área da câmara pulpar é menor do que a área da superfície externa do dente, esses túbulos adquirem uma disposição radial, determinando variações regionais de número e diâmetro em cada segmento da dentina (MJÖR; SVEEN e HEYERAAS ${ }^{47}$, 2001).

Dentro dos túbulos dentinários encontramos os fluidos tissulares da polpa e os prolongamentos citoplasmáticos das células odontoblásticas. O comprimento dos processos odontoblásticos e a real extensão que estes ocupam dentro dos túbulos dentinários é um fator muito importante, pois 
reflete na participação direta destas células no mecanismo da sensibilidade dentinária.

Cada túbulo dentinário é rodeado por um "colar" de dentina peritubular, rica em minerais de hidroxiapatita e pobre em colágeno. Originalmente, cada túbulo tem $3 \mu \mathrm{m}$ de diâmetro, mas a formação da dentina peritubular na dentina superficial, próximo a junção amelodentinária, estreita o lúmen dos túbulos para 0.6- $0.8 \mu \mathrm{m}$. Como próximo à polpa quase não existe a presença de dentina peritubular, principalmente em pacientes jovens, os túbulos mantêm seu diâmetro original de $3 \mu \mathrm{m}$ (GARBEROGLIO e BRÄNNSTRÖM ${ }^{27}$, 1976).

Devido à disposição radial dos túbulos, as características morfológicas da dentina variam de acordo com a região. Os túbulos dentinários podem representar apenas 5\% da área total da superfície da dentina junto a junção amelo-dentinária e aumentar em direção à polpa para mais de $25 \%$ da área total de superfície. Em outras palavras, o número de túbulos por $\mathrm{mm}^{2}$ varia de 20.000 na junção amelo-dentinária para 45.000 próximo à polpa (GARBEROGLIO e BRÄNNSTRÖM ${ }^{27}$, 1976). Como esses túbulos são preenchidos pelo fluido dentinário (constituído essencialmente por água), a dentina profunda é mais úmida, mais porosa e conseqüentemente mais permeável, devido a maior concentração de túbulos dentinários por unidade de área (PASHLEY $\left.{ }^{59}, 1996\right)$. 
Preenchendo os espaços entre os túbulos se encontra a dentina intertubular. Esta consiste em uma rede entrelaçada de fibrilas de colágeno tipo I, na qual cristais de apatita são depositados (TEN CATE ${ }^{98}$, 1998). A área de superfície ocupada pela dentina intertubular varia regionalmente em proporção inversa aos túbulos, ocupando somente $11 \%$ da superfície próxima à polpa e chegando a 96\% junto à junção amelo-dentinária (GARBEROGLIO e BRÄNNSTRÖM ${ }^{27}$, 1976).

\section{O complexo dentino-pulpar}

O tecido pulpar e o dentinário não só dividem um íntimo relacionamento de desenvolvimento embriológico, mas também são histologicamente e funcionalmente o mesmo tecido. Por isso, apesar de existirem algumas diferenças na composição dessas duas estruturas (a polpa é um tecido conjuntivo mole e a dentina um tecido conjuntivo duro), estes tecidos funcionam de forma integrada e daí a derivação do nome "Complexo Dentino-Pulpar" (GOLDBERG e LASFARGUES ${ }^{31}$, 1995).

Histologicamente a polpa é composta por quatro zonas distintas: a camada odontoblástica, uma camada acelular de Weil, uma camada rica em células e o centro da polpa, caracterizado por vasos e nervos. As células principais da polpa são os odontoblastos, fibroblastos, células 
ectomesenquimais indiferenciadas, macrófagos e outras células imunocompetentes (TEN CATE ${ }^{98}$, 1998).

Os vasos sanguíneos e linfáticos entram e deixam a polpa através dos forames apical e acessórios e estão associados intimamente às arteríolas e feixes nervosos mielinizados e não mielinizados, que também penetram pelo forame apical. Estes nervos seguem os vasos sanguíneos até que se ramificam e formam uma rede de terminações nervosas na região próxima às células odontoblásticas. As fibras mielinizadas do tipo $A$ e as não mielinizadas do tipo C são nervos somáticos aferentes responsáveis pelos impulsos da dor. Mediante estímulo, ambas terminações nervosas sensoriais e simpáticas são ativadas no início do processo inflamatório e são os iniciadores da vasodilatação, responsável pela resposta protetora através do aumento do volume sanguíneo e da permeabilidade vascular na área afetada (MJÖR, SVEEN E HEYERAAS ${ }^{47}$, 2001).

O fluido intersticial circunda os elementos morfológicos da polpa e funciona como uma ligação entre as células, o plasma sanguíneo e o fluido linfático. A pressão hidrostática normal no fluido intersticial da polpa é relativamente alta, na faixa de 5 a 20 mmHg ( HEYERAAS ${ }^{37}$, 1989).

A fisiologia pulpar sob condições de normalidade e principalmente durante respostas inflamatórias depende de interações entre as células, os vasos sanguíneos e linfáticos, o fluido intersticial e os nervos pulpares (MJÖR, SVEEN e HEYERAAS ${ }^{47}$, 2001). 
As células mais importantes do complexo dentino-pulpar são sem dúvida os odontoblastos. Uma única camada dessas células se localiza na periferia do tecido pulpar, separando-o da pré-dentina. Cada odontoblasto tem uma extensão para dentro dos túbulos dentinários chamada de processo odontoblástico. Essas células são as responsáveis pela formação da dentina durante a formação do órgão dentário, chamada de dentina primária. Após a erupção do dente, estes continuam a formar dentina em uma contínua deposição, porém, de uma forma mais lenta. Esta dentina é chamada de dentina secundária ou fisiológica e freqüentemente não pode ser distinguida da dentina coronária primária, pois possui a mesma proporção de mineral e material orgânico, além de uma estrutura tubular contínua com a dentina primária. A dentina formada em resposta a um estímulo localizado, como por exemplo, uma lesão cariosa ou um procedimento restaurador, pode ser chamada de dentina terciária, irregular, reacional ou reparadora. Diferente da dentina primária ou secundária, que se forma ao longo de toda margem dentina-polpa, a dentina terciária é produzida apenas pelas células diretamente afetadas pelos estímulos. Esta dentina pode apresentar túbulos regulares em continuidade com os da dentina secundária, túbulos esparsos em número e irregularmente arranjados, ou ausência de túbulos (TEN CATE $98,1998)$.

Se os odontoblastos primários forem destruídos por inflamação, bactéria, ou forem removidos durante o preparo cavitário, células 
mesenquimais precursoras na polpa são capazes de se diferenciar em novas células odontoblásticas para formar dentina reparadora (PASHLEY ${ }^{58}$, 1994; MJÖR, SVEEN e HEYERAAS ${ }^{47}$, 2001).

A formação da dentina terciária representa um importante mecanismo de defesa e capacidade de regeneração do complexo dentino-pulpar. A interface que se forma entre a dentina formada pelas células odontoblásticas primárias (dentina primária ou secundária) e pelas células que se diferenciaram (dentina terciária reparadora), pode ser particularmente importante, já que os túbulos das duas dentinas não se comunicam diretamente e, portanto, essa camada age como uma barreira ao ingresso de agentes agressores (MJÖR, SVEEN e HEYERAAS ${ }^{47}$, 2001). A incongruência de orientação dos túbulos também impede que haja livre movimentação de fluidos da polpa para a superfície e vice e versa, eliminando, ainda que localmente, os mecanismos de permeabilidade da dentina.

\section{Fatores relacionados com a hipersensibilidade dentinária}

Existem três mecanismos hipotéticos que buscam explicar o fenômeno da sensibilidade dentinária: (1) a dentina contém terminações nervosas que respondem quando ela é estimulada; (2) os odontoblastos servem como receptores e ligam-se aos nervos pulpares; (3) a natureza tubular da dentina permite o movimento de líquido dentro do túbulo quando o estímulo é 
aplicado e este movimento é registrado pelas terminações nervosas livres da polpa próxima à dentina (TEN CATE ${ }^{98}$, 1998, BRÄNNSTRÖM e ÄSTROM ${ }^{4}$, 1972).

Não há dúvidas que a polpa é amplamente inervada e é certo também que alguns nervos penetram em uma curta distância dentro de alguns túbulos dentinários. Por outro lado, não há evidência da presença de nervos na dentina externa, supostamente a mais sensível (LILJA ${ }^{45}, 1979$ ), contrariando assim a primeira hipótese em questão.

A segunda hipótese também foi reconsiderada, pois estudos não conseguiram demonstrar uma relação sináptica entre os odontoblastos e os nervos pulpares. Adicionalmente, para que isso ocorresse, os estímulos aplicados na superfície da dentina teriam que interagir diretamente com os processos citoplasmáticos.

Como os processos odontoblásticos são os responsáveis pela formação dos túbulos dentinários, por muitos anos admitiu-se que toda extensão do túbulo era ocupada pelo mesmo. Tal suposição foi contestada quando BRÄNNSTRÖM e GARBEROGLIO ${ }^{5}$ em 1972 examinaram a dentina humana fraturada com microscopia eletrônica de varredura. Os pesquisadores observaram que o processo odontoblástico se estendia apenas 0,7 $\mathrm{mm}$ para dentro da dentina, ficando o restante do túbulo vazio. Outros trabalhos em seqüência também demonstraram que os prolongamentos odontoblásticos 
não se estendem mais do que um terço do comprimento do túbulo em condições normais (HOLLAND ${ }^{38}$, 1976; MJÖR; SVEEN e HEYERAAS ${ }^{47}$, 2001). As evidências experimentais obtidas após uma série de estudos in vitro e in vivo realizados principalmente por BRÄNNSTRÖM e colaboradores levam-nos hoje a aceitar a teoria hidrodinâmica para explicar o fenômeno da hipersensibilidade dentinária. Esta teoria advoga que a movimentação rápida dos fluidos dentinários dentro dos túbulos excita os mecano-receptores da polpa e iniciam impulsos nas fibras nervosas, causando uma dor aguda, bem localizada e transitória (PASHLEY ${ }^{58}$, 1994; VONGSAVAN e MATTHEWS ${ }^{101}$, 1992; BRÄNNSTRÖM ${ }^{3}$, 1986), sem o envolvimento direto das células odontoblásticas.

Esta teoria explica por que a anestesia local falha em bloquear a sensibilidade dentinária e porque a dor pode ser produzida por mudanças térmicas, sondagem mecânica, soluções hipertônicas e desidratação (BRÄNNSTRÖM e ASTRÖM ${ }^{4}$, 1972).

Em concordância com a teoria hidrodinâmica, alguns estudos já comprovaram que a dentina hipersensível tem uma maior quantidade de túbulos abertos quando comparada com a dentina não sensível (ABSI, ADDY e ADAMS ${ }^{1}, 1987$; YOSHIYAMA et al. $\left.{ }^{107}, 1990\right)$. Portanto, a permeabilidade da dentina (condutividade hidráulica) exerce um papel fundamental no processo da sensibilidade dentinária. 
Quando a dentina é exposta aos fluidos bucais, estímulos táteis, térmicos, evaporativos e osmóticos podem ser transmitidos para polpa através dos túbulos dentinários, causando irritação pulpar (PASHLEY ${ }^{59}$, 1996). Como resposta, há um estímulo imediato para que os fluidos dentinários migrem rapidamente em direção à superfície, na tentativa de proteger a polpa e "limpar" os produtos irritantes. Quando isso ocorre, os nervos pulpares são ativados diretamente através de deformação (PASHLEY e MATTEWS 62, 1993; BRÄNNSTRÖM e ASTRÖM ${ }^{4}$, 1972). Esses nervos, quando ativados, não só provocam informações sensoriais, mas também liberam neuropeptídeos, os quais induzem efeitos locais no tecido pulpar, como a liberação de mediadores inflamatórios, aumento da permeabilidade vascular e do fluxo sanguíneo. A elevação da pressão no tecido pulpar torna a dentina "hipersensível" e toda a resposta causada por produtos bacterianos ou simplesmente pela inflamação neurogênica criada pelo estímulo da dor, aumenta ainda mais o fluxo de fluidos dentinários para o exterior (em direção à superfície) (PASHLEY $\left.{ }^{57}, 1986\right)$.

Existem inúmeros mecanismos físico-químicos que tendem a reduzir a permeabilidade dentinária e barrar o contato da polpa com o meio externo. Os fluidos dentinários são compostos por minerais, como cálcio e fosfato na forma ionizada. O seu movimento contínuo provocado pela exposição da dentina ao meio externo pode provocar, em longo prazo, a deposição de cristais nas paredes laterais dos túbulos reduzindo seu diâmetro (MJÖR ${ }^{46}$, 
1985; PASHLEY ${ }^{57}$, 1986). Como a saliva é uma solução saturada de cálcio e fosfato, também contribui para obstrução dos túbulos. Esta dentina composta de túbulos que foram obliterados fisiologicamente como resposta a um irritante pode ser chamada de dentina esclerótica (TEN CATE ${ }^{98}$, 1998).

O movimento de fluidos dentro dos túbulos dentinários pode ocorrer em ambas as direções. Por exemplo, a geração de calor durante um preparo cavitário ou durante a polimerização do adesivo ou resina causa o movimento dos fluidos para dentro, em direção à polpa. Ao contrário, a dessecação da dentina com ar, o estímulo térmico do frio e a aplicação de substâncias hipertônicas na dentina podem, osmoticamente, induzir o movimento dos fluidos em direção à superfície (PASHLEY ${ }^{58}$, 1994; HASHIMOTO et al. ${ }^{36}$, 2004). A diferença na direção do movimento determina características sensoriais diferentes. O movimento de fluidos em direção à superfície é o principal causador da sensibilidade dentinária propriamente dita, provavelmente por provocar uma maior deformação das terminações nervosas (BRÄNNSTRÖM e ASTRÖM ${ }^{4}$, 1972).

A permeabilidade da dentina não é uniforme e varia de acordo com a área de superfície e espessura da dentina, o comprimento, diâmetro e número de túbulos dentinários por unidade de área, proximidade da câmara pulpar e a presença ou ausência da smear layer (PASHLEY et al. ${ }^{67}$ 1978; MJÖR, SVEEN e HEYERAAS ${ }^{47}$, 2001; REEDER et al. ${ }^{77}$, 1978; PASHLEY et al. 71 , 2002). 
Como já foi visto, quanto mais próximo da polpa, maior a quantidade de túbulos por unidade de área e, conseqüentemente, maior a condutividade hidráulica da dentina e maior a influência da pressão pulpar estimulando o fluxo de fluidos em direção a superfície. Por isso, em um mesmo preparo cavitário existem regiões mais permeáveis e provavelmente mais sensíveis do que outras, devido a menor espessura dentinária e conseqüentemente maior proximidade do corno pulpar (PASHLEY ${ }^{57}$, 1986; RICHARDSON et al. ${ }^{79}$, 1991).

\section{Determinação da condutividade hidráulica da dentina}

A difusão e a filtração são os dois mecanismos responsáveis pela passagem de substâncias pela dentina e que podem ser usados para mensurar a condutividade hidráulica da dentina em testes laboratoriais (PASHLEY $\left.{ }^{58}, 1994\right)$.

Na difusão, o transporte de substâncias ocorre de uma área de alta concentração para uma área de baixa concentração. Neste processo não há movimento de fluidos, somente deslocamento molecular.

A quantificação do fluxo de moléculas através da dentina por difusão pode ser usada para mensurar a condutividade hidráulica da dentina (PASHLEY et al. ${ }^{67}$ 1978), porém, para que uma molécula atravesse 1-2 mm de dentina são necessários aproximadamente 30-120 minutos, dependendo 
do tamanho da molécula. Devido à lentidão do processo de difusão, este não é o método de escolha mais comumente empregado para medir a permeabilidade dentinária (PASHLEY ${ }^{58}$, 1994).

Por outro lado, o processo de difusão através da dentina é importante especialmente com relação aos efeitos terapêuticos de substâncias dessensibilizantes que atuam no tecido pulpar, através da alteração da excitabilidade dos nervos. Para que estes agentes atuem sobre os nervos pulpares, devem se difundir através da dentina para alcançar estes nervos (PASHLEY e MATTHEWS ${ }^{62}$, 1993).

O método mais simples e mais utilizado para se medir a permeabilidade dentinária, ou a eficácia de agentes dessensibilizantes é através da quantificação da filtração de líquidos através dos túbulos dentinários, representada pela condutividade hidráulica da dentina. Na filtração, a movimentação de fluidos ocorre devido à presença de um gradiente de pressão e não devido a diferenças na concentração das substâncias dissolvidas no líquido (REEDER et al. ${ }^{77}$, 1978; GREENHIL e PASHLEY ${ }^{33}, 1981$; PASHLEY ${ }^{56}, 1984$, PASHLEY ${ }^{59}$, 1996).

A condutividade hidráulica de um tecido expressa a facilidade com que os fluidos podem movimentar-se através de uma barreira permeável, sob uma determinada pressão, em um espaço de tempo (PASHLEY $\left.{ }^{56}, 1984\right)$, e é expressa pela seguinte fórmula: 


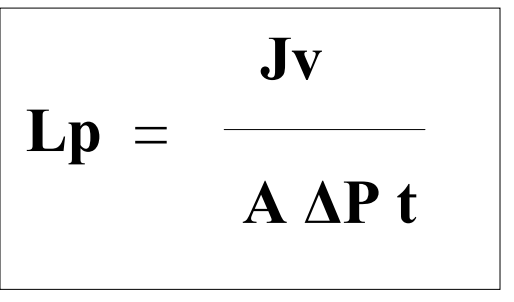

$\mathrm{Jv}=$ fluxo, em $\mu \mathrm{L}$

$A$ = área de superfície dentinária, em $\mathrm{cm}^{2}$

$\mathrm{t}=$ tempo, em minutos

$\Delta \mathrm{P}=$ gradiente de pressão hidrostática, em $\mathrm{cm} \mathrm{H}_{2} \mathrm{O}$

$\mathrm{Lp}=$ Condutividade hidráulica, em $\mu \mathrm{cm}^{-2} \mathrm{~min}^{-1} \mathrm{H}_{2} \mathrm{O}^{-1}$

Este método utiliza um sistema de fluido sob pressão constante, conectado a câmara pulpar através de tubos de aço inoxidável e polietileno e uma micropipeta. Quando a pressão é aplicada, o fluido é forçado a atravessar uma determinada área de dentina (com valores de espessura e área de superfície conhecida). Através do acompanhamento de uma bolha de ar inserida na micropipeta, a taxa de filtração de fluido, ou seja, de fluxo (em $\mu \mathrm{L}$ por minuto) é calculado, baseado no diâmetro da micropipeta e comprimento percorrido pela bolha. Desta forma, o deslocamento da bolha pode ser convertido por deslocamento de volume (PASHLEY e DEPEW ${ }^{61}$, 1986; REEDER et al. ${ }^{77}$,1978).

A pressão aplicada pode coincidir com a pressão fisiológica pulpar (1.47 $\mathrm{kPa}$ ou $14 \mathrm{~cm}$ de $\mathrm{H}_{2} \mathrm{O}$ ) ou ser acima desta, usada nestes casos como conveniência para forçar uma quantidade de fluido suficiente para uma medição acurada em menor tempo. Como a pressão e o fluxo estão proporcionalmente ligados, quanto maior a pressão maior a filtração de fluidos (POMMEL e CAMPS ${ }^{76}, 2001$; CAMPS et al. ${ }^{6}, 1997$ ).

A influência do tempo de medição nos resultados dos testes de permeabilidade esta relacionada com a pressão empregada nesses testes. 
Um estudo realizado por CAMPS e colaboradores ${ }^{6}$, em 1997 , mostrou que a permeabilidade dos espécimes não varia com o tempo de medição, se a pressão empregada for de $1.3 \mathrm{kPa}$ (pressão fisiológica). Nestes casos, a água atravessa a dentina sem alterar os constituintes orgânicos dos túbulos dentinários. Ao contrário, quando uma maior pressão é aplicada, esta pode ser capaz de remover ou alterar os constituintes orgânicos dos túbulos dentinários, superestimando ou subestimando a permeabilidade dos espécimes (PASHLEY, LIVINGSTON e GREENHILL ${ }^{64}$, 1978). Isso significa que quanto maior a sensibilidade do aparelho leitor, menor pressão pode ser empregada e tempos curtos de medição são recomendados.

Segundo PASHLEY 56 1984, devido ao formato cônico dos túbulos dentinários, o cálculo do fluxo de fluidos na dentina ("Jv" da fórmula acima) deve obedecer à mesma lei física para líquidos em capilares. A fórmula que rege o movimento de fluidos através de capilares é conhecida como equação de Poieseuille-Hagen:

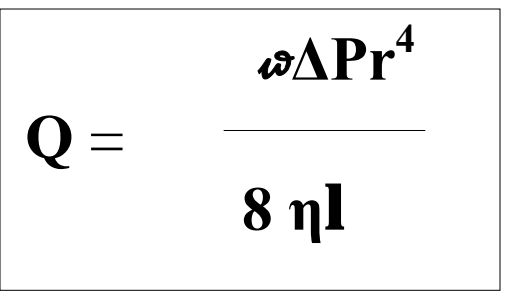

$\mathrm{Q}=$ taxa de fluxo de fluido

$\mathrm{I}$ = comprimento do túbulo

$\Delta \mathrm{P}=$ gradiente de pressão hidrostática

$\eta=$ viscosidade do fluido

$r^{4}=$ raio do túbulo 
Desta forma, o fluxo (necessário para o cálculo da condutividade hidráulica da dentina) será determinado basicamente por alterações no comprimento e diâmetro dos túbulos dentinários (ELGALAID et al. ${ }^{22}$, 2004; PASHLEY 59, 58, 1996; 1994).

Pela análise da fórmula acima, entende-se que a variável mais influente no fluxo de fluidos através da dentina é o raio dos túbulos dentinários elevado à quarta potência. Esta variável determina que pequenas mudanças no diâmetro dos túbulos exerçam um grande efeito sobre a permeabilidade dentinária (PASHLEY ${ }^{56,57}$, 1984, 1986).

Por este motivo, duas situações básicas devem ser utilizadas como parâmetros quando se quer mensurar o fluxo de fluidos ou a condutividade hidráulica da dentina. A primeira determina que a presença da smear layer é a condição mais efetiva para obstruir os túbulos e reduzir o fluxo de líquidos através da dentina; e a segunda determina que a desmineralização através do condicionamento ácido é a condição que permite maior permeabilidade da dentina, pois altera o diâmetro dos túbulos (RICHARDSON, TAO e PASHLEY 79 , 1991; PASHLEY, LIVINGSTON e GREENHILL ${ }^{64}$, 1978).

Por isso, a condutividade hidráulica dos espécimes é sempre medida inicialmente na presença da smear layer e em seguida após sua remoção através do condicionamento com ácidos, estabelecendo desta maneira os valores de permeabilidade mínima e máxima de cada espécime individualmente. Dessa forma, em experimentos dessa natureza cada dente 
serve como seu próprio controle (BOUILLAGUET ${ }^{2}$, 2000; PASHLEY e DEPEW 61,1986 ; ELGALAID et al. ${ }^{22}$, 2004; CHERSONI et al. ${ }^{15}$, 2004).

\section{Agentes redutores da condutividade hidráulica da dentina}

Baseado na teoria hidrodinâmica, a obliteração dos túbulos dentinários interfere na movimentação dos fluidos e conseqüentemente diminui o potencial de ativação dos nervos, reduzindo assim a sensibilidade dentinária. Por isso, os agentes usados no tratamento da sensibilidade dentinária devem atuar sobre a condutividade hidráulica da dentina através da redução no diâmetro dos túbulos, que seria a forma mais eficiente de redução da permeabilidade da dentina (MJÖR, SVEEN e HEYERAAS ${ }^{47}$, 2001; PASHLEY ${ }^{57}$, 1986).

A aplicação tópica de géis contendo sais solúveis como, por exemplo, fluoreto de sódio a 1,23\%, oxalato de potássio, oxalato férrico, nitrato de potássio, etc... constitui um método usado para barrar a permeabilidade dentinária (GILLAM et al. ${ }^{30}$, 1999; FOGEL e PASHLEY ${ }^{26}$, 1993). Estes sais reagem com os constituintes dentários formando cristais relativamente insolúveis que se depositam na superfície dentinária, bloqueando ou reduzindo o calibre dos túbulos (PASHLEY ${ }^{57}$, 1986). Estes agentes provocam um alívio temporário, pois como se formam na superfície podem ser mais facilmente solubilizados ou removidos pela escovação diária. 
A efetividade do oxalato de potássio como agente de oclusão dos túbulos dentinários e, conseqüentemente, de redução da sensibilidade dentinária já foi comprovada por inúmeros trabalhos in vitro (PEREIRA, SEGALA e GILLAM ${ }^{74}$, 2004; TAY et al. 95, 2003; PASHLEY e GALLOWAY ${ }^{60}$, 1985) e in vivo (MUZZIN e JOHNSON $\left.{ }^{48}, 1989\right)$. O composto preenche dois requisitos necessários para efetividade de um agente dessensibilizante. Além de apresentar afeito oclusivo nos túbulos dentinários, através da formação dos cristais de oxalato de cálcio (PASHLEY ${ }^{57}$, 1986), também apresenta efeito sobre as terminações nervosas. O aumento da concentração de potássio extracelular causa a despolarização do nervo, diminuindo assim sua excitabilidade (MUZZIN e JOHSON ${ }^{48}$, 1989; PASHLEY $\left.{ }^{57}, 1986\right)$.

Um outro método para redução da sensibilidade dentinária faz uso de dessensibilizantes aquosos a base de HEMA ou primers contendo HEMA, sem a utilização do adesivo. Sua ação ocorre devido à precipitação de proteínas do plasma presentes no fluido dentinário (KOLKER et al. ${ }^{44}$, 2002) causando assim a obstrução dos túbulos.

Sob a justificativa de garantir um selamento hermético da dentina exposta através da microretenção, os sistemas adesivos foram sugeridos como um procedimento eficaz para o tratamento da hipersensibilidade dentinária (YOSHIYAMA et al. ${ }^{106}$, 1992). Porém, a obtenção de uma adequada adesão e conseqüente selamento dentinário em dentina profunda de dentes vitais continua sendo imprevisível, devido ao aumento 
considerável da condutividade hidráulica da dentina após a remoção da smear layer (PASHLEY $\left.{ }^{57}, 1986\right)$. A presença de fluido dentinário dentro dos túbulos durante a aplicação dos sistemas adesivos faz com que haja migração desse fluido para a superfície, resultando em micro-bolhas que podem ficar aprisionadas na embocadura dos túbulos, mediante a polimerização do adesivo (TAY, GWINNET e WEI ${ }^{90}$, 1996). Adicionalmente, a contração de polimerização do adesivo faz com que os prolongamentos dentro dos túbulos se afastem das paredes laterais, permitindo a movimentação do fluido dentinário nessa interface (NÄRHI $\left.{ }^{50}, 1985\right)$.

O uso de adesivos autocondicionantes fracos ou moderados pode reduzir a sensibilidade dentinária através da preservação da smear layer e smear plugs e prevenção da diluição dos monômeros resinosos pelos fluidos dentinários (PERDIGÃO 72, 2002). Se versões mais agressivas forem utilizadas, a smear layer é completamente dissolvida e a ação dessensibilizante se dá também pela coagulação das proteínas do plasma causada pelos constituintes do primer (NIKAIDO et al. ${ }^{51}$, 1995). Porém, os monômeros adesivos formam uma fina camada na superfície dentinária (20$50 \mu \mathrm{m}$ de espessura) e apresentam pouca resistência. Estes também podem ser removidos devido à escovação diária ou contato com meio oral.

Alternativamente, um método utilizado na tentativa de reduzir a condutividade hidráulica da dentina faz uso de dessensibilizantes a base de oxalato de potássio não resinosos em associação com adesivos dentinários 
(PASHLEY et al ${ }^{70}, 2001$ ). Estudos prévios demonstraram que quando o cálcio é removido da superfície antes da aplicação do gel de oxalato (através do condicionamento ácido da dentina), os íons de oxalato se difundem através dos túbulos dentinários até que encontrem íons cálcio na subsuperfície $(5-7 \mu \mathrm{m})$ para reagir. Dessa maneira, os cristais de oxalato de cálcio se formam dentro dos túbulos dentinários, reduzindo a permeabilidade dos mesmos e, ao mesmo tempo, não comprometem a infiltração dos sistemas adesivos na superfície da dentina, permitindo a formação da camada híbrida acima desses cristais (TAY et al. ${ }^{95}, 2003$; PASHLEY et al. ${ }^{70}$, 2001).

\section{Mecanismos atuais de adesão ao substrato dentário}

O princípio fundamental de adesão aos tecidos dentais baseia-se em um processo de troca, onde material inorgânico é substituído por resina. Este processo envolve duas fases: a primeira consiste na remoção de minerais do substrato (fosfato de cálcio) para criação de microporosidades; e a segunda, também chamada de fase de hibridização, envolve a infiltração e polimerização in situ de monômeros resinosos através das porosidades criadas (VAN MEERBEEK et al. ${ }^{100}$ 2003; PASHLEY et al. ${ }^{69}$, 1993).

O processo de hibridização dos tecidos dentais pode ser realizado em um, dois ou três passos operatórios. Porém, independente do número de 
passos, os adesivos atuais são classificados de acordo com sua "estratégia de adesão" em convencionais e autocondicionantes (CARVALHO et al. ${ }^{13}$, 2004; VAN MEERBEEK et al. ${ }^{100}$ 2003).

Os adesivos convencionais de três passos compreendem os passos de condicionamento ácido, aplicação do primer e aplicação do adesivo, todos separadamente. O primer desses sistemas é uma solução de monômeros hidrofílicos diluídos em solventes orgânicos. Enquanto os solventes desempenham a função de remover a água que mantém as fibrilas de colágeno expandidas, os monômeros hidrofílicos revestem as fibrilas de colágeno expostas pela desmineralização, a fim de facilitar a posterior infiltração do adesivo. Como a água é a responsável por manter as fibrilas de colágeno da dentina desmineralizada expandidas, a técnica de adesão com estes adesivos é também chamada de "técnica úmida" (PASHLEY e CARVALHO ${ }^{63}$, 1997).

Na versão simplificada dos adesivos convencionais (2 passos), os componentes do primer hidrofílico foram misturados com os monômeros resinosos hidrofóbicos do adesivo, permitindo a aplicação de uma única solução compatível com o substrato úmido da dentina, após o condicionamento ácido.

Os adesivos convencionais requerem uma maior atenção e cuidado durante sua aplicação devido a sua sensibilidade técnica, principalmente quando se trabalha com dentina profunda de dentes vitais (TAY e PASHLEY 
89 , 2003), pois a remoção da smear layer provoca o profuso movimento de fluidos em direção a superfície, principalmente em áreas próximas ao corno pulpar (PASHLEY et al. ${ }^{71}$, 2002; PASHLEY et al. ${ }^{68}$, 1987). Quando o adesivo é aplicado, os fluidos oriundos da dentina subjacente, somados à água proveniente da técnica úmida, permeiam por entre sua estrutura antes da sua completa polimerização, resultando no aprisionamento de bolhas de água ao longo da interface adesiva. Este fenômeno é conhecido como "overwet" ou "sobremolhamento" (TAY, GWINNETT e WEI, $1996{ }^{90}$ ) e pode ser o responsável por relatos de sensibilidade pós-operatória após restaurações adesivas (BRÄNNSTRÖM e ASTRÖM ${ }^{4}, 1972$; OPDAM et al ${ }^{53}$, 1998).

Os sistemas autocondicionantes não requerem a aplicação isolada de um ácido para produzir as porosidades no substrato, portanto não utilizam a "técnica úmida" de adesão. Estes adesivos incorporam em sua formulação monômeros resinosos ácidos que simultaneamente desmineralizam e infiltram os tecidos dentais. Nesses casos, a smear layer é dissolvida ou incorporada ao substrato de adesão (PASHLEY e CARVALHO ${ }^{63}$, 1997), o que teoricamente reduz a probabilidade de ocorrência de sensibilidade pósoperatória e problemas relacionados ao movimento de fluidos dentinários durante o procedimento adesivo (ITTHAGARUN e TAY ${ }^{39}$, 2000).

Estes adesivos são classificados em fracos, moderados e fortes, baseados na habilidade de solubilizar a smear layer e desmineralizar a 
dentina subjacente. As versões mais fracas desses adesivos ( $\mathrm{pH} 2.0$, por exemplo), preservam a smear layer e smear plugs e incorporam este substrato como parte constituinte da camada híbrida. As versões mais agressivas são capazes de dissolver a smear layer e smear plugs e formar uma camada híbrida similar em espessura àquela formada com os adesivos convencionais (TAY e PASHLEY ${ }^{87}$, 2001).

Nos adesivos autocondicionantes de dois passos, o caráter ácido e fluido é encontrado no primer do sistema. O segundo passo é representado pela aplicação de uma resina de baixa viscosidade de características hidrofóbicas, que não contém solvente nem água na sua formulação. Os adesivos autocondicionantes nos quais o primer é a solução acidificada recebem o nome de "primer autocondicionante".

A versão ainda mais simplificada dos sistemas adesivos é a do adesivo autocondicionante de "passo único". Nesse caso, uma única solução que contém monômeros ácidos, solventes, diluentes e água é aplicada diretamente sobre o substrato dental, desempenhando a função de desmineralização, infiltração e ligação com o material restaurador. Como o adesivo é o responsável pela desmineralização, estes são chamados de "adesivos autocondicionantes".

Devido à demanda por praticidade clínica, rapidez e diminuição da sensibilidade técnica, os adesivos autocondicionantes têm ganhado espaço 
no cenário da odontologia adesiva, ainda que limitações significativas existam para esses materiais.

\section{Os adesivos simplificados são membranas permeáveis}

O fenômeno da nanoinfiltração foi originalmente utilizado para definir a passagem de moléculas traçadoras, como por exemplo, o nitrato de prata, através da camada híbrida, mesmo na ausência de fendas interfaciais. A descrição inicial da nanoinfiltração foi originada a partir de espécimes tratados com adesivos convencionais, onde se acreditava ser causada pela incompleta infiltração dos monômeros resinosos na dentina desmineralizada (SANO et al. ${ }^{81}$, 1995; PASHLEY et al. ${ }^{71}$, 2002).

Estudos mais recentes, no entanto, demonstraram a ocorrência do fenômeno da nanoinfiltração também em espécimes tratados com adesivos autocondicionantes, onde teoricamente não deveria haver discrepância entre a zona desmineralizada e a zona infiltrada, já que ambos os processos ocorrem simultaneamente (TAY e PASHLEY ${ }^{89}$, 2003; TAY, PASHLEY e YOSHIYAMA ${ }^{91}$, 2001; TAY et al. ${ }^{93}$, 2002; CARVALHO et al. ${ }^{13}$, 2004).

Como a nanoinfiltração nesses casos não pode ser atribuída à incompleta infiltração dos monômeros resinosos, a teoria para explicar o fenômeno é a de que os solventes presentes nos sistemas adesivos, juntamente com a água do substrato dentinário, permanecem na interface 
de união após a polimerização do adesivo, promovendo canais para a ocorrência da nanoinfiltração e degradação da interface ao longo do tempo (TAY et al. ${ }^{93}$, 2002; TAY, PASHLEY e YOSHIYAMA ${ }^{91}$, 2002).

O padrão reticular da nanoinfiltração observado em camadas de adesivos odontológicos (depósitos de prata orientados perpendicularmente a superfície da camada híbrida) assemelha-se a manifestação morfológica do "water treeing", termo introduzido primeiramente no Japão por MIYASHITA em 1969, o qual se refere à manifestação morfológica do processo de deterioração induzida pela água em polímeros de cabos elétricos.

Em cabos revestidos por polietileno, os "water trees" representam caminhos preenchidos por água, os quais são formados eletroquimicamente pela oxidação dos polímeros hidrofóbicos em misturas mais hidrofílicas. 0 termo originou-se devido à semelhança aos galhos de uma árvore quando esses "canais" são analisados microscopicamente (TAY e PASHLEY ${ }^{89}$, 2003).

No contexto da adesão dentinária, um processo eletroquímico não é necessário para formação dos "water trees", desde que monômeros hidrofílicos e água estejam presentes nos adesivos. A água é capaz de permear pelas porções mais hidrofílicas do adesivo, criando caminhos de infiltração, os quais podem ser detectados por microscopia de transmissão com o auxílio de agentes traçadores como o nitrato de prata amoniacal. As análises qualitativas destas interfaces mostram a localização dos sítios 
hidrofílicos no adesivo e vias de circulação da água (TAY e PASHLEY ${ }^{89}$, 2003; TAY, PASHLEY e YOSHIYAMA ${ }^{91}$, 2002).

"Water trees" ao longo da interface adesiva podem agir como "sólidos hidrofílicos" que permitem a passagem contínua de água da dentina vital adjacente em direção à superfície, mesmo após a polimerização do adesivo. Como este movimento através do adesivo é lento, clinicamente é improvável que esta permeabilidade seja acompanhada de severa sensibilidade pósoperatória (TAY e PASHLEY ${ }^{89}$, 2003), mas representa um processo de degradação da união que pode levar, em longo prazo, à formação de fendas associadas à sensibilidade dentinária.

Devido à simplificação, os adesivos atuais são caracterizados pela ausência de uma camada adicional de resina hidrofóbica. Portanto, os monômeros ácidos não polimerizados (inibidos pelo oxigênio) presentes na camada superficial do adesivo ficam em contato direto com os compósitos aplicados em seguida.

Trabalhos realizados por SANARES, TAY e colaboradores ${ }^{80}$ em 2001, mostraram que compósitos de polimerização química, que utilizam a amina terciária aromática como um dos componentes da catalização, são incompatíveis com adesivos que contém monômeros ácidos. Quando uma resina de polimerização dual ou química é colocada em contato com os sistemas adesivos simplificados, a amina terciária desses sistemas reage com os monômeros ácidos do adesivo, prejudicando o processo de polimerização 
e reduzindo a resistência adesiva por comprometimento da união entre adesivo e resina.

Outros estudos reportaram que a reação adversa que ocorre entre os adesivos simplificados e os compósitos químicos não era a única responsável pelas falhas que ocorriam nesta interface (TAY et al. ${ }^{93}, 2002$; TAY et al. ${ }^{94}$, 2003). Os autores desses trabalhos evidenciaram que a permeabilidade dos adesivos simplificados também afeta a ligação entre resinas compostas químicas ou fotopolimerizáveis (quando a polimerização é retardada). Especula-se que durante o processo lento de polimerização haja um aumento do gradiente de concentração osmótica na interface, induzindo a migração dos fluidos dentinários em direção à interface não polimerizada. A água advinda da dentina hidratada atravessa a camada híbrida alcançando a interface entre o sistema adesivo e a resina composta, formando bolhas que agiriam como indutoras de tensão e contribuiriam para as falhas de resistência de união.

A aplicação de uma resina hidrofóbica neutra em associação com os adesivos simplificados, técnica também conhecida como "resin coating" (CARVALHO et al. ${ }^{11}$, 2004), impede que esta incompatibilidade ocorra, pois além de evitar o contato entre a camada superficial do adesivo simplificado e o cimento resinoso, também contribui para impedir que a umidade da dentina migre para superfície e contribua para esta incompatibilidade (KING et al. $\left.{ }^{43}, 2004\right)$. 
A hidrofilia e a estabilidade hidrolítica dos monômeros resinosos são propriedades antagônicas. As características hidrofílicas dos adesivos atuais os tornam propensos à absorção de água oriunda da dentina subjacente ou do meio externo. A água, além de ter a capacidade de plastificar os monômeros e comprometer suas propriedades mecânicas, contribui para sua degradação com o passar do tempo (CARRILHO et al. ${ }^{9}$, 2004).

Os conhecimentos aqui apresentados fundamentam a elaboração deste projeto, no qual uma solução de oxalato de potássio é empregada com a expectativa de que possa reduzir ou eliminar a permeação de fluidos da câmara pulpar para a superfície. Adicionalmente, verifica-se a possibilidade de que adesivos simplificados, permeáveis por natureza, possam ser empregados em associação à solução de oxalato como instrumentos para a redução da permeabilidade dentinária. 


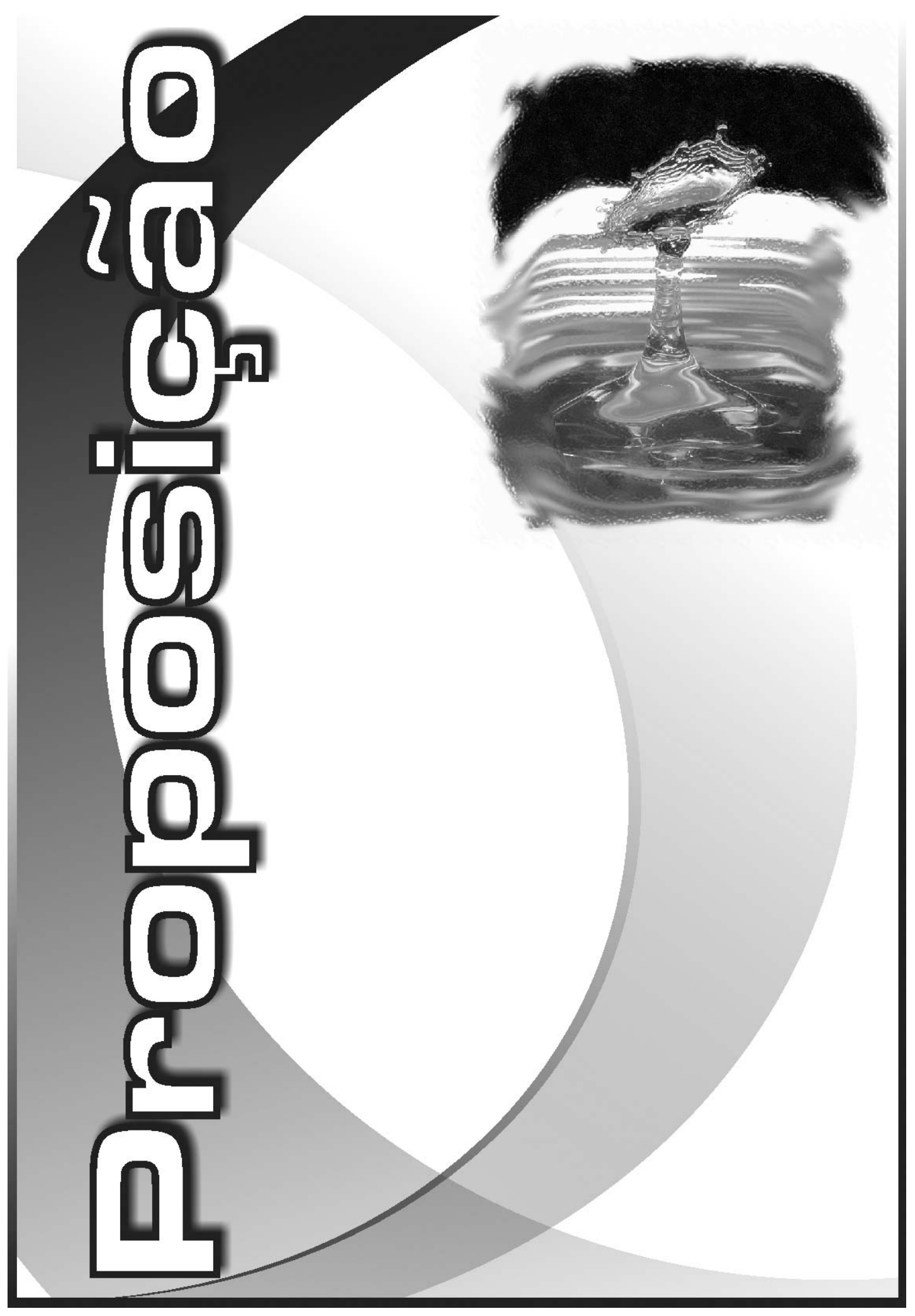




\section{Proposição}

\section{Objetivo geral}

Determinar os efeitos da aplicação de sistema adesivo simplificado convencional e autocondicionantes, em combinação ou não com um produto a base de oxalato de potássio, na condutividade hidráulica da dentina.

\section{Objetivos específicos}

1) Testar a hipótese de que a aplicação de sistema adesivo convencional ou autocondicionantes elimina a condutividade hidráulica da dentina.

2) Testar a hipótese de que a aplicação de oxalato de potássio em combinação com os sistemas adesivos reduz a condutividade hidráulica da dentina. 


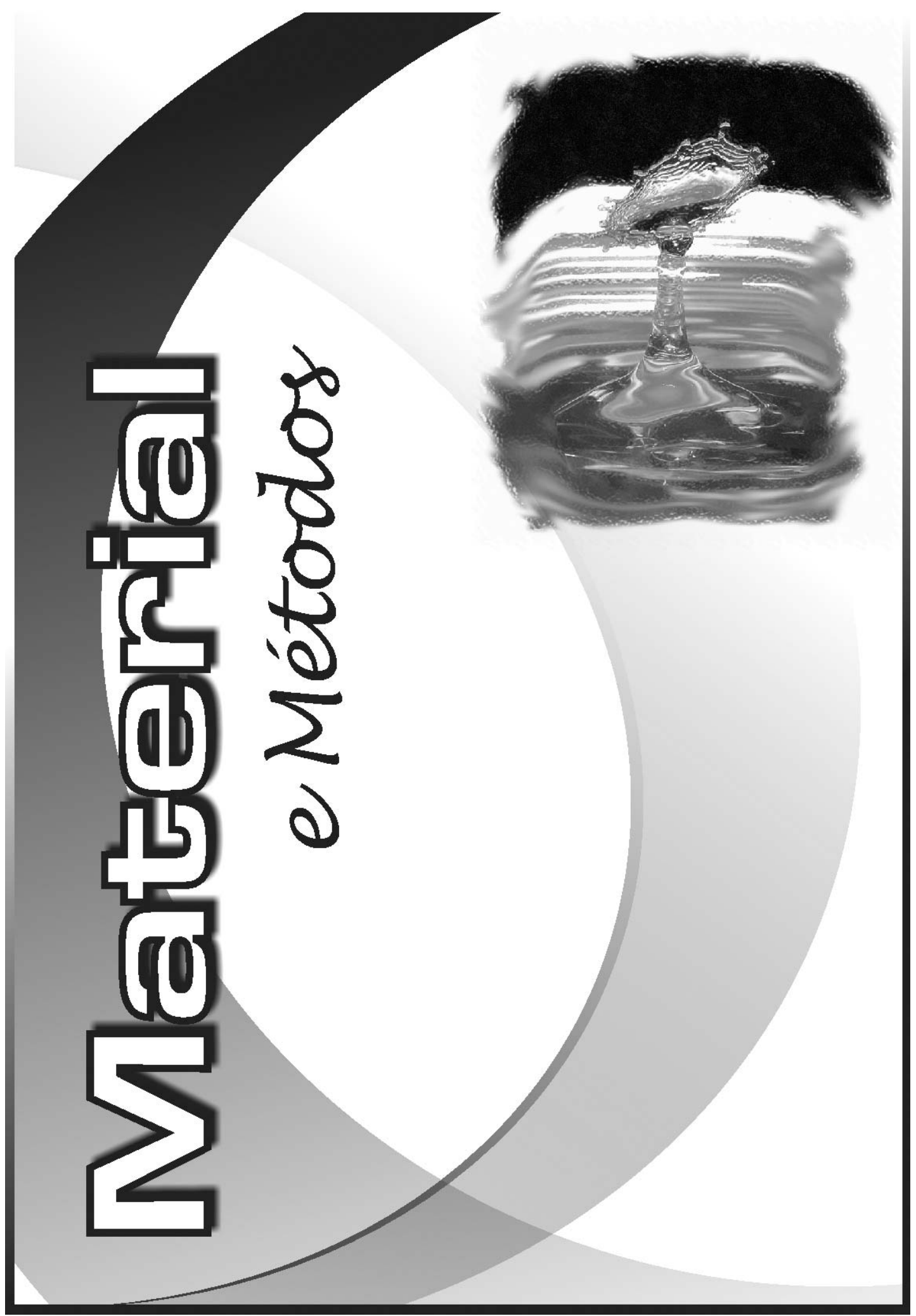




\section{Materiale Métodos}

\section{Seleção dos dentes}

Foram selecionados 59 dentes terceiros molares humanos hígidos, extraídos sob indicação e após assinatura de um termo de consentimento livre esclarecido. O trabalho foi aprovado pelo Comitê de Ética em Pesquisa da FOB-USP (protocolo 71/2003, em anexo). Os dentes foram mantidos sob refrigeração e conservados em timol a $0,1 \%$ até o momento em que foram utilizados.

\section{Confecção dos espécimes para medição da condutividade hidráulica}

Em todos os dentes foram realizados preparos do tipo coroa total, utilizando-se a ponta diamantada 4137 (KG SORENSEN, Ind. Com. Ltda, Barueri-São Paulo) sob alta rotação e irrigação constante. Estas pontas eram substituídas após a confecção de 6 preparos de coroa total. O término dos preparos, em chanfro, localizava-se ao nível da junção amelo-cementária (figura 1). 
Os preparos eram realizados de forma a expor dentina profunda, cuja densidade e o diâmetro médio dos túbulos dentinários são relativamente maiores do que em regiões mais superficiais deste substrato (GARBEROGLIO \& BRANNSTROM $\left.{ }^{27}, 1976\right)$.

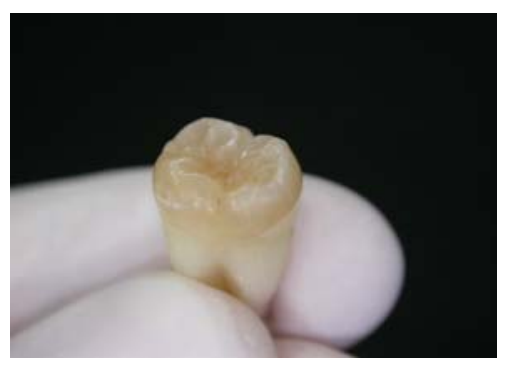

Fig. 1a. Dente terceiro molar hígido

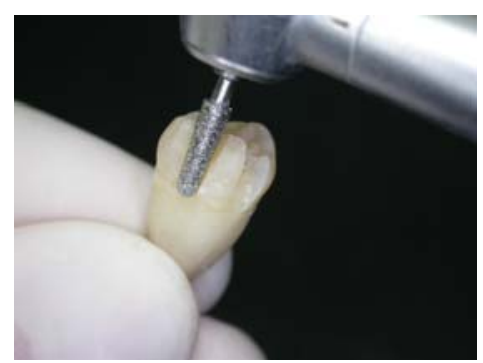

Fig.1b. Preparo tipo coroa total sendo realizado

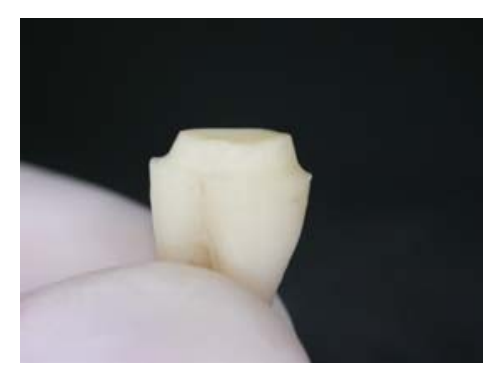

Fig.1c. Preparo confeccionado

Figura 1. Realização do preparo coronário

Após o preparo da porção coronária, os dentes tiveram suas raízes secionadas aproximadamente $2 \mathrm{~mm}$ abaixo da junção amelo-cementária, usando a máquina de corte (I MPTECH PC 10- Boksbrug, Republic of SA), sob lubrificação em água. A polpa coronária foi cuidadosamente removida, evitando tanto o esmagamento da pré-dentina quanto possíveis danos à superfície do teto da câmara pulpar (figura 2). 


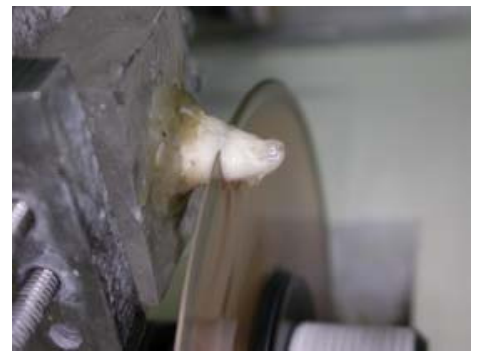

Fig.2a. Seção da porção radicular

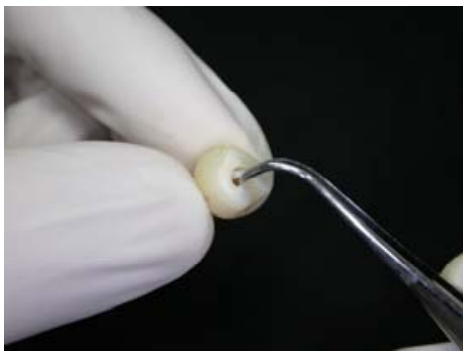

Figs. 2b e 2c. Remoção da polpa coronária

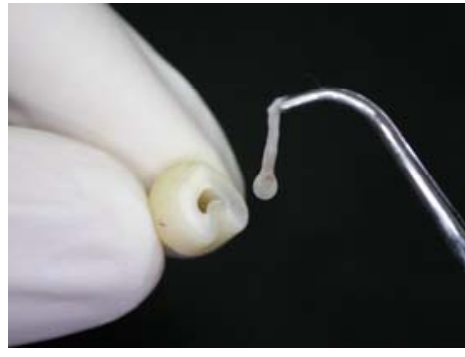

Fig. 2c.

Figura 2. Seção da porção radicular e remoção da polpa coronária

Os segmentos coronários resultantes foram fixados, pela porção radicular, ao centro de uma placa de acrílico de $2 \times 2 \times 0.7 \mathrm{~cm}$, com auxílio de um adesivo a base de cianocrilato (Model Repair II Blue, Sankin Kogyo, K.K., Japão).

Em seguida, a placa de acrílico utilizada foi perfurada em seu lado oposto com ponta diamantada (\#3205) sob alta rotação, de modo que o espaço correspondente à câmara pulpar fosse acessado. Neste orifício foi introduzido uma cânula de aço inoxidável (18 gauge) de aproximadamente 2 cm de comprimento, que foi fixada em posição com adesivo de cianoacrilato (figura 3). A conexão dessa cânula aos capilares flexíveis de polietileno do aparelho de medição de condutividade hidráulica (FLODEC- System, De marco Engineering Geneva, Switzerland) permitiu que a câmara pulpar fosse preenchida com água, e que, assim, a permeabilidade do substrato pudesse ser estimada (PASHLEY ${ }^{57}$, 1986; GREENHILL e PASHLEY ${ }^{33}$, 1981). 

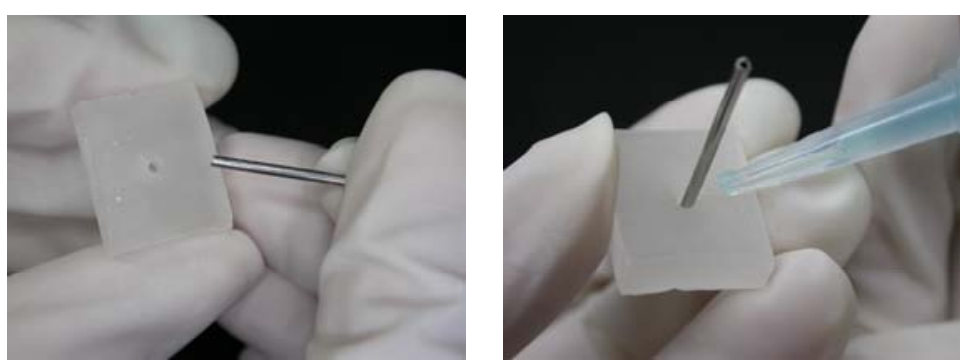

Fig. 3a. Placa perfurada

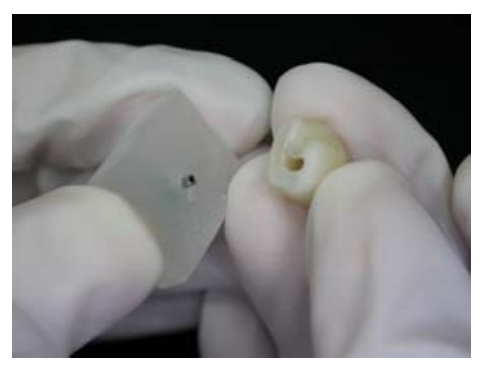

Fig. 3 d,e. Fixação do espécime com cola cianocrilato
Fig. 3b. Fixação do tubo de aço com cola cianocrilato

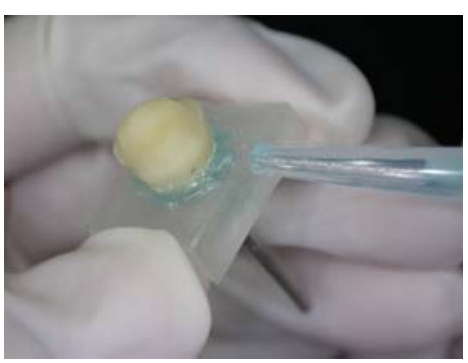

Fig. $3 e$.

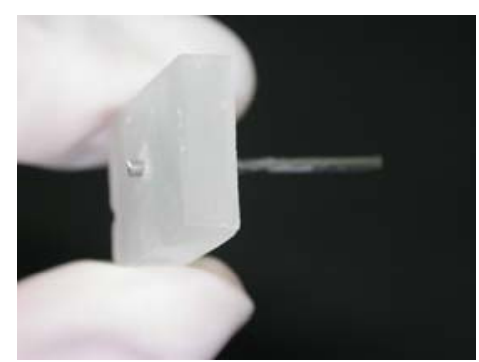

Fig. 3c. Placa pronta para fixação do espécime

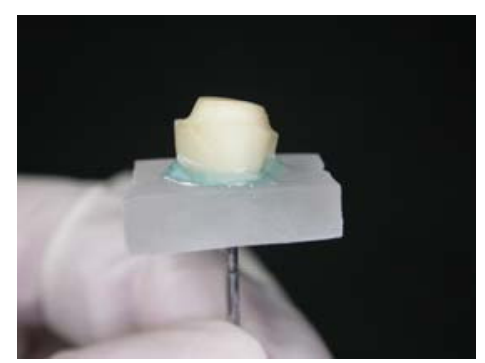

Fig. 3f. Espécime montado na placa de acrílico

Figura 3. Preparo e montagem do espécime na placa de acrílico

A condutividade hidráulica foi mensurada pelo método proposto por PASHLEY e DEPEW ${ }^{61}$, em 1986. O protocolo detalhado é descrito a seguir. 


\section{Medição da condutividade hidráulica}

O segmento coronário (espécime) foi conectado a uma das extremidades do aparelho de medição de condutividade hidráulica (Flodec), por meio de um sistema de tubos de polietileno.

Na extremidade oposta do aparelho, outro capilar de polietileno foi conectado a um reservatório de água, que, por sua vez, foi posicionado a uma altura de $15 \mathrm{~cm}$ em relação à base de sustentação do espécime (BOUILLAGUET et al. ${ }^{2}$, 2000). A elevação desse reservatório a esta posição permitiu que o fluxo de água ocorresse sob uma pressão que simulava àquela que é, aproximadamente, imposta pela polpa em condições fisiológicas (CIUCCHI et al. ${ }^{18}$, 1995).

Todo sistema de tubos de polietileno é conectado por uma porção central, que corresponde a um tubo capilar de vidro de $370 \mathrm{~mm}$ de comprimento e 0,75mm de diâmetro interno, posicionado no aparelho Flodec (figura 4). 


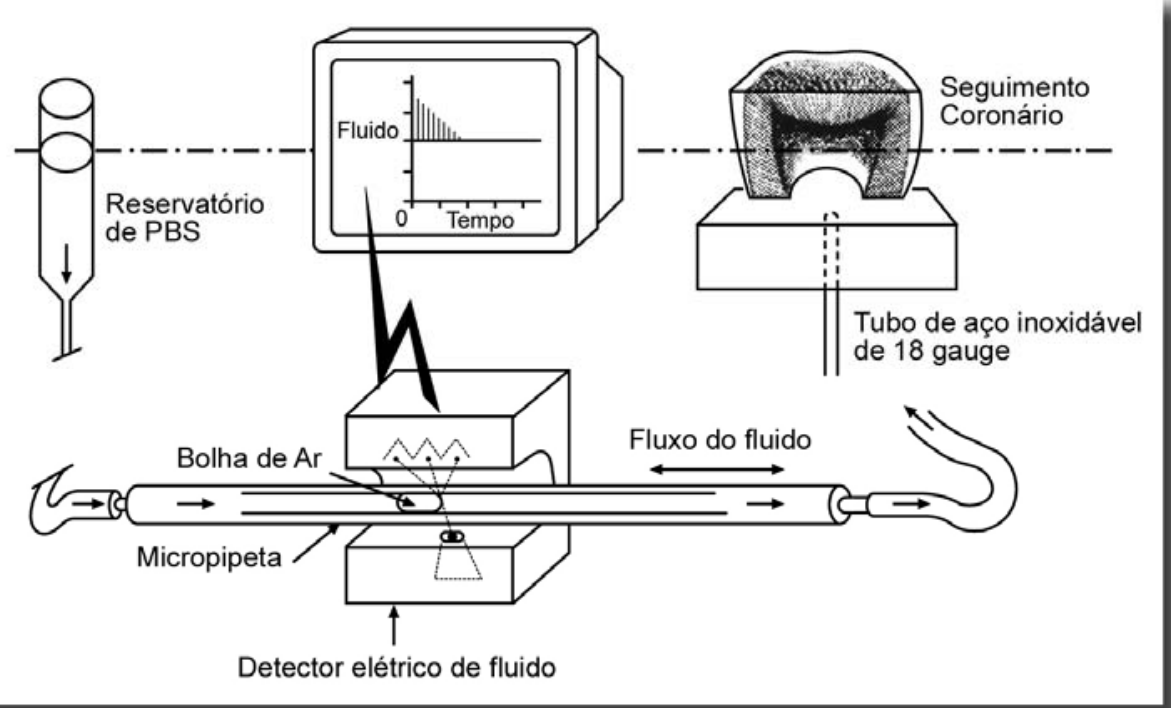

Figura 4. Aparato de medição da condutividade hidráulica

Antes de dar início à mensuração da condutividade hidráulica, o sistema foi totalmente preenchido com água deionizada. Então, no interior do capilar de vidro, introduziu-se uma pequena bolha de ar pela simples desconexão e re-conexão de uma das junções dos tubos de polietileno próxima ao capilar de vidro. Neste momento, todo sistema era checado a procura de bolhas de ar adicionais ou, mesmo, vazamentos que pudessem comprometer as medições de condutividade hidráulica que seriam feitas a seguir. Cuidado especial foi dado para remoção de bolhas de ar aprisionadas dentro da câmara pulpar, as quais podem interferir com a área interna disponível para permeação de fluidos através da dentina e, consequentemente, com a condutividade hidráulica. 
O aparelho Flodec é dotado de detectores elétricos que são capazes de detectar o deslocamento da bolha no interior do capilar de vidro. Esta informação é transmitida a um computador acoplado ao aparelho que por meio de um software específico, converte automaticamente esse deslocamento para dados de fluxo.

As medições em cada espécime foram realizadas, em média, por 5 minutos. Entretanto, estas medições eram somente finalizadas se o fluxo permanecesse constante durante este período. Se durante esses 5 minutos o fluxo sofresse alterações bruscas, a medição era interrompida e todo o sistema de capilares era checado a procura de vazamentos ou bolhas que pudessem estar causando o aumento ou diminuição do fluxo. Após essa verificação, nova medida era realizada.

Os dados da medição de fluxo eram importados para o programa Excel (Windows) (figura 5). 

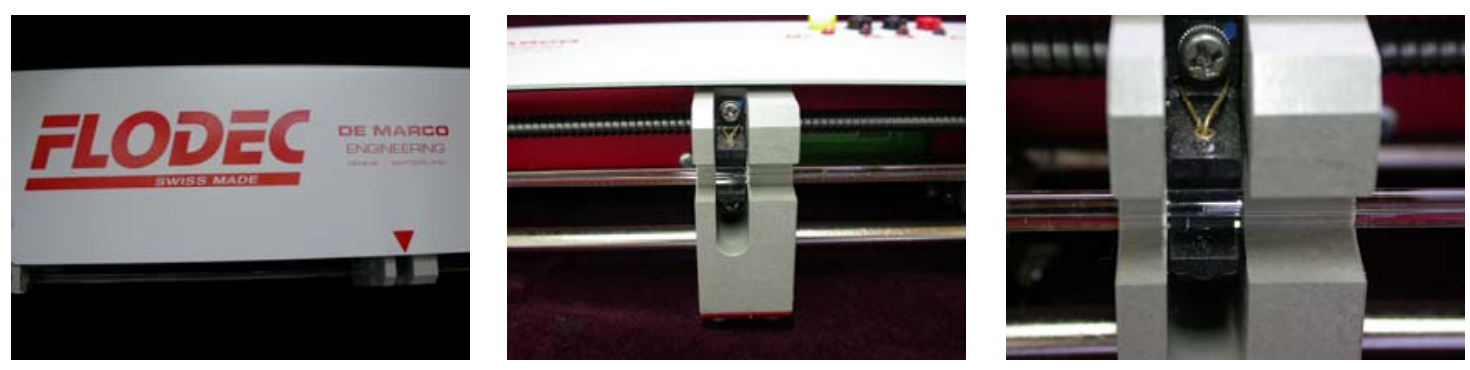

Fig. 5a. Aparelho Flodec

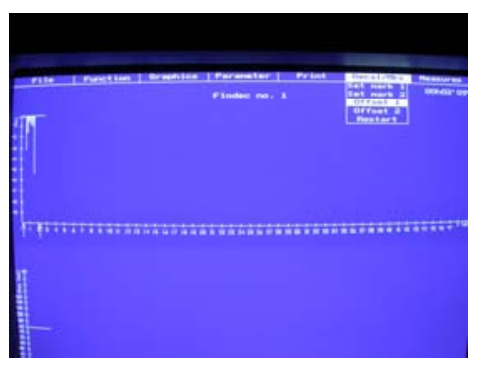

Fig. 5d. Configuração da tela do computador no momento da medição
Fig. 5b. Bolha inserida no capilar de vidro

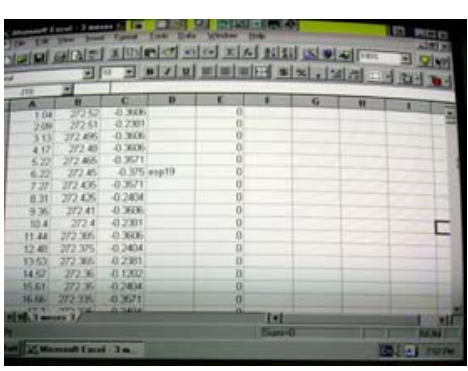

Fig. 5e. Configuração dos dados no Excel
Fig. 5c. Detectores elétricos acompanhando o movimento da bolha

Figura 5. Detalhes do aparelho Flodec indicando a forma de coleta e leitura dos dados de condutividade hidráulica.

Inicialmente, todos os espécimes tiveram a condutividade hidráulica mensurada após o término do preparo cavitário, isto é, com o substrato recoberto pela smear layer. Em seguida, os espécimes foram condicionados com ácido fosfórico a 35\% por 15 segundos (3M ESPE), lavados por 20 segundos e a condutividade hidráulica novamente medida. Os valores obtidos com presença da smear layer e após o condicionamento ácido 
serviram como parâmetros de valores de condutividade hidráulica mínima e máxima, respectivamente (BOUILLAGUET et al. ${ }^{2}$, 2000).

Todas as medições foram realizadas com os espécimes imersos em água, para prevenir qualquer movimento de fluido por evaporação (KING et al. ${ }^{43}, 2004$; CAMPS et al. $\left.{ }^{7}, 2003\right)$.

\section{Aplicação dos diferentes tratamentos}

Para avaliar o efeito dos procedimentos adesivos associados ou não ao oxalato de potássio na permeabilidade dos espécimes em estudo, após a medida da condutividade hidráulica máxima (i.e., após remoção da smear layer), as superfícies de dentina foram novamente desgastadas com a mesma ponta diamantada em baixa rotação, para que uma nova smear layer fosse criada antes dos tratamentos experimentais.

Foram selecionados dois sistemas adesivos autocondicionates, AdheSE (Ivoclar Vivadent, Schaan- Liechtenstein) e One UP Bond F (Tokuyama Inc., Japão) e um sistema convencional, Single Bond (3M ESPE, EUA). A composição básica, o lote e modo de aplicação destes materiais estão expressos no quadro 1.

Os sistemas adesivos foram aplicados à superfície dentinária em associação ou não ao gel de oxalato de potássio monohidratado (3\%; pH 4.1) (Merck-Darmstadt, Germany) em espessante de carboximetilcelulose 
(Henrifarma- SP, Brazil), desenvolvido pelo Departamento de Dentística, Endodontia e Materiais Dentários da FOB.

Desta forma, os espécimes, em média 7 para cada grupo experimental, foram aleatoriamente alocados em um dos grupos descritos a seguir.

- Grupo SBF: As superfícies de dentina foram condicionadas com ácido fosfórico a 35\% por 15 s, lavadas com água destilada por 20 s, levemente secas com papel absorvente e hibridizadas com o sistema adesivo convencional Single Bond, aplicado de acordo com as instruções do fabricante.

- Grupo ADF: A aplicação do primer do sistema adesivo autocondicionante AdheSE foi realizada de forma ativa sobre as superfícies de dentina e recobertas por smear layer e após 20 s, a resina adesiva fluida deste sistema foi aplicada tal como recomenda o fabricante.

- Grupo ADExperimental: Antes da aplicação primer do sistema adesivo autocondicionante AdheSE, as superfícies de dentina foram condicionadas com ácido fosfórico a 35\% por 15 s, lavadas com água por 20 s e levemente secas com papel absorvente. Em seguida foram 
hibridizadas com o primer, e recobertas com a resina adesiva fluida do sistema adesivo AdheSE tal como recomendado por seu fabricante.

- Grupo OBF: Aplicação do sistema adesivo autocondicionante One UP Bond $\mathrm{F}$ foi realizada sobre as superfícies de dentina recobertas por smear layer, de acordo com as instruções do fabricante.

- Grupo OBExperimental: Antes de receberem a aplicação do sistema One UP Bond $F$, as superfícies de dentina foram condicionadas com ácido fosfórico a $35 \%$ por 15 s, lavadas com água por 20 s e levemente secas com papel absorvente. Em seguida, essas superfícies foram hibridizadas com o sistema adesivo One UP Bond F, como recomendado pelo fabricante.

- Grupo SBO: As superfícies de dentina foram condicionadas com ácido fosfórico a $35 \%$ por 15 s, lavadas com água destilada por 20 s e levemente secas com papel absorvente. Então, receberam a aplicação passiva do gel de oxalato de potássio monohidratado que agiu por 3 min. Então, essas superfícies foram lavadas com água destilada por 20 s, levemente secas com papel absorvente seguida da aplicação do sistema adesivo convencional Single Bond. 
- Grupo ADO: As superfícies de dentina foram condicionadas com ácido fosfórico a $35 \%$ por 15 s, lavadas com água destilada por $20 \mathrm{~s}$, e levemente secas com papel absorvente. Então, receberam a aplicação passiva do gel de oxalato de potássio monohidratado por 3 min. Essas superfícies foram lavadas com água destilada por $20 \mathrm{~s}$, levemente secas com papel absorvente, seguida da aplicação do sistema adesivo AdheSE.

Grupo OBO: As superfícies de dentina foram condicionadas com ácido fosfórico a 35\% por 15 s, lavadas com água destilada por 20 s e levemente secas com papel absorvente. Receberam a aplicação passiva do gel de oxalato de potássio monohidratado por $3 \mathrm{~min}$. Foi efetuada a lavagem da superfície com água destilada por 20 s, seguida da aplicação do sistema adesivo One UP Bond F.

Os sistemas adesivos foram foto-ativados com o aparelho Degulux Softstart, (DEGUSSA HÜLS) com densidade de potência de $500 \mathrm{~mW} / \mathrm{cm}^{2}$, por 30 segundos.

Estudos prévios mostraram que o emprego de anestésicos locais contendo vasoconstrictores causa uma diminuição ou quase completa inibição do fluxo sanguíneo pulpar e, conseqüentemente, no fluxo de fluidos dentinários em direção à superfície de dentina exposta pelo preparo cavitário 
(OLGART e GAZELIUS ${ }^{52}$, 1976). Desta forma, durante os procedimentos de adesão, a simulação da pressão fisiológica da polpa foi interrompida, a fim de mimetizar os efeitos dos vasoconstrictores presentes nos anestésicos locais sobre a polpa e para que os fluidos oriundos da dentina não interferissem na formação da camada híbrida (HASHIMOTO ${ }^{36}$ et al., 2004).

Os grupos ADE, ADO; OBE e OBO apresentam modificações na técnica de aplicação dos respectivos adesivos. Esta estratégia foi empregada para testar a hipótese de que a associação do oxalato com os adesivos não causa alterações na permeabilidade dentinária. O condicionamento ácido foi necessário para impedir a formação de cristais sobre a superfície da smear layer, o que prejudicaria a adesão com os adesivos autocondicionantes.

Nos grupos experimentais, os adesivos autocondicionantes foram aplicados após o condicionamento ácido e remoção da smear layer. Esta estratégia foi empregada para se determinar o efeito do adesivo "per se" em selar a dentina, sem a contribuição da smear layer neste processo. Dessa forma tínhamos subsídios para comparar o efeito do oxalato em associação com estes adesivos, na redução da permeabilidade dentinária.

Os sistemas adesivos e suas respectivas características estão descritos no

\section{Quadro 1.}


Quadro 1. Materiais selecionados e seus respectivos

\begin{tabular}{|c|c|c|c|c|}
\hline \multicolumn{2}{|c|}{ Material } & Composição & Modo de aplicação & Lote \\
\hline \multirow[t]{3}{*}{$\begin{array}{l}\text { Sistemas } \\
\text { Adesivos }\end{array}$} & $\begin{array}{l}\text { Single Bond } \\
3 \mathrm{M} / \mathrm{ESPE}^{\star}\end{array}$ & $\begin{array}{l}\text { Primer + Adesivo: Bis- } \\
\text { GMA, HEMA, copolímero } \\
\text { de ácido polialcenóico, } \\
\text { água, etanol e } \\
\text { fotoiniciadores. }\end{array}$ & 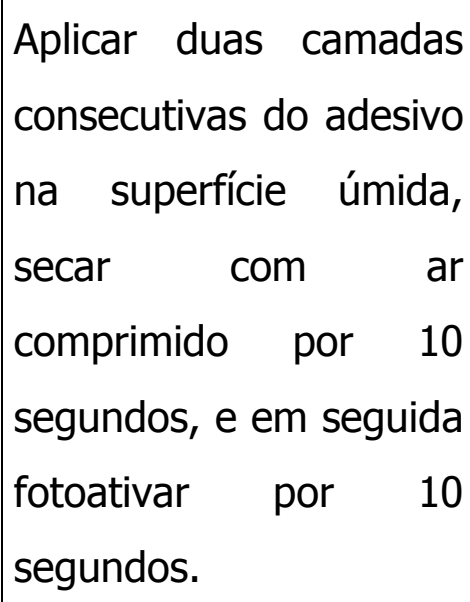 & $3 \mathrm{HW}$ \\
\hline & $\begin{array}{l}\text { AdheSE } \\
\text { IVOCLAR } \\
\text { VIVADENT• }\end{array}$ & $\begin{array}{l}\text { Primer: dimetacrilato, } \\
\text { ácido fosfonico acrilato, } \\
\text { água e estabilizadores } \\
\text { Adesivo: dimetacrilato, } \\
\text { HEMA, sílica, iniciadores e } \\
\text { estabilizadores }\end{array}$ & 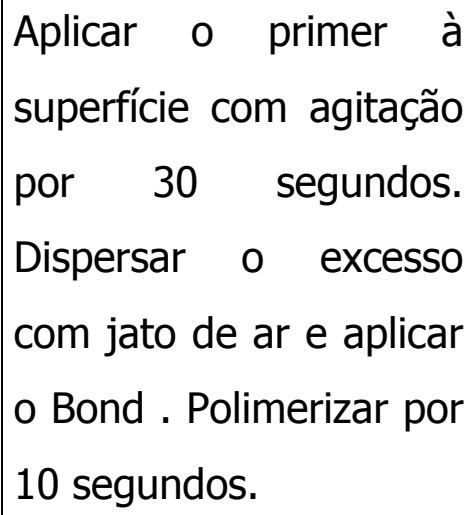 & F27468 \\
\hline & $\begin{array}{l}\text { One Up Bond F } \\
\text { TOKUYAMA } \\
\text { Inc }^{\vee}\end{array}$ & $\begin{array}{l}74 \% \text { de metacrilato, } 10 \% \\
\text { de água, } 16 \% \text { de } \\
\text { partículas de vidro de } \\
\text { fluoraminosilicato. }\end{array}$ & 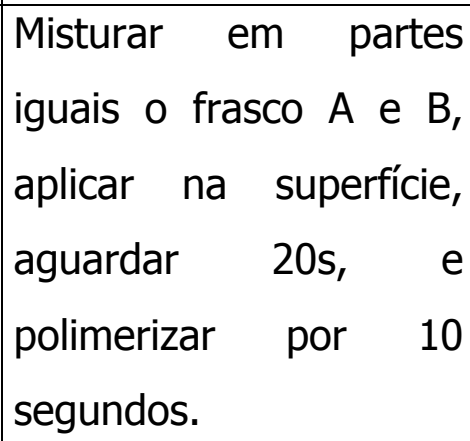 & 096M \\
\hline
\end{tabular}

\section{fabricantes}

- Ivoclar Vivadent, Schaan, Liechtenstein

- TOKUYAMA Inc, Tóquio, Japão

-3M/ESPE, St. Paul, MN, EUA 
A medida da condutividade hidráulica foi realizada imediatamente após a aplicação dos tratamentos, calculada em $\mu \mathrm{L} / \mathrm{min}$ e expressa como porcentagem da permeabilidade máxima obtida após o condicionamento ácido. Assim, as respectivas variações percentuais de permeabilidade de cada espécime, resultantes dos tratamentos, eram comparadas ao seu respectivo valor fixo de permeabilidade máxima (100\%) e, desta forma, cada dente serviu como seu próprio controle (CHERSONI et al. ${ }^{14}$ 2004; BOUILLAGUET et $\mathrm{al}^{2}$, 2000).

Para cada espécime, a permeabilidade foi mensurada 3 vezes: a) após o preparo da coroa total e criação da smear layer, b) após o condicionamento ácido da dentina, e c) após o selamento da dentina com o sistema adesivo (figura 6). 

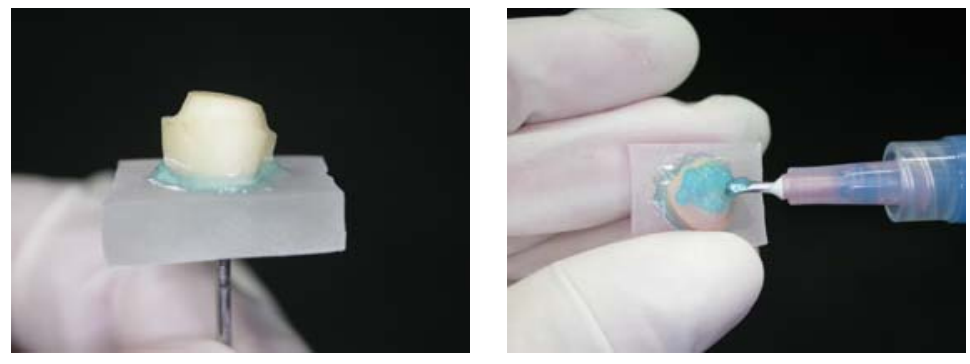

Fig. 6a. Medição inicial da SL (permeabilidade mínima)

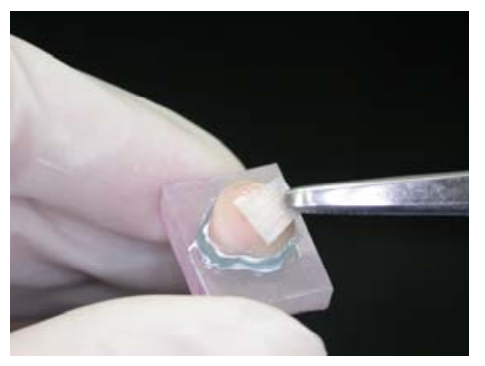

Fig. 6d. Secagem com papel absorvente

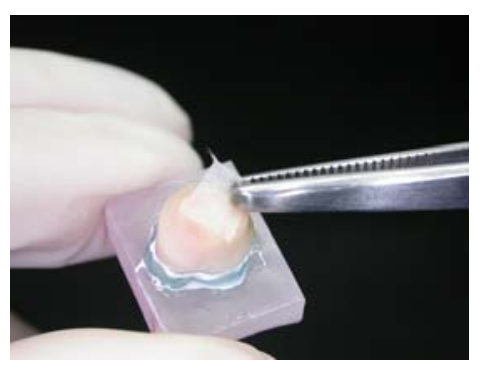

Fig. 6g. Lavagem e secagem com papel absorvente
Fig. 6b. Condicionamento ácido do espécime

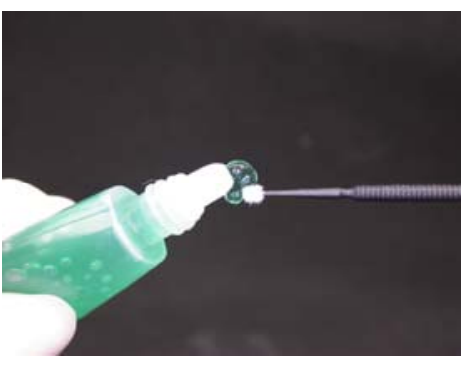

Fig. 6e. Gel de oxalato de potássio

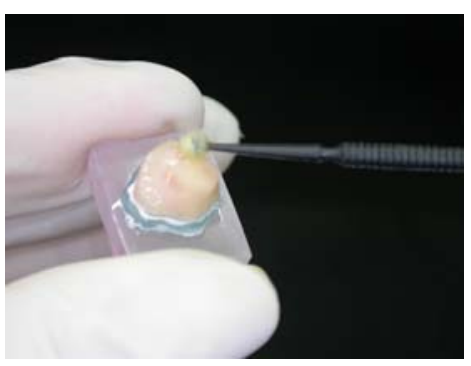

Fig. 6 h. Aplicação do sistema adesivo

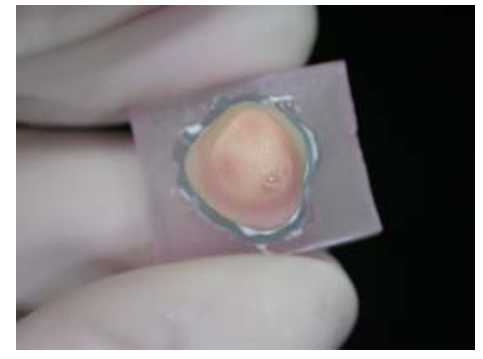

Fig 6c. Medição da permeabilidade máxima

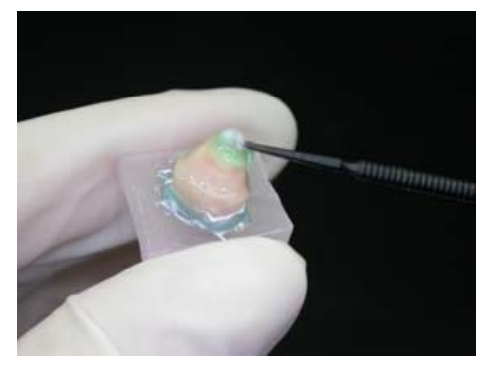

Fig. 6f. Aplicação do oxalato de potássio

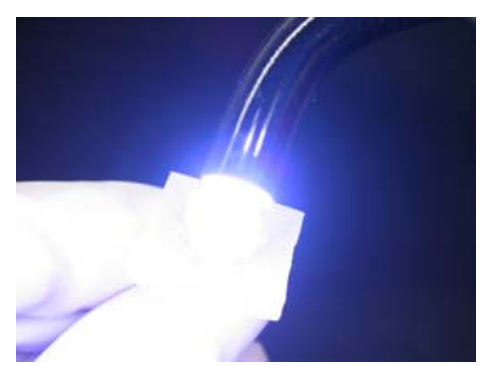

Fig. 6i. Polimerização do sistema adesivo

Figura 6. Seqüência de aplicação dos diferentes tratamentos 


\section{Tratamento estatístico dos dados}

A análise foi feita com base em um modelo para análise de dados oriundos de um experimento inteiramente casualizado com dois fatores e interação - adesivo e tratamento. Dentro do fator "adesivo" existem três níveis (Single Bond, One Up Bond F, AdheSe) e dentro do fator "tratamento" existem três níveis (segundo fabricante, experimental e combinado com oxalato).

A análise de variância 2 critérios foi o modelo adotado para quantificar e testar os efeitos dos fatores "adesivos", "tratamento" ou a associação de ambos (adesivo versus tratamento) na permeabilidade dentinária. As comparações individuais das médias foram analisadas pelo teste de Tukey, com nível de significância alfa de $5 \%(a=0,05)$.

Como em todos os espécimes o valor permeabilidade na presença da smear layer foi mensurado antes da aplicação dos sistemas adesivos, a comparação entre os valores percentuais da smear layer e dos diferentes grupos experimentais foi realizada através do teste $t$ de Student.

As análises foram calculadas com o uso do sistema SAS*.

* SAS Institute Inc. The SAS System Release 8.2, SAS Institute Inc, Cary: NC, 1999. 


\section{Moldagem da superfície adesiva}

A permeação de fluidos através da dentina e de sistemas adesivos pode ser qualificada através da moldagem e obtenção de réplicas da superfície interessada (KERDVONGBUNDIT, et al. ${ }^{41}, 2004$ ).

Após as medidas de condutividade hidráulica de cada espécime, estes eram mantidos sob pressão fisiológica constante por 1 minuto. Em seguida, ainda sob pressão constante, foi realizada uma moldagem da superfície do espécime com uma silicona de adição (3M EXPRESS) de consistência leve.

Estudos anteriores demonstraram que a moldagem da superfície adesiva não afeta a integridade do adesivo polimerizado (NAHON et al. ${ }^{49}$, 2001).

Antes do procedimento de moldagem, a camada superficial de adesivo não polimerizada (inibida pelo oxigênio) era limpa cuidadosamente com uma bolinha de algodão contendo acetona e seca com jato de ar.

Após a moldagem e completa polimerização do material (5 minutos), o molde era removido, identificado e armazenado em frascos fechados (figura 7). 


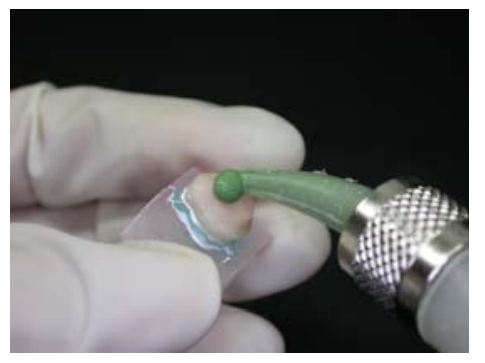

Fig. 7a, b Moldagem da interface adesiva com silicona de consistência leve

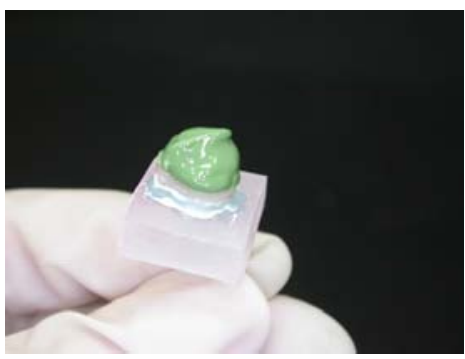

Fig. 7b.

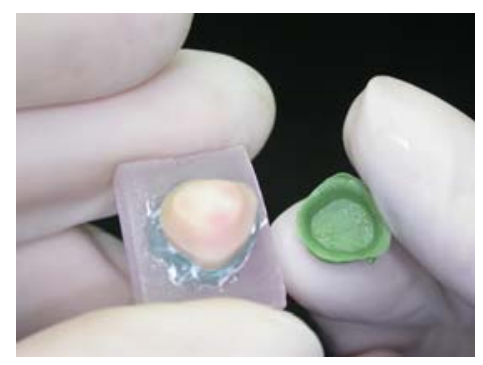

Fig. 7c. Molde sendo removido após a sua polimerização

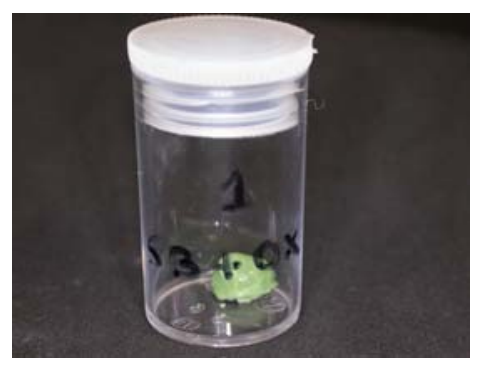

Fig. 7d. Identificação e armazenagem em frascos fechados

Figura 7. Seqüência do procedimento de moldagem da superfície adesiva

Preparo das réplicas para análise em Microscopia Eletrônica de Varredura (MEV)

A técnica de confecção das réplicas para microscopia seguiu o protocolo de ITTHAGARUN e TAY ${ }^{39}$, em 2000.

Logo após o procedimento de moldagem, cada molde obtido era lavado em água destilada e seco com jato de ar livre de óleo e resíduos. Em seqüência, permaneciam na estufa a $40^{\circ} \mathrm{C}$ por 24 horas para liberação do 
hidrogênio formado durante a polimerização do material. Após a coleta de todos os moldes, estes eram limpos no ultrassom por 10 minutos e secos com jato de ar antes de serem vazados com a resina epóxica POLYSCIENCES, Inc. (Warrington, PA, USA).

A resina epóxica era preparada pela mistura das soluções de base, endurecedor e catalizador em um recipiente de plástico, o qual era levado a uma câmara de vácuo por 30 minutos para remoção das bolhas.

Os moldes eram então vazados sob auxílio de uma lupa com 40x de aumento e permaneciam na estufa a $40^{\circ} \mathrm{C}$ por 48 horas para completa polimerização da resina (figura 8). 

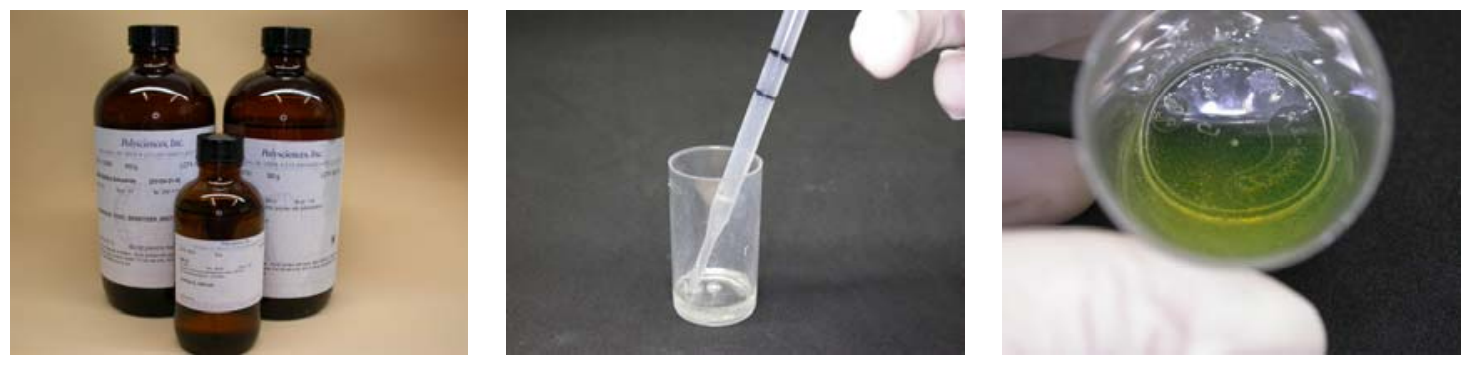

Fig. 8a. Resina epóxica POLYSCIENCES

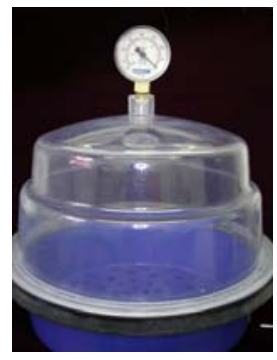

Fig. 8d. Câmara à vácuo utilizada

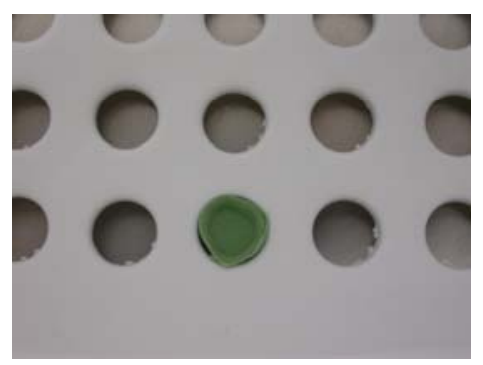

Fig. 8g. Molde no aparelho de ultrasson
Fig. 8b. Manipulação da resina

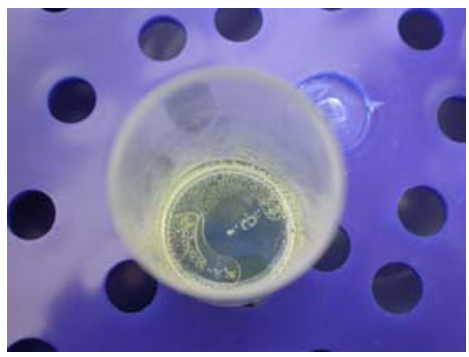

Fig. 8e. Resina recém colocada na câmara à vácuo

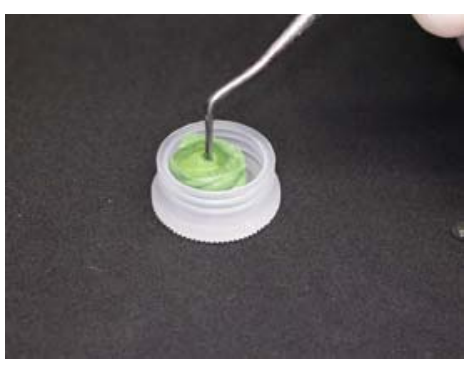

Fig. 8h. Vazamento do Fig molde com resina epóxica
Fig. 8c. Aspecto logo após a manipulação

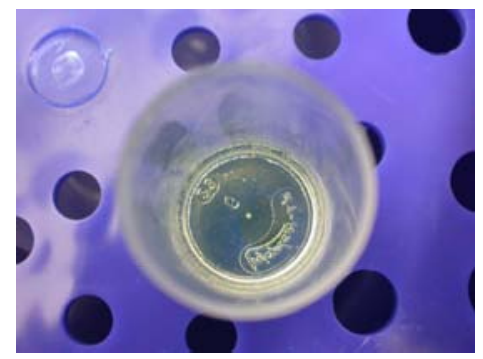

Fig. 8f. Aspecto da resina após 30 minutos

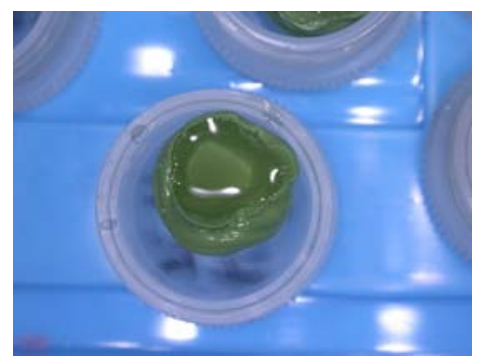

Fig. $\quad 8 i$. confeccionada

Figura 8. Técnica de preparo da resina epóxica e vazamento dos moldes 
As réplicas confeccionadas eram limpas no aparelho de ultrassom por 10 minutos e secas com jato de ar antes de serem finalmente cobertas com ouro e examinadas em MEV (JEOL 2800, Japão).

A qualificação da permeabilidade dos adesivos de acordo com os grupos experimentais foi determinada a partir das fotomicrografias. 


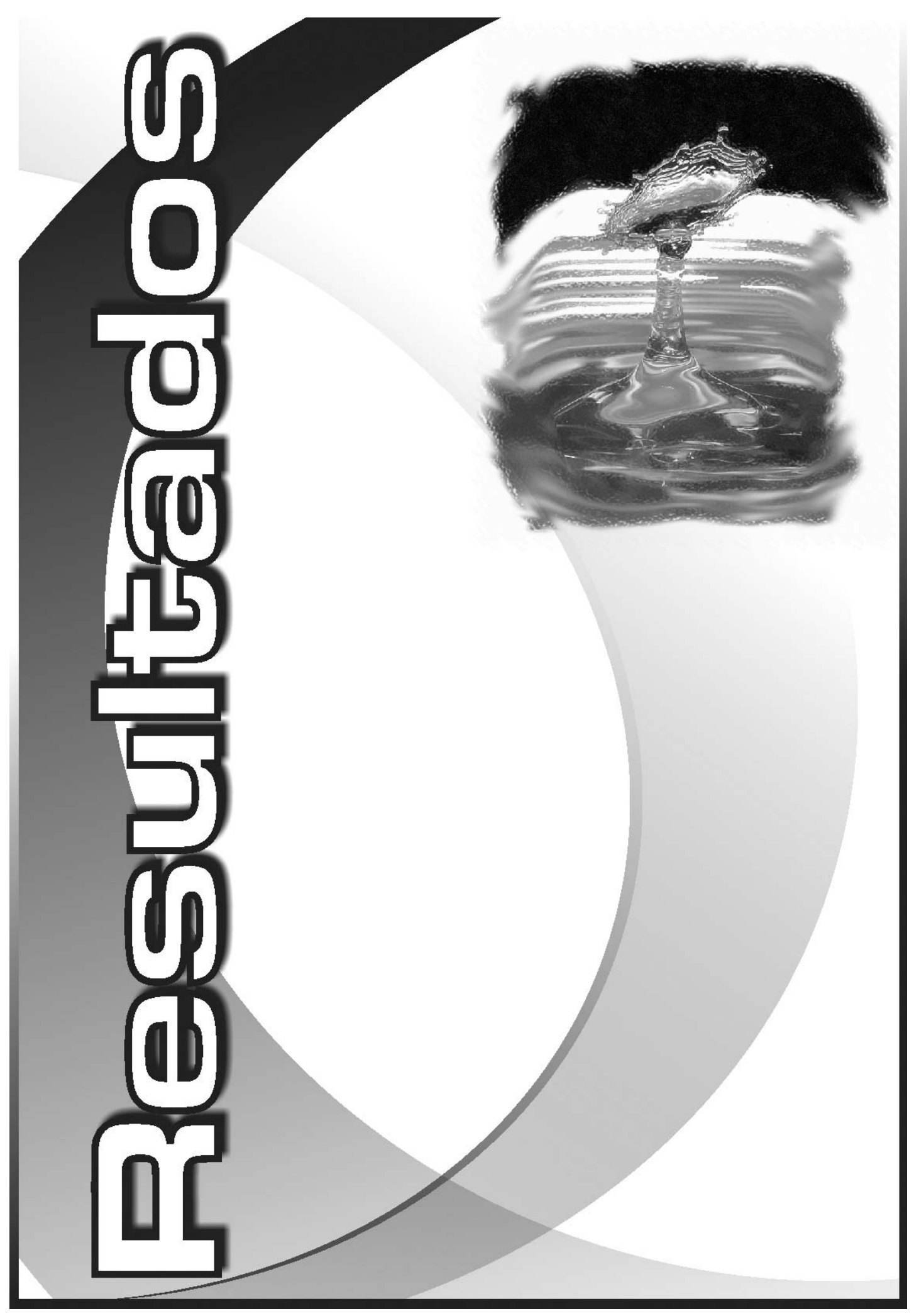




\section{Resultados}

\section{1-Análise do efeito dos tratamentos na redução da condutividade hidráulica}

Os resultados mostraram que apesar dos procedimentos de adesão terem causado uma redução significante $(p<0.05)$ na condutividade hidráulica da dentina condicionada com ácido fosfórico, nenhum foi capaz de eliminá-la completamente.

A análise de variância a 2 critérios revelou fracos indícios do efeito da interação dos fatores tratamento X adesivo na permeabilidade dos substratos de dentina avaliados ( $p>0,05)$. Da mesma forma, o fator adesivo (Single Bond, AdheSe e One Up Bond) não determinou diferenças estatisticamente significativas entre as médias de permeabilidade nas diferentes condições experimentais $(p>0,05)$. Porém, foram detectados fortes indícios $(p<0,01)$ da existência de diferenças entre as médias de condutividade hidráulica da dentina quando foi considerado o fator tratamento (segundo fabricante, experimental e combinado com oxalato).

O teste de Tukey de comparações múltiplas evidenciou diferenças entre os tratamentos empregados, revelando que a redução da condutividade hidráulica da dentina foi mais efetiva para os grupos que 
receberam a prévia aplicação do gel de oxalato de potássio. As diferenças entre os tratamentos estão representadas na Tabela $\mathbf{1}$.

Tabela 1. Média \pm desvio-padrão da condutividade hidráulica verificada para grupos formados pelos diversos tratamentos e adesivos, tendo como base a medida de condutividade hidráulica máxima (100\%). Valores estão expressos em porcentagem.

\begin{tabular}{c|c|c|c}
\hline ADESIVOS & FABRI CANTE & EXPERI MENTAL & OXALATO \\
\hline Single Bond & $33 \pm 10$ & - & $1 \pm 2$ \\
\hline One Up Bond & $34 \pm 21$ & $45 \pm 36$ & $20 \pm 19$ \\
\hline AdheSE & $23 \pm 12$ & $37 \pm 15$ & $17 \pm 19$ \\
\hline Média & $\begin{array}{c}30,14 \pm 15,53 \\
\text { A }\end{array}$ & $\begin{array}{c}40,64 \pm 25,01 \\
\text { A }\end{array}$ & $\begin{array}{c}13,37 \pm 17,44 \\
\text { B }\end{array}$ \\
\hline
\end{tabular}

Letras iguais representam semelhança estatística $(p>0,05)$

A interpretação dos dados da tabela 1 mostra que, considerando a condição tratamento, os dados relativos ao adesivo Single Bond indicam que a associação com o oxalato de potássio resultou num valor de condutividade hidráulica correspondente a $1 \%$ do valor de referência máximo, isto é, essa associação de tratamentos determinou uma redução de 99\% na condutividade hidráulica da dentina. Porém, quando aplicado segundo as recomendações do fabricante (sem a associação com o oxalato), o adesivo Single Bond determinou um valor de condutividade de $33 \%$, 
proporcionando, portanto, uma redução da condutividade hidráulica da dentina hibridizada de $67 \%$. Seguindo a mesma tendência, pode ser verificado que para o sistema One Up Bond F, a condutividade hidráulica, quando de sua aplicação segundo as recomendações do fabricante, equivale a 34\% de seu valor de referência máxima, ou seja, a capacidade do mesmo em reduzir a permeabilidade da dentina foi de $66 \%$. Em contrapartida, quando este adesivo foi associado ao oxalato de potássio verificou-se um aumento significativo do potencial de redução da condutividade hidráulica, representando cerca de $80 \%$. Fica evidente também que a aplicação do adesivo One Up Bond F sob a forma experimental, isto é, após a remoção da smear layer, foi menos efetiva quanto ao bloqueio da condutividade hidráulica da dentina, provocando uma redução de apenas 55\%. Finalmente, a tabela 1 revela que, assim como para os demais sistemas, a associação do adesivo AdheSE com o oxalato foi o tratamento mais eficaz no bloqueio da condutividade hidráulica da dentina, apresentando um valor de condutividade de cerca de $17 \%$, que indica, portanto, uma redução de $83 \%$. Quando o AdheSe foi aplicado segundo a recomendação do fabricante houve uma redução de $77 \%$ e, por fim, quando aplicado na condição experimental, foi menos efetivo em bloquear a condutividade hidráulica, reduzindo-a em $63 \%$. 
O gráfico 1 ilustra o comportamento de cada adesivo frente a cada tratamento de superfície empregado. Embora a análise estatística tenha revelado que os adesivos não diferiram entre si, esta representação gráfica oferece uma visão mais minuciosa do efeito de cada um dos tratamentos de superfície sobre à variação da condutividade hidráulica da dentina.

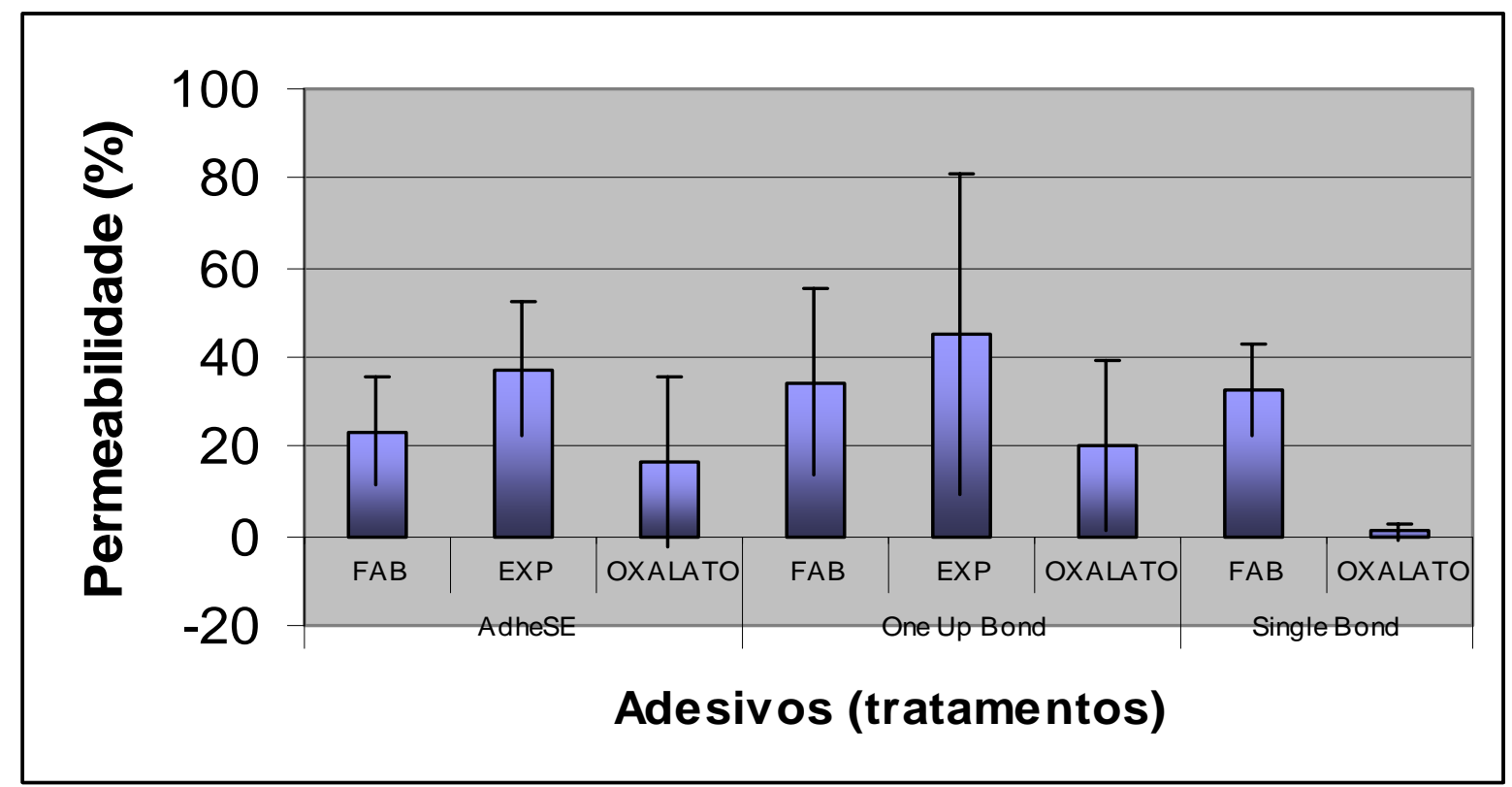

Gráfico 1. Média \pm desvio-padrão da condutividade hidráulica da dentina de acordo com os diferentes tratamentos de superfície para cada adesivo estudado. Os valores são percentuais relativos à condutividade hidráulica máxima. 


\section{2-Análise do efeito da smear layer na condutividade hidráulica da dentina}

A tabela 2 mostra os valores percentuais de permeabilidade da dentina coberta pela "smear layer" e dos diferentes grupos experimentais quando comparados ao valor fixo de permeabilidade máxima (100\%).

Tabela 2. Efeitos da presença da smear layer e dos procedimentos adesivos na permeabilidade dentinária. Os valores expressam a permeabilidade como porcentagem do valor máximo, dentina condicionada, definido como $100 \%$. Valores designados com a mesma letra na mesma linha não são estatisticamente significantes quando comparados pelo teste $\mathrm{t}$ de Student para dados pareados.

\begin{tabular}{c|cc|cl} 
GRUPOS & \multicolumn{2}{c}{ Smear Layer } & APÒs TRATAMENTO \\
SBF & $14 \pm 17 \mathrm{~A}$ & $33 \pm 10$ & $\mathrm{~B}$ \\
\hline ADF & $17 \pm 21 \mathrm{~A}$ & $23 \pm 12$ & $\mathrm{~A}$ \\
\hline OBF & $7 \pm 13$ & $\mathrm{~A}$ & $34 \pm 21$ & $\mathrm{~A}$ \\
\hline OBEx & $4 \pm 7$ & $\mathrm{~A}$ & $45 \pm 36$ & $\mathrm{~B}$ \\
\hline ADEx & $1 \pm 2$ & $\mathrm{~A}$ & $37 \pm 15$ & $\mathrm{~B}$ \\
\hline SBO & $2 \pm 2$ & $\mathrm{~A}$ & $1 \pm 2$ & $\mathrm{~A}$ \\
\hline ADO & $2 \pm 4$ & $\mathrm{~A}$ & $17 \pm 19$ & $\mathrm{~A}$ \\
\hline OBO & 0 & $\mathrm{~A}$ & $20 \pm 18$ & $\mathrm{~B}$ \\
\hline
\end{tabular}

Letras iguais representam semelhança estatística $(p>0,05)$ 
O teste $\mathrm{t}$ de Student foi utilizado para comparar as médias dos valores da condutividade hidráulica dos espécimes recobertos com a smear layer com os diferentes grupos experimentais. Esta análise mostrou que, para o Single Bond, no grupo onde o adesivo foi aplicado segundo o fabricante, a smear layer foi capaz de reduzir $86 \%$ da condutividade hidráulica, porém, após o condicionamento ácido e aplicação do adesivo segundo as recomendações do fabricante houve um aumento significante $(p<0.05)$ da condutividade hidráulica. Quando a dentina foi tratada com o Single Bond associado ao oxalato de potássio, a condutividade hidráulica foi reduzida para valores que não diferiram significantemente daqueles obtidos na presença da smear layer $(p>0,05)$.

O condicionamento ácido da dentina previamente à aplicação do One Up Bond (Experimental) resultou em aumento significante da condutividade hidráulica quando comparado à presença da smear layer $(p<0.05)$. Por outro lado, quando o One Up Bond foi aplicado segundo o fabricante, ou seja, sobre a smear layer, o aumento da condutividade hidráulica não foi significante em relação à presença da smear layer somente ( $p>0.05)$.

Nos grupos do adesivo AdheSe, o teste pareado mostrou que não houve diferença estatisticamente significante $(p>0.05)$ entre os valores de condutividade hidráulica obtidos com a smear layer e após a aplicação do adesivo segundo o fabricante, ou em associação com o oxalato. Em contrapartida, houve um aumento significante da condutividade hidráulica 
quando o adesivo foi aplicado de forma experimental, quando comparado com os valores da smear layer $(p<0.05)$.

\section{3- Análise das fotomicrografias eletrônicas de varredura}

A análise das réplicas em microscopia eletrônica de varredura adicionou informação aos achados de condutividade hidráulica, mostrando que, mesmo após a polimerização do adesivo, a permeação da água ocorreu através do mesmo e atingiu a superfície durante o procedimento de moldagem, deixando a impressão negativa da transudação de água no material de moldagem. Nenhum dos sistemas adesivos estudados foi impermeável à passagem de fluidos através da sua estrutura polimerizada.

As réplicas obtidas com o adesivo Single Bond aplicado segundo as recomendações do fabricante mostraram que houve a formação de bolhas na superfície do adesivo. Estas bolhas eram mais proeminentes na região cervical (Figura 9). Quando o SB foi associado ao oxalato de potássio, a análise das réplicas em MEV mostrou a existência bolhas na superfície, mesmo nos espécimes em que o Flodec não detectou movimentação de fluidos (Figura 10). 


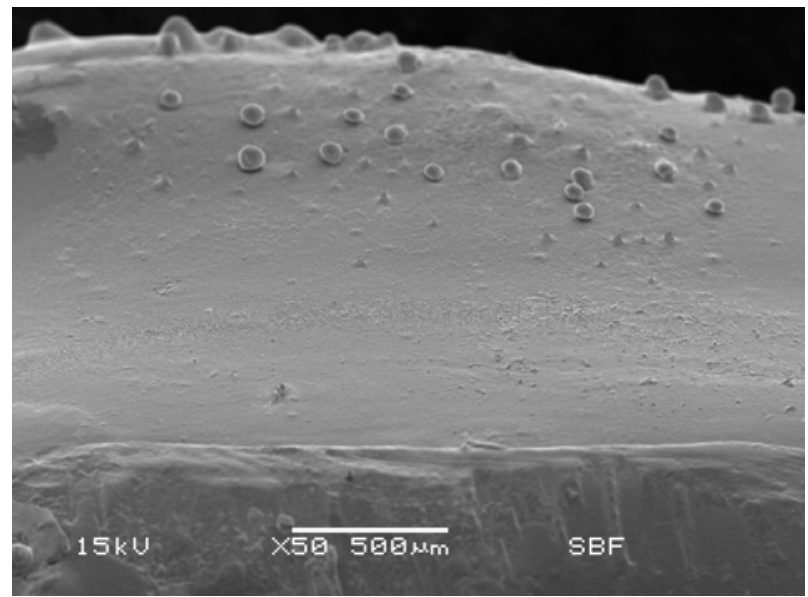

Figura 9.

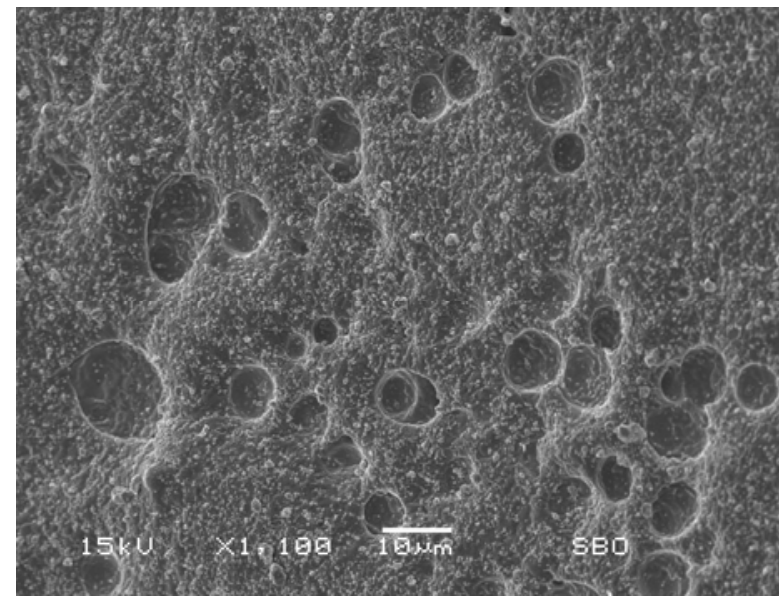

Figura 10.

As réplicas do adesivo One Up Bond $\mathrm{F}$ também mostraram que a água foi capaz de permear o adesivo polimerizado, independente do tratamento empregado. A figura 11 mostra uma réplica obtida após aplicação do adesivo segundo as recomendações do fabricante e, na figura 12, o adesivo foi aplicado em associação com o oxalato de potássio.

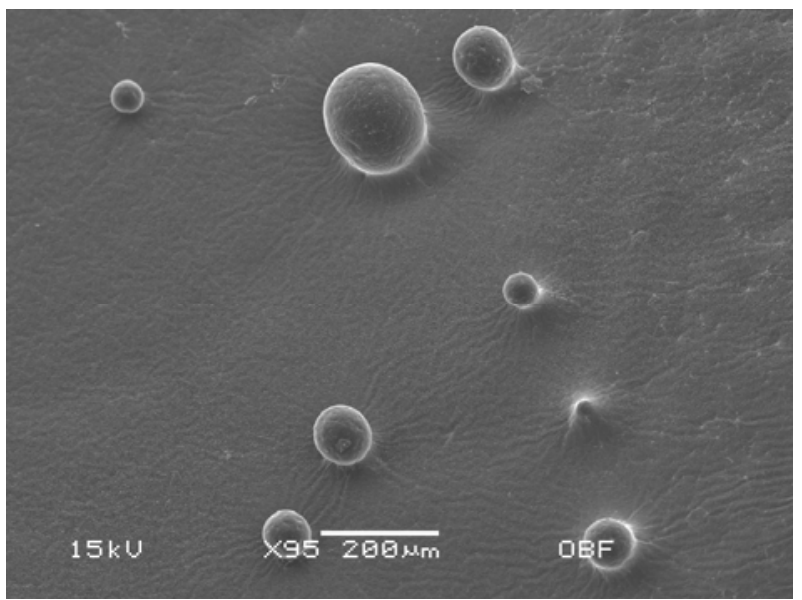

Figura 11.

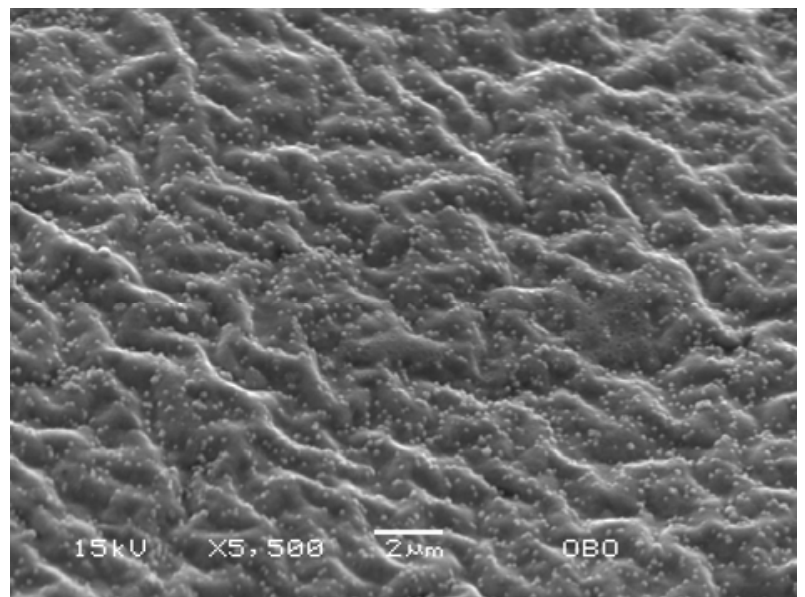

Figura 12. 
Da mesma forma, as imagens obtidas com o adesivo AdheSE mostram o mesmo padrão encontrado nos outros grupos. Nas figuras 13 e 140 adesivo foi aplicado segundo as recomendações do fabricante em diferentes espécimes. Na figura 14 nota-se uma maior quantidade de bolhas na superfície do adesivo, provavelmente devido a maior condutividade hidráulica do preparo. Quando o AdheSE foi aplicado em associação com o oxalato (Figura 15), a escassa presença de bolhas sugere que uma menor quantidade de água permeou o adesivo polimerizado. A imagem mostra a formação de poucas bolhas, localizadas predominantemente na região cervical do preparo (Figura 16).
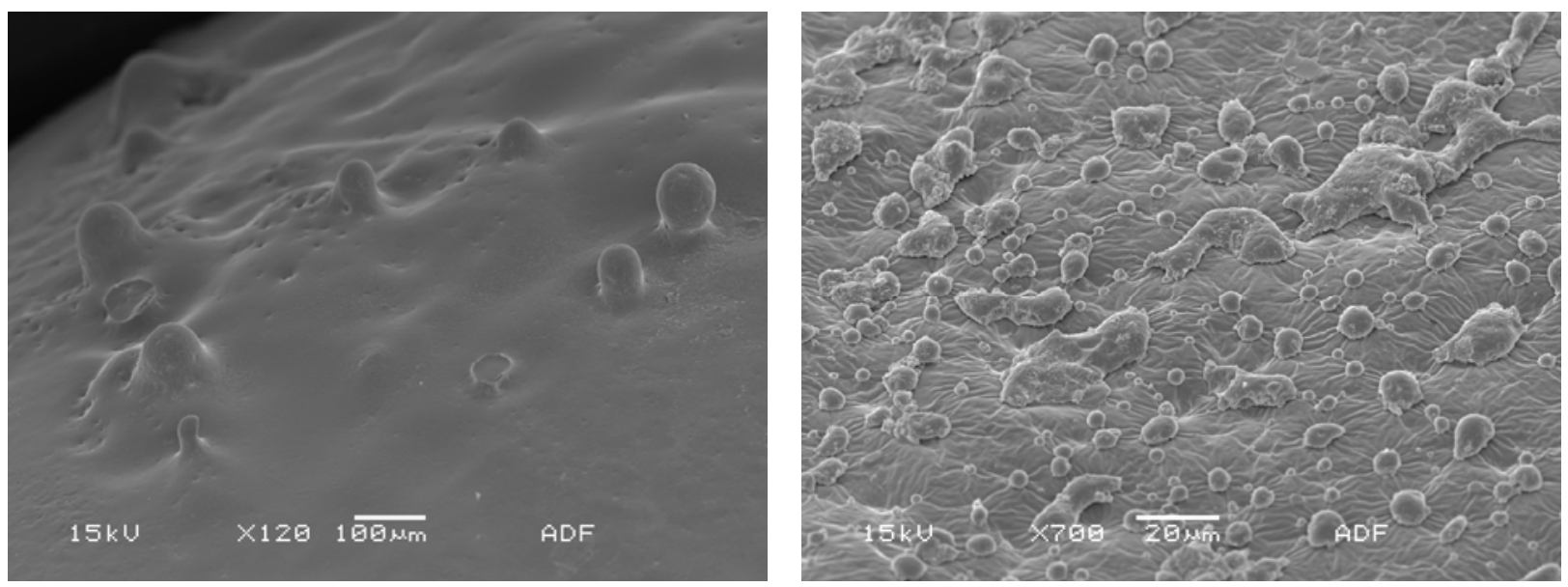

Figura 13

Figura 14 


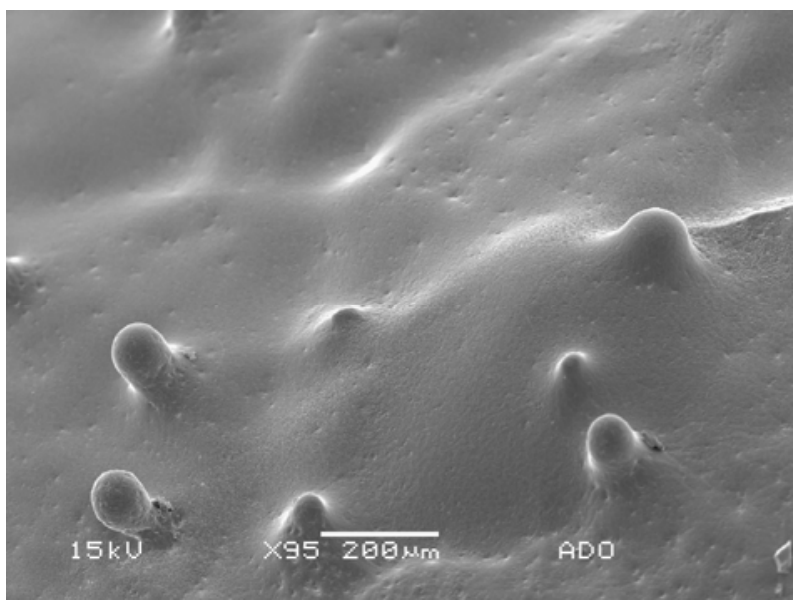

Figura 15

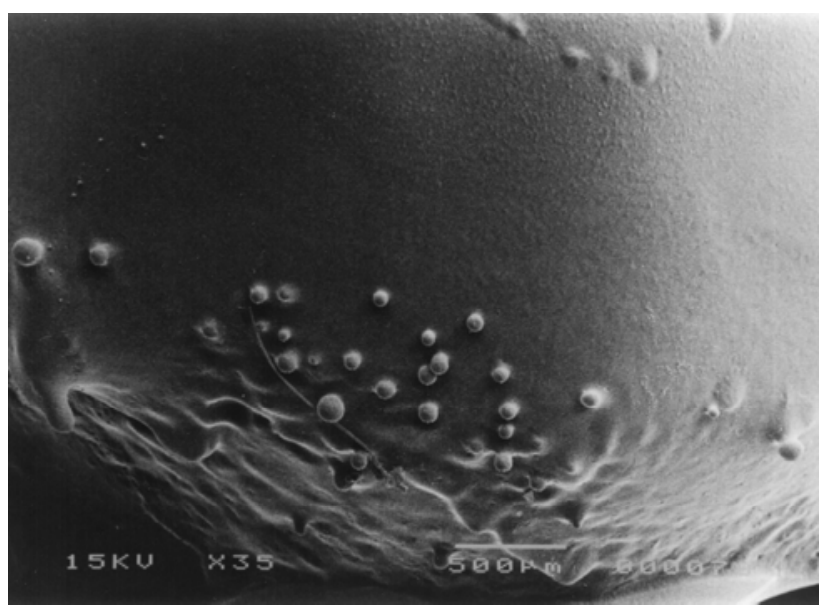

Figura 16

\section{Legenda das figuras}

As figuras de 9 a 16 representam fotomicrografias eletrônicas de varredura das réplicas obtidas das superfícies dos preparos após os procedimentos adesivos. Figura 9. Adesivo Single Bond aplicado segundo as recomendações do fabricante. A imagem mostra maior formação de bolhas na região cervical do preparo. Figura 10. Adesivo Single Bond aplicado após aplicação do gel de oxalato de potássio. A imagem mostra a formação de bolhas e a presença de irregularidades e provavelmente impurezas na superfície do adesivo polimerizado. Figura 11. Adesivo One up Bond $F$ aplicado segundo as recomendações do fabricante mostrando a presença de poucas bolhas, provavelmente em áreas mais permeáveis do preparo. Figura 12. Adesivo One Up Bond $F$ em associação com o oxalato de 
potássio. A imagem mostra em maior aumento a presença de pequenas bolhas de água em toda superfície do adesivo. Figuras 13 e 14. Adesivo AdheSE aplicado segundo as recomendações do fabricante. Figura 15 e 16. Adesivo AdheSE após aplicação do oxalato de potássio, mostrando a presença de poucas bolhas na superfície do adesivo. 


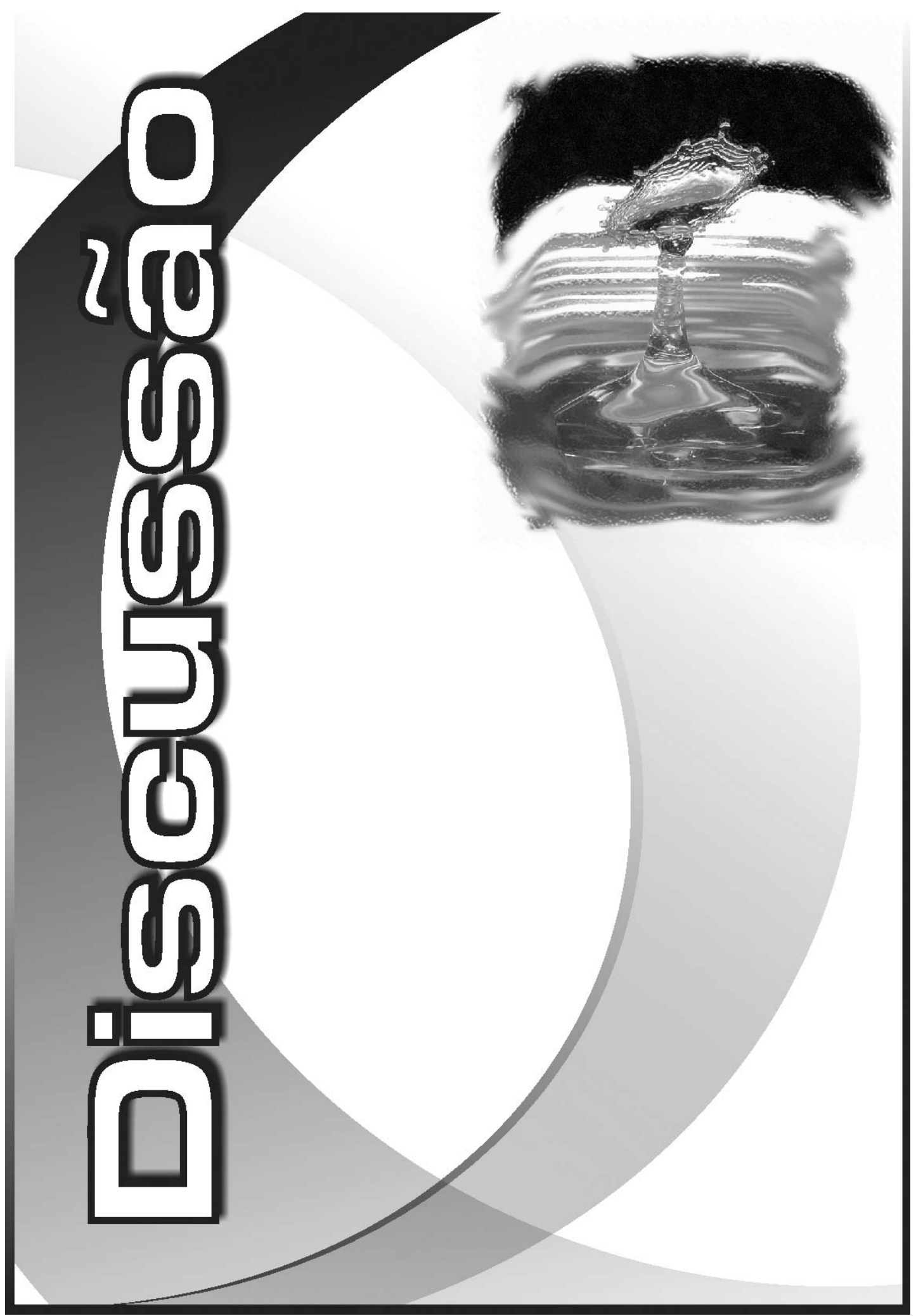




\section{Discussão}

Os resultados deste estudo in vitro reforçam o conceito de que a presença da smear layer e smear plugs reduz a permeabilidade dentinária em até 90\% (PASHLEY, LIVINGSTON e GREENHILL ${ }^{64}$, 1978; CHERSONI et al. ${ }^{14}, 2004$; PASHLEY, MICHELICH e KEHL ${ }^{65}, 1981$; PASHLEY et al. $\left.{ }^{70}, 2001\right)$, podendo até mesmo impedir completamente a passagem de fluidos através dos túbulos dentinários.

O condicionamento ácido requerido para a aplicação de adesivos convencionais, como o Single Bond, por exemplo, além de promover a completa remoção da smear layer e smear plugs, também determina o aumento do diâmetro da embocadura dos túbulos, permitindo a livre passagem de fluidos em direção à superfície, principalmente em regiões próximas à polpa (ITTHAGARUN e TAY ${ }^{39}, 2000$, PASHLEY et al. ${ }^{71}, 2002$; PASHLEY e CARVALHO ${ }^{63}$, 1997). Em teoria, a aplicação do sistema adesivo após o condicionamento ácido deveria promover o completo selamento, tanto dos túbulos dentinários quanto da própria dentina intertubular. Entretanto, como observado, a aplicação do sistema Single Bond não foi capaz de interromper a condutividade hidráulica da dentina, permitindo que a água permeasse a própria camada do adesivo polimerizado. 
De fato, este resultado confirma os achados de outros estudos previamente realizados (TAY et al. 93,94,96 ,2002, 2003, 2004). Em recente estudo in vivo, Tay e colaboradores ${ }^{97}$ também observaram por MEV que a transudação de fluidos pode ocorrer através de sistemas adesivos polimerizados.

Supõe-se que a própria transudação de fluidos através dos túbulos dentinários expostos pelo condicionamento ácido prejudique a infiltração dos monômeros resinosos para o interior da dentina desmineralizada, resultando na formação deficiente da camada híbrida (TAY et al. ${ }^{97}$, 2004; HASHIMOTO et al. $^{36}$, 2004; ELGALAID et al. ${ }^{22}$, 2004; ÖZOK et al. ${ }^{55}$, 2004). Deste modo, a cada híbrida deficientemente formada não seria capaz de barrar o fluxo dentinário e selar a dentina (TAY, PASHLEY e YOSHIYAMA ${ }^{91}$, 2002; TAY et al. $\left.{ }^{93}, 2002\right)$.

Embora tenha sido demonstrado que, em condições clínicas, a ação de anestésicos com vasoconstrictores seja capaz de inibir quase que por completo o fluxo sanguíneo pulpar e, conseqüentemente, o fluxo de fluidos dentinários em direção à superfície de dentina (OLGART e GAZELIUS ${ }^{52}$, 1976), é possível especular a partir dos resultados deste e de outros estudos (HASHIMOTO et al. ${ }^{36}$, 2004; KING et al. ${ }^{43}$, 2004) que outros fatores podem estimular o aumento do fluxo dentinário em direção à superfície. No presente estudo, a pressão fisiológica simulada da polpa foi reduzida a zero durante os procedimentos adesivos para que a umidade excessiva não interferisse na 
formação da camada híbrida (ÖZOK et al. ${ }^{55}$, 2004; HASHIMOTO et al. ${ }^{36}$, 2004). Entretanto, esta estratégia talvez não tenha sido suficiente para impedir que os fluidos presentes na câmara pulpar migrassem em direção à superfície durante o procedimento adesivo. É muito provável, portanto, que o próprio adesivo tenha se comportado como uma solução hipertônica, estimulando por diferenças no gradiente de concentração osmótico o movimento de fluidos da câmara pulpar em direção à superfície (KING et al. 43, 2004). Além desse fato, é provável que a habitual aplicação do jato de ar sobre os adesivos, com o intuito de favorecer a evaporação dos solventes, possa também ter acentuado esse efeito, estimulando o fluxo do fluido dentinário em direção à superfície (TAY, PASHLEY e YOSHIYAMA ${ }^{91}$, 2002).

Além de dificultar a infiltração de monômeros resinosos pela dentina desmineralizada, a presença de umidade excessiva na superfície de dentina durante os procedimentos adesivos pode diluir a mistura que constituí o sistema adesivo e promover a separação física de seus componentes em duas fases distintas: uma fase hidrofóbica, rica em monômeros como o BisGMA e outra hidrofílica, constituída basicamente de monômeros como HEMA (SPENCER et al. ${ }^{84}, 2000 ;$ ELIADES, VOUGIOUKLAKIS e PALAGHIAS ${ }^{23}$, 2001). Esta separação de fases faz com que os componentes hidrofílicos do adesivo sejam capazes de se difundir mais rapidamente na intimidade da dentina desmineralizada, enquanto que os monômeros hidrofóbicos sofrem restrições em se infiltrar pelo substrato úmido e tendem a se acumular no 
topo da zona desmineralizada. Isto implica em uma maior participação de monômeros hidrofílicos, como HEMA, na formação da camada híbrida (SPENCER e WANG ${ }^{83}$,2002). Assim, em contraste à formação de uma barreira impermeável ideal, a camada híbrida formada por adesivos convencionais aplicados sobre a dentina condicionada e úmida tem sido caracterizada por ser uma estrutura porosa (TAY e PASHLEY ${ }^{89}, 2003$; TAY et

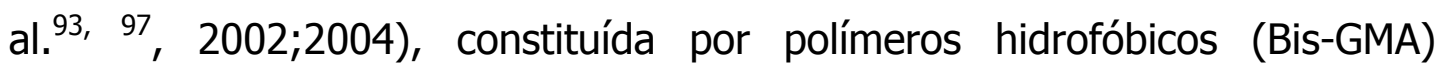
irregularmente dispersos em uma matriz predominantemente hidrofílica (poliHEMA), propensa a maior absorção de água (SPENCER e WANG ${ }^{83}$, 2002) e, conseqüentemente, mais suscetível à degradação ao longo do tempo ( YIU et al. ${ }^{105}$, 2005). Desta maneira, concluiremos que as implicações negativas da umidade nos adesivos convencionais advêm da genuína necessidade de remoção da smear layer, o que leva a um aumento significante da permeabilidade dentinária.

Visto que os sistemas adesivos autocondicionantes não preconizam a remoção da smear layer, poderíamos supor que o uso destes materiais se constituiria como uma vantagem no sentido de minimizar a permeabilidade da dentina (HASHIMOTO ${ }^{36}$ et al., 2004; ÖZOK et al. ${ }^{55}$, 2004). Adicionalmente, por não requererem a utilização da técnica úmida, os adesivos autocondicionantes poderiam, em teoria, promover melhor selamento do substrato. Entretanto, não foi o que ocorreu neste experimento. Assim como o adesivo convencional, os adesivos 
autocondicionantes utilizados não foram eficazes na redução da permeabilidade dentinária e permitiram a passagem de água pelo interior de sua estrutura polimerizada.

Estes resultados estão em concordância com o estudo realizado por CHERSONI ${ }^{15}$ e colaboradores em 2004, no qual os autores também avaliaram a permeabilidade da dentina tratada por diferentes adesivos autocondicionantes. Além da medição da condutividade hidráulica da dentina in vitro, os autores avaliaram em MEV a superfície adesiva de preparos realizados in vivo. Os resultados demonstraram que todos os adesivos autocondicionantes simplificados foram permeáveis e que nenhum foi mais eficaz do que a própria smear layer no selamento dentinário.

Uma provável explicação para tal ocorrência pode também ser sustentada pela deficiente formação do polímero que constituí a camada híbrida produzida por esses sistemas simplificados. Porém, neste caso, a deficiência de formação da camada híbrida não seria atribuída ao excesso de umidade gerado pela remoção da smear layer, mas sim pela retenção dos solventes e da própria água que compõem a formulação dos adesivos autocondicionantes (TAY e PASHLEY ${ }^{88}$, 2003).

Adesivos autocondicionantes são constituídos de misturas de monômeros ácidos, monômeros hidrofílicos e hidrofóbicos, aditivos e solventes orgânicos que obrigatoriamente incluem água na sua composição. A água é necessária para promover a ativação dos monômeros ácidos. 
Contudo, esta deve ser removida antes da polimerização do adesivo, pois além de comprometer a conversão dos monômeros em polímeros, dificulta a interação dos monômeros resinosos com os tecidos dentais (SPENCER e WANG ${ }^{83}$, 2002). Sabe-se que a eliminação da água, um solvente que em condições normais de pressão e temperatura exibe baixa capacidade de volatilização quando comparado a solventes como acetona e etanol, não ocorre de forma eficiente (YIU ${ }^{105}$, 2005). Adicionalmente, os adesivos autocondicionantes são compostos por um grande percentual de monômeros hidrofílicos como o HEMA, por exemplo, que, ao se ligarem às moléculas de água, podem diminuir ainda mais a capacidade de evaporação deste solvente, fazendo com que o mesmo fique retido no interior desses materiais (YIU ${ }^{105}$ et al, 2005). A ligação dos monômeros hidrófilicos com a água não somente desacelera a evaporação deste solvente, como também prejudica a conversão e resulta na formação de uma menor quantidade de ligações cruzadas entre as cadeias poliméricas. Em conseqüência, o polímero formado quase sempre será mais frágil e altamente propenso à absorção de fluidos (FERRACANE 25 2004). Por outro lado, em sistemas adesivos com maior conteúdo de monômeros hidrofóbicos, como o Bis-GMA, especula-se que este efeito seja menos acentuado, já que interação destes com a água é reduzida e, deste modo, há chance de que a conversão destes monômeros resulte numa estrutura mais homogênea, com maior quantidade de ligações cruzadas e menos susceptível a permeação de fluidos (KING et al. ${ }^{43}$, 2005). 
Assim, a retenção de água durante a polimerização, aliada ao alto conteúdo de monômeros hidrófilos, provavelmente justifiquem o fato dos adesivos autocondicionantes empregados neste estudo terem sido tão permeáveis quanto o adesivo convencional. Esta observação está em concordância com o que foi reportado por GRÉGOIRE et al. ${ }^{34}$ em 2003. Estes autores avaliaram in vitro a permeabilidade dentinária após aplicação de adesivos autocondicionantes (Clearfil SE Bond e o Prompt L- Pop) e convencionais (Optibond Solo Plus, Excite, Prime Bond NT e Single Bond), os quais apresentam diferentes solventes e monômeros em suas composições. A maior redução da permeabilidade dentinária foi, comparativamente, alcançada com o emprego dos adesivos convencionais.

Estudos sugerem que a aplicação de uma resina fluida de característica hidrofóbica e livre de solvente sobre a dentina hibridizada tende a minimizar os efeitos da permeabilidade dentinária (CHERSONI et al. 14, 2004; TAY et al. 93,97, 2002; 2004). De outro modo, adesivos simplificados, sejam esses convencionais de dois passos de aplicação ou autocondicionantes de passo único, tenderiam a se comportar como membranas altamente permeáveis após a polimerização (CHERSONI et al. ${ }^{14}$, 2004; TAY et al. 93,97, 2002; 2004). Portanto, o aumento da permeabilidade dos adesivos pode estar relacionado com a tendência de simplificação dos mesmos, o que implica na ausência da aplicação de uma camada de uma 
resina hidrofóbica e não solvatada sobre o adesivo hidrofílico (KING et al. ${ }^{43}$, 2004).

Seguindo este raciocínio, o AdheSe não deveria ter sido tão permeável como foi, pois a aplicação do primer ácido é sucedida pela aplicação de uma resina relativamente hidrofóbica e livre de solventes. Verificamos, porém, que a água também foi capaz de permear pelo AdheSe polimerizado, mesmo após a aplicação da segunda camada de resina livre de solvente. Entender o ocorrido pode não ser difícil, pois a resina que constitui o segundo passo do AdheSe é a base de HEMA. Desta forma, apesar desta resina não conter solvente e, assim, promover a formação de um polímero com maior densidade de ligações cruzadas, o caráter hidrófilo deste polímero favorece a absorção de água do meio (YIU et al, ${ }^{105}$ 2005; FERRACANE ${ }^{25}$, 2004) e, portanto, também determina um comportamento similar a uma membrana semi-permeável.

A utilização do gel de oxalato de potássio após o condicionamento ácido da dentina faz com que as moléculas de oxalato de potássio se difundam através dos túbulos dentinários até que encontrem íons cálcio disponíveis para reação. Os cristais de oxalato de cálcio são formados na sub-superfície e contribuem para a redução da permeabilidade dentinária e movimento de fluidos osmoticamente induzidos durante os procedimentos adesivos, impedindo que a umidade do substrato influencie na formação da camada híbrida ou possam permear através do adesivo polimerizado 
(PASHLEY et al. ${ }^{70}$, 2001; TAY et al. ${ }^{96}$, 2003). Desta forma, não foi surpreendente verificar que a utilização do oxalato de potássio tenha se revelado como fator mais efetivo na redução da permeabilidade dentinária.

Embora o tipo de adesivo utilizado não tenha exercido influência significativa na ação do oxalato sobre a redução da permeabilidade, é notável que a associação do oxalato de potássio com o adesivo convencional Single Bond foi o tratamento mais eficaz quando comparado às demais associações estudadas.

Em estudo recente, YIU ${ }^{104}$ e colaboradores (2005) mostraram que o pH dos adesivos e a presença do flúor na composição dos mesmos podem ter forte influência sobre a eficácia do oxalato de potássio como agente limitador da permeabilidade dentinária e na posterior adesão das resinas sobre a dentina tratada. Dos adesivos empregados naquele estudo, OptiBond Solo Plus e o Prime \& Bond NT proporcionaram valores de resistência adesiva mais baixos quando associados ao oxalato de potássio. Os autores sugerem que a acidez desses adesivos contribuiu para a solubilização dos cristais de oxalato de cálcio, e que, adicionalmente, os íons de flúor livres do adesivo teriam interagido com os íons cálcio e fosfato da dentina ou dos próprios cristais solubilizados, causando a precipitação de um composto semelhante ao fluoreto de cálcio. A análise em MEV dos espécimes mostrou a presença de glóbulos esféricos distribuídos por toda extensão da interface adesiva, que se assemelhavam ao fluoreto de cálcio formado no esmalte 
após aplicação tópica de flúor. A presença desses glóbulos pode ter prejudicado a infiltração do adesivo e a conseqüente hibridização na dentina desmineralizada. Talvez, por este motivo, o AdheSE e, principalmente, o One Up Bond $\mathrm{F}$ tenham se comportado de maneira menos efetiva que o Single Bond quando associados ao oxalato de potássio. Além desses adesivos apresentarem um pH mais baixo do que o Single Bond, o One Up Bond também contém flúor na sua composição. Assim, é possível que essas características de composição tenham gerado uma incompatibilidade do gel de oxalato com os sistemas AdheSE e One Up Bond F, fazendo que os mesmos fossem menos efetivos em reduzir a permeabilidade dentinária.

O elevado desvio-padrão encontrado nos resultados é comum em experimentos que avaliam a permeabilidade dentinária (ELGALAID ${ }^{22}$ et al., 2004; ÖZOK et al. ${ }^{55}$, 2004). A variabilidade inicial dos valores de permeabilidade entre os espécimes (em $\mu \mathrm{L}$ por minuto) foi bastante elevada, independente de a medição ser feita com a presença da smear layer ou após o condicionamento ácido. Isso ocorre porque há também uma grande variabilidade inerente a cada dente, ou seja, fatores como a quantidade e o diâmetro dos túbulos dentinários, a idade e tempo de armazenagem dos dentes individualizam o substrato e o torna único quanto à sua permeabilidade (OUTHWAITE, LIVINGSTON e PASHLEY ${ }^{54}$, 1976). Além disso, como os procedimentos adesivos foram realizados em preparos do tipo coroa total e não em discos de dentina, a espessura e a área total da dentina 
sobre a qual os sistemas adesivos foram aplicados também variavam, e este fato provavelmente colaborou para que as diferenças de permeabilidade intrínsecas de cada espécime fossem ainda maiores (REEDER et al. ${ }^{77}$, 1978).

Diante desses fatos, a única forma de avaliar a eficácia de um tratamento sobre a permeabilidade de dentes com permeabilidades iniciais diferentes é fazer com que essa permeabilidade inicial sirva como controle e, conseqüentemente, como parâmetro para avaliação. Por isso, os resultados foram normalizados, ou seja, expressos como percentual do valor máximo de permeabilidade $(100 \%)$ de cada dente, conseguido após condicionamento ácido. Desta forma, cada dente serviu como seu próprio controle (GREENHILL e PASHLEY ${ }^{33}$, 1981; PASHLEY ${ }^{56}$, 1984), permitindo as análises comparativas realizadas neste estudo.

Mesmo normalizando os dados, os elevados desvios padrões ocorreram porque a variabilidade de comportamento frente aos tratamentos foi grande entre os espécimes. Em muitos casos, dentes que exibiram uma permeabilidade inicial menor apresentaram melhores resultados frente aos tratamentos empregados, mas em outros casos isso não ocorreu. O fato é que a dentina é um substrato bastante dinâmico e, independente do tratamento utilizado, vários fatores afetam a qualidade da adesão, como, por exemplo, a espessura da smear layer, diferenças no grau de condicionamento, molhamento da superfície pelo adesivo, forças de contração de polimerização e qualidade da polimerização frente à umidade 
(PASHLEY e CARVALHO ${ }^{63}$, 1997; PASHLEY et al. ${ }^{71}$ 2002). Além disso, como o gel de oxalato de potássio age através da reação com cálcio da dentina para formação dos cristais, a disponibilidade de cálcio para reação é fundamental (PEREIRA, SEGALA e GILLAM ${ }^{74}$, 2004; MUZZIN e JOHNSON ${ }^{48}$, 1989). No presente estudo, o cálcio disponível para reagir com o gel de oxalato de potássio estava presente na sub-superfície, já que o condicionamento ácido foi realizado previamente. Podemos especular que as diferenças que existiram entre os diferentes dentes ocorreram devido à disponibilidade de cálcio para reação, tamanho dos cristais formados e diâmetro dos túbulos dentinários.

Na análise das fotomicrografias podemos notar que a transudação de fluidos dentinários não foi uniforme e localizavam-se em áreas específicas, refletindo a variação da permeabilidade em diferentes regiões do mesmo espécime (RICHARDSON, TAO e PASHLEY ${ }^{79}$, 1991; PASHLEY et al. ${ }^{68}, 1987$ ). Na maioria das imagens pôde-se notar que uma maior quantidade de bolhas ocorria na região cervical do preparo, provavelmente devido ao fato de que nesta região a densidade dos túbulos dentinários é efetivamente maior, portanto sendo maior sua permeabilidade (BRÄNNSTRÖM e ASTRÖM ${ }^{4}$, 1972).

Um aspecto interessante a se observar é que durante a moldagem da superfície do adesivo e durante o tempo que o material leva para polimerizar (5 minutos), o material de moldagem pode funcionar como um agente 
hipertônico, estimulando a passagem de água através da camada híbrida. Esta água pode ser proveniente da câmara pulpar, da camada híbrida ou do adesivo.

Em todos os preparos avaliados em MEV foram identificadas bolhas na superfície adesiva, mesmo em espécimes nos quais o Flodec não havia detectado permeabilidade. A partir deste fato, surgiram 2 hipóteses: a primeira de que estas bolhas poderiam ser oriundas da dentina subjacente e o Flodec não teria sido capaz de detectar essa mínima movimentação de fluido da camada mais superficial da dentina para o adesivo; e a segunda hipótese é a de que esta água seria oriunda do próprio adesivo (que contém água em sua composição), a qual foi atraída para superfície durante o procedimento de moldagem, por gradiente de concentração osmótico.

Para confirmar a hipótese de que as bolhas encontradas na superfície adesiva também poderiam ser oriundas do próprio sistema adesivo, alguns espécimes (2 dentes para cada grupo) foram desidratados através da imersão em concentrações ascendentes de etanol (50\%, 70\%, 90\% e 100\%) por pelo menos 24 horas em cada solução (CARVALHO et al. ${ }^{12}$, 2004). Estes foram mantidos em etanol até o momento do uso. Nesses espécimes, o adesivo foi aplicado segundo as recomendações do fabricante, porém, o ácido foi lavado com etanol a 100\%. A confecção das réplicas seguiu o mesmo protocolo descrito anteriormente. As réplicas obtidas com o adesivo Single Bond e One Up Bond F, ambos aplicados segundo o fabricante sobre a 
dentina desidratada, também mostraram bolhas (ainda que em menor quantidade) na superfície adesiva, confirmando a hipótese de que as bolhas encontradas podem ser oriundas da água retida no próprio sistema adesivo. A presença de bolhas sobre a camada de adesivo aplicado sobre dentina desidratada (dentes tratados endodonticamente) foi recentemente demonstrada por CHERSONI ${ }^{16}$ et al. em 2005. Ainda que no estudo de CHERSONI, as evidências tenham sido observadas in vivo, elas apontam para a possibilidade de que a água que migra para a superfície durante os procedimentos de moldagem seja oriunda da estrutura do adesivo, fato este corroborado em nosso estudo.

São inúmeras as implicações negativas da água no que diz respeito à qualidade de formação da camada híbrida e à capacidade de degradação dos polímeros que a constitui. A simplificação dos passos com certeza não é o melhor caminho para solucionar estes problemas. Como já discutido, os monômeros hidrofóbicos e hidrofílicos colocados em um único frasco podem causar o fenômeno conhecido como "separação de fase" quando estas misturas são aplicadas na dentina úmida desmineralizada. A utilização de um adesivo composto por um segundo passo de resina livre de solventes é uma forma de amenizar o problema, mas também não impede que a permeabilidade e a sorção de água ocorram, pois os túbulos dentinários estão abertos permitindo a passagem do fluxo. 
A simplificação dos sistemas adesivos atuais traz vantagens como redução do número de passos operatórios, diminuição do tempo clínico e menor sensibilidade técnica. Os resultados deste trabalho e de outros apresentados na revisão nos fazem refletir sobre estas "vantagens" no que diz respeito à qualidade da adesão e, principalmente, durabilidade de união. A associação do oxalato de potássio aos procedimentos adesivos vai de encontro à tendência atual de simplificação, mas baseia-se numa tentativa inteligente de melhorar o selamento obtido com os sistemas adesivos e manter a integridade deste selamento ao longo do tempo. 


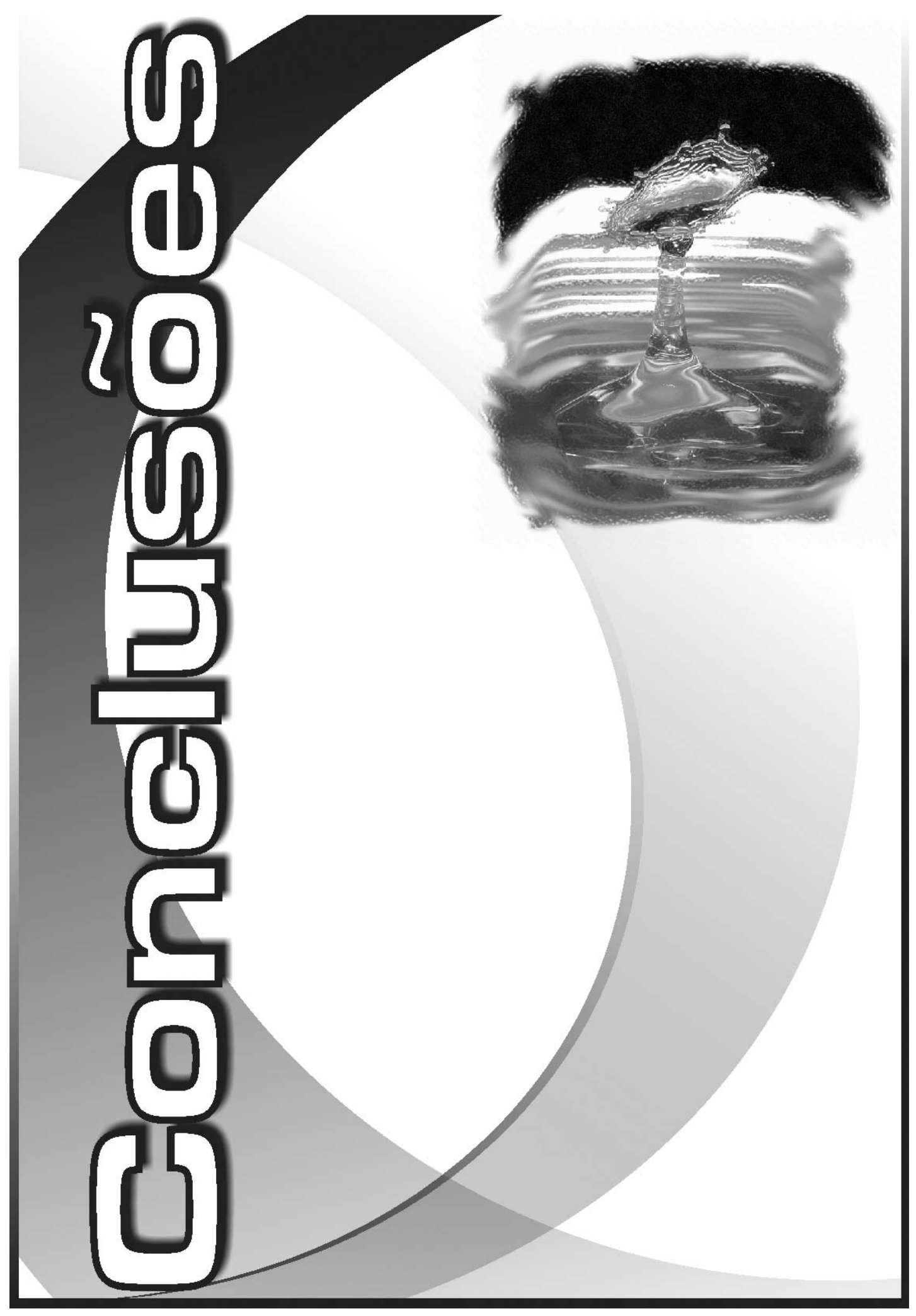




\section{Conclusões}

A análise dos dados nos permite concluir que:

1) A aplicação de sistemas adesivos convencionais ou autocondicionantes não elimina a condutividade hidráulica da dentina.

2) A aplicação de oxalato de potássio em combinação com os sistemas adesivos reduz de forma significante a condutividade hidráulica da dentina. 


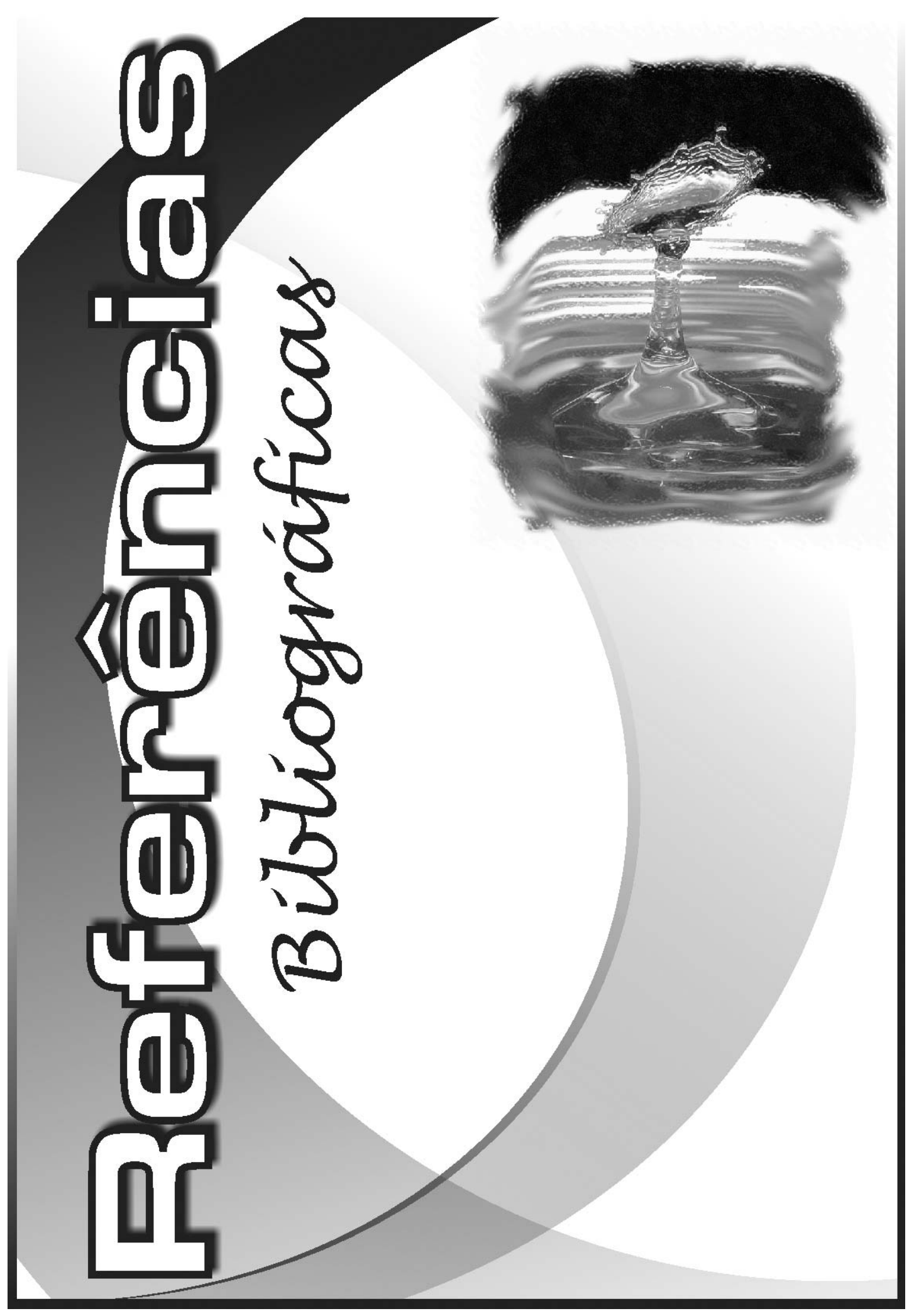




\section{Referências Bibliográficas}

1- ABSI E.G; ADDY M., ADAMS D. Dentine hypersensitivity. A study of the patency of dentinal tubules in sensitive and non-sensitive cervical dentine. J . Clin. Periodontol., v.14, n.5, p.280-4, May 1987.

2- BOUILLAGUET, S. et al. Ability of adhesive systems to seal dentin surfaces: an in vitro study. J. Adhes. Dent., v.2, n.3, p. 201-208, 2000.

3- BRÄNNSTRÖM M. The hydrodynamic theory of dentinal pain: sensation in preparations, caries, and the dentinal crack syndrome. J Endod., v.12, n.10, p.453-7, Oct. 1986.

4- BRÄNNSTRÖM M.; ASTRÖM A. The hydrodynamics of the dentine; its possible relationship to dentinal pain. Int. Dent. J., v.22, n.2, p.219-27, Jun.1972.

5- BRÄNNSTRÖM M, GARBEROGLIO R. The dentinal tubules and the odontoblast processes. A scanning electron microscopic study. Acta Odontol. Scand., v.30, n.3, p.291-311, Sep. 1972.

6- CAMPS, J. et al. Effects of desensitizing agents on human dentin permeability. Am. J. Dent., v.11, n.6, p.286-90, 1997.

\footnotetext{
* Normas recomendadas para uso no âmbito da Universidade de São Paulo, com base no documento "Referências Bibliográficas: exemplos", emanado do Conselho Supervisor do Sistema Integrado de Bibliotecas da USP, em reunião de 20 de setembro de 1990.
} 
7- CAMPS, J. et al. Dentin permeability and eugenol diffusion after full crown preparation. Am. J. Dent., v.16, n.2, p.112-16, Apr.2003.

8- CARRIGAN, P.J. et al. Scanning electron microscopic evaluation of human dentinal tubules according to age and location. J. Endodont., v.10, n.8 , p.359-63, 1984.

9- CARRILHO, M.R. et al. Effects of storage media on mechanical properties of adhesive systems. Am. J. Dent., v. 17, n.2, p.104-8, Apr. 2004.

10- CARVALHO, R.M. et al. Resin diffusion through demineralized dentin matrix. Rev. Odontol. Univer. São Paulo, v.13, n.4, p.417-24, out./dez. 1999.

11- CARVALHO, R.M., et al. Adhesive permeability affects coupling of resin cements that utilize self-etching primers to dentine. J. Dent., v.32, n.1, p.55-65, Jan. 2004.

12- CARVALHO, R.M., et al. Effects of Pre-bonding hydration on bond strength to dentin. J. Adhes. Dent., v. 6, n.1, p.13-17, 2004.

13- CARVALHO, R.M. et al. Sistemas adesivos: fundamentos para aplicação clínica. Biodonto, v.2, n.1, p. 9-86, jan./fev. 2004.

14- CHERSONI S. et al. In vivo and in vitro permeability of one-step selfetch adhesives. J. Dent. Res., v.83, n.6, p.459-64, Jun. 2004. 
15- CHERSONI, S. et al. Water movement in the hybrid layer after different dentin treatments. Dent. Mater., v.20, n.9, p.796-803, Nov. 2004.

16- CHERSONI, S. et al. In vivo fluid movement through dentin adhesives in endodontically treated teeth. J Dent Res. v. 84, n.3, p.223-7, Mar. 2005.

17- CHRISTENSEN, G.J. Preventing postoperative tooth sensitivity in class I, II and V restorations. J. Am. Dent. Assoc. v.133, n.2 p.229$231,2002$.

18- CIUCCHI, B. et al. Dentinal Fluid Dynamics in Human Teeth, in vivo. J. Endod., v.21, n.4, p.191-94, Apr.1995.

19- CIUCCHI B. et al. Volume of the internal gap formed under composite restorations in vitro. J Dent., v.25, n.3-4, p.305-12, May-Jun. 1997.

20- COX, C.F. Pulp protection and direct capping with $\mathrm{Ca}(\mathrm{OH}) 2$ versus adhesive resin systems: a review of factors leading to failure or success. Proceedings of the 3rd International Kuraray Symposium on Advanced Adhesive Dentistry, Granada, Spain, Eds. Tagami J, Toledano M, Prati C: $149-175$.

21- CUENIN, M.F. et al. An in vivo study of dentin sensitivity: the relation of dentin sensitivity and the patency of dentin tubules. J. Periodontol., v.62, n.11, p.668-73, Nov.1991. 
22- ELGALAID, T.O. et al. In vitro dentine permeability: the relative effect of a dentine bonding agent on crown preparations. J. Dent., v.32, n.5, p.413-21, Jul. 2004.

23- ELIADES G, VOUGIOUKLAKIS G.; PALAGHIAS G. Heterogeneous distribution of single-bottle adhesive monomers in the resin-dentin interdiffusion zone. Dent Mater., v.17, n.4, p.277-83, Jul. 2001.

24- FERRARI, M.; TAY, F.R. Technique sensitivity in bonding to vital, acidetched dentin. Oper. Dent., v.28, p.3-8, 2003.

25- FERRACANE, J.L. Hygroscopic and hydrolytic effects in polymer networks. In: Proceedings of Conference on Scientific insights into dental Ceramics and photopolymer networks. Transactions of the Academy of Dental Materials- Geneve (2004); 18: $118-128$.

26- FOGEL H.M; PASHLEY D.H. Effect of periodontal root planing on dentin permeability. J Clin Periodontol., v.20, n.9, p.673-7, Oct.1993.

27- GABEROGLIO, R.; BRÄNNSTRÖM, M. A scanning electron microscopic investigation of human dentinal tubules. Archs. Oral Biol., v. 21,n.6 p. 355-62, 1976.

28- GARCIA, F.C.P. et al. O paradoxo da evolução dos sistemas adhesivos. Rev. APCD, v.57, n.6, p.449-53, 2003. 
29- GILLAM D.G et al. Scanning electron microscopy (SEM) investigation of selected desensitizing agents in the dentine disc model. Endod Dent Traumatol., v.15, n.5, p.198-204, Oct.1999.

30- GILLAM, D.G. et al. The effects of oxalate-containing products on the exposed dentine surface: an SEM investigation. J. Oral. Rehabil., v.28, n.11, p.1037-44, Nov. 2001.

31- GOLDBERG M.; LASFARGUES J.J. Pulpo-dentinal complex revisited. J Dent., v.23, n.1, p.15-20, Feb. 1995.

32- GOODIS, H.E.; MARSHAL, G.W.; WHITE, J.M. The effects of storage after extraction of the teeth on human dentine permeability in vitro. Archs. Oral Biol., v. 36, n.8, p.561-66, 1991.

33- GREENHILL, JD; PASHLEY, DH. The effects of desensitizing agents on the hydraulic conductance of human dentin in vitro. J. Dent. Res., v. 60, n.3 p.686-98, 1981.

34- GRÉGOIRE, G. et al. Dentin permeability: self-etching and one-bottle dentin bonding systems. J. Prosthet. Dent., v.90, p. 42-9, 2003.

35- GWINNETT, A.J. Quantitative contribution of resin infiltration/hybridization to dentin bonding. J. Dent., v.6, n. p. 79, 1993.

36- HASHIMOTO, M. et al. Fluid movement across resin-dentin interface during and after bonding. J. Dent. Res., v.83, n.11, p.843-8, Nov.2004. 
37- HEYERAAS KJ. Pulpal hemodynamics and interstitial fluid pressure: balance of transmicrovascular fluid transport. J. Endod., v.15, n.10, p.468-72, Oct. 1989.

38- HOLLAND GR. The extent of the odontoblastic process in the cat. J. Anat. v.120, p.133-149, 1976.

39- ITTHAGARUN A.; TAY F.R. Self-contamination of deep dentin by dentin fluid. Am. J. Dent., v.13, n.4, p.195-200, Aug. 2000.

40- JACOBSEN T.; SODERHOLD K.J. Some effects of water on dentin bonding. Dent. Mater., v.11, n.2, p.132-6, Mar.1995.

41- KERDVONGBUNDIT, $\mathrm{V}$. et al. The use of the replica technique to record fluid emerging from exposed dentine. Arch. Oral. Biol., v.49, n.8, p.613-19, Aug. 2004.

42-KERNS, D.G. et al. Dentinal tubule occlusion and root hypersensitivity. J.Periodontol., v.62, n.7 p.421-28, Jul.1991.

43- KING, N.M. et al. Conversion of one-step to two-step self-etch adhesives for improved efficacy and extended application. Am. J. Dent. v.17, 2005/in press/.

44- KOLKER J.L. et al. Effect of desensitizing agents on dentin permeability and dentin tubule occlusion. J Adhes. Dent., v.4, n.3, p.211-21, 2002. 
45- LILJA J. Innervation of different parts of the predentin and dentin in young human premolars. Acta Odontol. Scand., v.37, n.6, p.339-46, 1979.

46- MJÖR I.A. Dentin-predentin complex and its permeability: pathology and treatment overview. J Dent. Res., v.64, p.621-7, Apr. 1985.

47- MJÖR I.A.; SVEEN O.B.; HEYERAAS K.J. Pulp-dentin biology in restorative dentistry. Part 1: normal structure and physiology. Quintessence Int., v.32, n.6, p.427-46, Jun. 2001.

48- MUZZIN K.B, JOHNSON R. Effects of potassium oxalate on dentin hypersensitivity in vivo. J. Periodontol., v. 60, n.3, p.151-8, Mar.1989.

49- NAHON M., et al. Effects of impression materials on the hybridized dentin. J. Prost. Dent., v. 85, p.568-74, 2001.

50- NÄRHI M.V.O. Dentin sensitivity: A review. J. Biol. Buccale, v.13, p. 75-96, 1985.

51- NIKAIDO T. et al. Effect of pulpal pressure on adhesion of resin composite to dentin: bovine serum versus saline. Quintessence Int., v.26, n.3, p.221-6, Mar. 1995.

52-OLGART, L.; GAZELIUS, B. Effects of adrenaline and felypressin (octapressin) on blood flow and sensory nerve activity in the tooth. Odont. Scand., v.35, p.69-75, 1977. 
53- OPDAM, N.J. et al. Class I occlusal composite resin restorations: in vivo post-operative sensitivity, wall adaptation, and microleakage. Am. J. Dent., v.11, n.5 p. 229-34, 1998.

54- OUTHWAITE W.C; LIVINGSTON M.J.; PASHLEY D.H. Effects of changes in surface area, thickness, temperature and post-extraction time on human dentine permeability. Arch Oral Biol., v.21, n.10, p.599-603, 1976.

55- OZOK A.R. et al. Effect of dentin perfusion on the sealing ability and microtensile bond strengths of a total-etch versus an all-in-one adhesive. Dent Mater., v.20, n.5, p.479-86, Jun. 2004.

56-PASHLEY, D.H. Smear layer: Physiological Considerations. Oper. Dent., v.3, p.13-29, 1984.

57- PASHLEY D.H. Dentin permeability, dentin sensitivity and treatment through tubular occlusion. J. Endod., v.12, n.10, p.465-74, Oct. 1986.

58- PASHLEY, D.H. Dentine permeability and its role in the pathobiology of dentine sensitivity. Archs. Oral Biol., v.39, p.73S-80S, Suppl., 1994.

59- PASHLEY D.H. Dynamics of the pulpo-dentin complex. Crit. Rev. Oral Biol. Med., v.7, n.2, p.104-33, 1996. 
60- PASHLEY D.H; GALLOWAY S.E. The effects of oxalate treatment on the smear layer of ground surfaces of human dentine. Arch. Oral Biol., v.30, n.10n p.731-7, 1985.

61- PASHLEY D.H.; DEPEW D.D. Effects of the smear layer, Copalite, and oxalate on microleakage. Oper. Dent., v.11, n.3, p. 95-102, Summer 1986.

62- PASHLEY D.H.; MATTHEWS W.G. The effects of outward forced convective flow on inward diffusion in human dentine in vitro. Arch. Oral. Biol., v.38, n.7, p.577-82, Jul. 1993.

63- PASHLEY D.H; CARVALHO R.M. Dentine permeability and dentine adhesion. J. Dent., v.25, n.5, p.355-72, Sep. 1997.

64- PASHLEY D.H; LIVINGSTON M.J.; GREENHILL J.D. Regional resistances to fluid flow in human dentine in vitro. Arch. Oral Biol., v.23, n.9, p.807-10, 1978.

65- PASHLEY D. H.; MICHELICH V.; KEHL T. Dentin permeability: effects of smear layer removal. J. Prosthet. Dent., v.46, n.5, p.531-7, Nov. 1981.

66- PASHLEY, E.L.; TAO, L.; PASHLEY, D.H. Effects of oxalate on dentin bonding. Am. J. Dent., v.6, n.3, p.116-8, Jun. 1993.

67- PASHLEY, D.H et al. Effects of the degree of tubule occlusion on the permeability of human dentine in vitro. Archs. Oral. Biol., v. 23, p.1127-33, 1978. 
68- PASHLEY D.H. et al. Regional variability in the permeability of human dentine. Arch. Oral Biol., v.32, n.7, p.519-23, 1987.

69- PASHLEY D.H. et al. Permeability of dentin to adhesive agents. Quintessence I nt., v.24, n.9, p.618-31, Sep. 1993.

70- PASHLEY, D.H. et al. The use of oxalate to reduce dentin permeability under adhesive restorations. Am. J. Dent., v.14, n.2, p.89-94, 2001.

71- PASHLEY D.H. et al. The effects of dentin permeability on restorative dentistry. Dent. Clin. North Am., v.46, n.2, p.211-45, Apr. 2002.

72- PERDIGAO J. Dentin bonding as a function of dentin structure. Dent. Clin. North Am., v.46, n.2, p.277-301, Apr. 2002.

73- PEREIRA G.D et al. How wet should dentin be? Comparison of methods to remove excess water during moist bonding. J Adhes Dent., v.3, n.3, p.257-64, 2001.

74-PEREIRA, J.C.; SEGALA, A.D.; GILLAM, D.G. Effect of desensitizing agents on the hydraulic conductance of human dentin subjected to different surface pre-treatments- an in vitro study. Dent. Mater., v.21, n.2, p. 129-38, Feb.2005.

75- PEREIRA, P.N. et al. Effect of intrinsic wetness and regional difference on dentin bond strength. Dent. Mater., v.15, n.1 p.46-53, 1999. 
76- POMMEL L.; CAMPS J. Effects of pressure and measurement time on the fluid filtration method in endodontics. J. Endod., v.27, n.4, p.256-8, Apr. 2001.

77- REEDER O.W. et al. Dentin permeability: determinants of hydraulic conductance. J. Dent. Res., v.57, n.2, p.187-93, Feb. 1978.

78- REIS A. et al. Moisture spectrum of demineralized dentin for adhesive systems with different solvent bases. J Adhes Dent., v.5, n.3, p.183-92, 2003.

79- RICHARDSON D.; TAO L.; PASHLEY D.H. Dentin permeability: effects of crown preparation. Int. J. Prosthodont., v.4, n.3, p.219-25, May-Jun. 1991.

80- SANARES A.M. et al. Adverse surface interactions between one-bottle light-cured adhesives and chemical-cured composites. Dent. Mater., v.17,n.6,p.542-56,Nov.2001.

81- SANO H. et al. Comparative SEM and TEM observations of nanoleakage within the hybrid layer. Oper. Dent., v.20, n.4, p.160-7, Aug.1995.

82- SILVEIRA PEREIRA, G.D.da et al., How wet should dentin be? Comparison of methods to remove excess water during moist bonding. J . Adhes. Dent., v.3, p. 257-64, 2001. 
83- SPENCER, P.; WANG, Y. Adhesive phase separation at the dentin interface under wet bonding conditions. J. Biomed. Mater. Res., v.62, n.3, p. 447-56, Dec. 2002.

84- SPENCER P. et al. Interfacial chemistry of the dentin/adhesive bond. J . Dent. Res., v.79, n,7, p.1458-63, Jul. 2000.

85- STEFAN, P.; SCHARER, P. Factors in dentin bonding. Part I: a review of the morphology and physiology of human dentin. J. Esthet. Dent., v.5 n.1 jan./feb. 1993.

86- SWIFT, E.J.; PERDIGÃO, J.; HEYMANN, H.O. Bonding to enamel and dentin: a brief history and state of art. Quintessence, v.26, n.2, p.95-110, Feb. 1995.

87- TAY, F.R.; PASHLEY, D.H. Aggressiveness of contemporary self-etching systems. I: Depth of penetration beyond dentin smear layers. Dent. Mater., v.17, p. 296-308, 2001.

88- TAY F.R.; PASHLEY D.H. Have dentin adhesives become too hydrophilic? J. Can. Dent. Assoc., v.69, n.11, p.726-31, Dec.2003.

89- TAY F.R.; PASHLEY D.H. Water treeing--a potential mechanism for degradation of dentin adhesives. Am. J. Dent.,v.16, n.1, p.6-12, Feb. 2003.

90- TAY, F.R., GWINNETT, A.J., WEI, S.H. The overwet phenomenon: a transmission electron microscopic study of surface moisture in the 
acid-conditioned, resin-dentin interface. Am. J. Dent., v. 9, n.4, p.161-6, Aug.1996.

91- TAY F.R.; PASHLEY D.H.; YOSHIYAMA M. Two modes of nanoleakage expression in single-step adhesives J. Dent. Res., v.81, n.7, p.472-6, Jul. 2002.

92- TAY F.R. et al. Effect of delayed activation of light-cured resin composites on bonding of all-in-one adhesives. J . Adhes. Dent., v.3, n.3, p.207-25, 2001.

93- TAY, F.R. et al. Single-step adhesives are permeable membranes. J. Dent., v.30, n.7-8, p.371-82, Sept./ Nov. 2002.

94- TAY F.R. et al. Factors contributing to the incompatibility between simplified-step adhesives and chemically-cured or dual-cured composites. Part I. Single-step self-etching adhesive. J. Adhes. Dent., v.5, n.1, p.27-40, 2003.

95- TAY, F.R. et al. Integrating oxalate desensitizing agents with a totaletch two-step adhesive. J. Dent. Res., v. 82, n.9, p. 703-7, Sep.2003.

96- TAY, F.R. et al. Single-step, self-etch adhesives behave as permeable membranes after polymerization. Part I. Bond strength and morphologic evidence. Am. J. Dent., v.17, n.4, p.271-8, 2004. 
97-TAY, F.R. et al. Single-bottle adhesives behave as permeable membranes after polymerization. I. In vivo evidence. J. Dent., v.32, n.8, p.611-21, Nov. 2004.

98- TEN CATE, A.R. Histologia Bucal - Desenvolvimento, estrutura e função. 5. ed. Rio de Janeiro, Guanabara Koogan 1998.

99- UNEMORI, M. et al. Composite resin restoration and post-operative sensitivity: clinical follow-up in an undergraduate program. J. Dent., v.29, n.1 p. 7-13, 2001.

100- VAN MEERBEEK et al. Buonocore memorial lecture. Adhesion to enamel and dentin: current status and future challenges. Oper. Dent., v.28, n.3, p.215-35, May-Jun. 2003.

101- VONGSAVAN N.; MATTHEWS B. Changes in pulpal blood flow and in fluid flow through dentine produced by autonomic and sensory nerve stimulation in the cat. Proc. Finn. Dent. Soc., v.88, p.4917, Suppl 1, 1992.

102- WANG Y., SPENCER P. Hybridization efficiency of the adhesive/dentin interface with wet bonding J. Dent Res., v.82, n.2, p.141-5, Feb.2003.

103- WHITTAKER, D.K.; KNEALE, M.J. The dentine-predentine interface in human teeth. Br. Dent. J., v. 146, n.2 ,p.43-6, 1979.

104- YIU, C.K.Y., et al. IADR/AADR/CADR 83rd General Session in Baltimore, Maryland: Incompatibility of Oxalate Desensitizers with 
Acidic, Fluoride-Containing Total-Etch Adhesives. J Dent Res 84 (Spec Iss A) / abstract 1450/, 2005.

105- YIU, C.K.Y., et al. IADR/AADR/CADR 83rd General Session in Baltimore, Maryland: Solvent and water retention in dental adhesive films after evaporation. J Dent Res 84 (Spec Iss A) /abstract.0511/, 2005.

106- YOSHIYAMA M.; OZAKI K.; EBISU S. Morphological characterization of hypersensitive human radicular dentin and the effect of a lightcuring resin liner on tubular occlusion. Proc. Finn. Dent. Soc., v.88, Suppl 1, p.337-44, 1992.

107- YOSHIYAMA M et al. Transmission electron microscopic characterization of hypersensitive human radicular dentin. J Dent. Res., v.69, n.6, p.1293-7, Jun. 1990. 


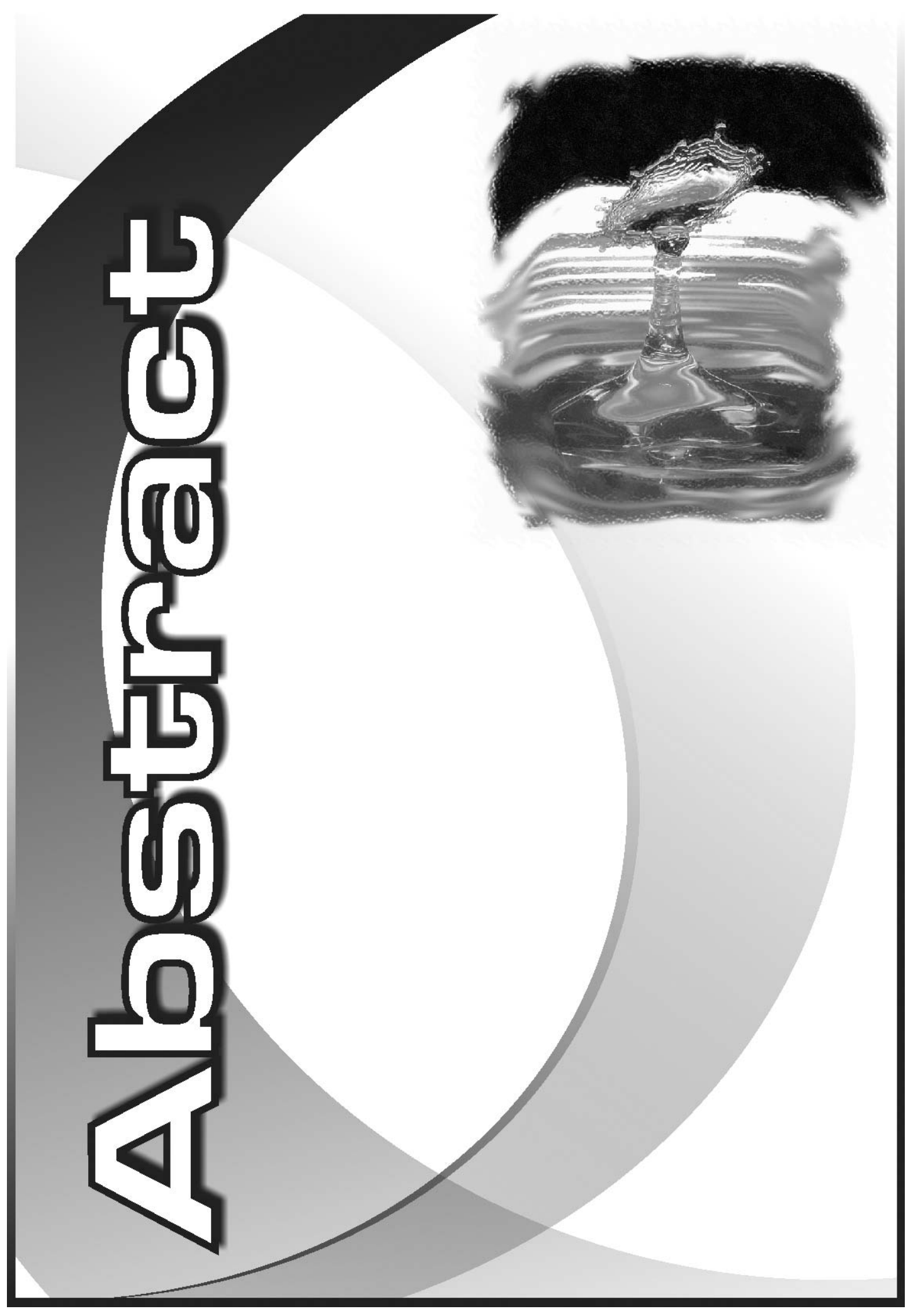




\section{Abstract}

There is an ongoing trend to move away from classical multi-component bonding systems toward simplified adhesives. An immediate consequence of adhesive simplification is the intrinsic permeability to water that result from their increase in hydrophilicity. Current studies have demonstrated that single-step adhesives may act as semi-permeable membranes that allow water diffusion through its structure. Oxalate desensitizers are effective in reducing the hydraulic conductance of dentin. When oxalates are used after acid- etching they do not interfere with subsequent resin bonding. The objective of this study was to test the effects of adhesives systems with or without the application of an oxalate desensitizer on dentin permeability. Crown preparations were made from human extracted teeth. After the roots were sectioned and the coronal pulp removed, the crown segments were connected to an automatic flow-recording device (Flodec-System, De Marco Engineering, Switzerland). Fluid conductance was measured before and after the bonding procedures with the adhesives Single Bond -3M ESPE, One UP Bond F -Tokuyama Inc and AdheSe- Ivoclar Vivadent. Specimens were prepared and tested after the surface had been bonded according to manufacturer's instructions (SBF,ADF and OBF groups), in a experimental 
way (ADE and OBE groups) or integrating with a oxalate desensitizer gel (SBO, ADO and OBO groups). For each specimen, fluid flow across the smear-layer and bonded dentin was expressed as a percentage of acidetched dentin, which was assigned a value of $100 \%$ flow rate. After the hydraulic conductance measures, impressions were taken from the crown segments and epoxy resin replicas were produced for SEM examination. Two-Way ANOVA reveled that the adhesive systems reduced dentin permeability significantly $(p<0.05)$ compared to acid etched dentin, but no bonding system was able to eliminate the fluid flow though dentin. For the three bonding systems tested, treating the acid-etched dentin with potassium oxalate prior to the application of the adhesive was the most effective in reducing the hydraulic conductance of the specimens, and this difference was significant $(p<0.05)$ when comparing to the other treatments. There were no significant differences among the adhesives in their ability to reduce dentin permeability ( $p>0.05)$. SEM micrographs of resin replicas showed that transudation of dentinal fluid droplets could be identified on the surfaces of all replicas examined. 


\begin{tabular}{|l} 
Silisa, S. M. A. \\
Avaliação in vitro dos efeitos da aplicação de sistemas adesivos, do \\
oxalato de potássio, ou a combinação de ambos, na permeabilidade \\
dentinária./ Safira Marques de Andrade e Silva - Bauru, 2005. \\
$108 p ;$ il. ; $30 \mathrm{~cm}$. \\
Dissertação, (Mestrado)-Faculdade de Odontologia de Bauru/USP. \\
Orientador: Prof. Dr. Ricardo Marins de Carvalho
\end{tabular}

Autorizo, exclusivamente para fins acadêmicos e científicos, a reprodução total
ou parcial desta dissertaçãoltese, por processos fotocopiadores elou meios
eletrônicos.
Assinatura do autor:
Data:

